\title{
STUDY OF CURVATURE EFFECTS IN COMPOSITE STEEL I-GIRDER BRIDGES \\ USING THE V-LOAD METHOD
}

By

Mohammad Reza Davoodi

B.Sc. Civil Engineering, Shiraz University, 1984

\author{
A MRP \\ presented to Ryerson University \\ in partial fulfillment of the \\ requirements for the degree of \\ Master of Engineering \\ in the program of \\ Civil Engineering
}

Toronto, Ontario, Canada, 2019

(C) Mohammad Reza Davoodi, 2019 


\section{Author's Declaration}

I hereby declare that I am the sole author of this Major Research Project (MRP). This is a true copy of the MRP, including any required final revisions.

I authorize Ryerson University to lend this MRP to other institutions or individuals for the purpose of scholarly research.

I further authorize Ryerson University to reproduce this MRP by photocopying or by other means, in total or in part, at the request of other institutions or individuals for the purpose of scholarly research. I understand that my MRP may be made electronically available to the public. 


\title{
STUDY OF CURVATURE EFFECTS IN COMPOSITE STEEL I-GIRDER BRIDGES \\ USING THE V-LOAD METHOD \\ BY Mohammad Reza Davoodi, Ryerson University - Civil Engineering \\ Toronto, Ontario, Canada, 2019
}

\begin{abstract}
Horizontally curved composite I-girder bridges are being increasingly used for highway interchanges and river crossings. The $\mathrm{V}$-load method is widely used as a simplified method for the analysis of horizontally curved I-girder highway bridges as a straight I-girder considering the effect of torsion due to curvature. Recently, North American bridge design codes and specifications have specified certain limitations to treat horizontally curved bridges as straight ones in structural analysis and design. The purpose of this study is to investigate the applicability of those specified limitations by the V-Load method, to compare the results from the V-Load method with those obtained from the finite element analysis and to develop empirical expressions for curvature limitation. The results of this study shows that the North American codes and specifications underestimate the response with their specified curvature limitations. Based on this study, a modified equation for the curvature limitation is proposed.
\end{abstract}




\section{Acknowledgements}

I wish to express my deep appreciation to my supervisor Dr. Khaled Sennah, Who made this work possible. His friendly guidance and expert advice have been invaluable throughout all stages of the work.

Dr. Sennah devoted his time and effort to make this study a success. His most helpful guidance is greatly appreciated.

I am also very grateful to my family for always being there for me. It is difficult finding words to express the unfailing support and continuous encouragement they provided. Special thanks are due to my family for his continuous support and understanding.

Thank you 
Author's Declaration $\quad$ ii

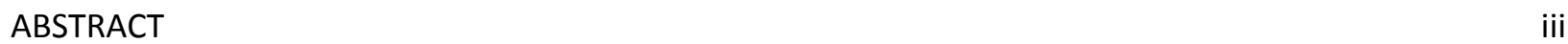

ACKNOWLEDGEMENTS

LIST OF TABLES

LIST OF FIGURES

NOTATIONS

1. Introduction $\quad 1$

2. Overall Review, the Problem and Objectives of This Study 2

3. Introduction of the V-Load Method 3

4. V-Load Method History and Review of Previous Work 5

5. Approximate Analysis of Horizontally Curved Bridges using the V-Load Method 6

5.1 Two-Girder Bridge $\quad 6$

$\begin{array}{ll}\text { 5.2 Multi-Girder Bridge } & 8\end{array}$

5.3 Torsional Response of Girders 10

6. Analysis Procedure $\quad 13$

7. Slab-On-Steel I-Girder Bridge Configurations 13

7.1 Parameters Considered to Compare the Result with the Finite Element Method 14

7.2 Parameters Considered for Limiting Warping Stress 14

$\begin{array}{ll}7.3 \text { Assumptions } & 15\end{array}$

7.4 Loads $\quad 15$

7.5 Stress Magnification Factor 15

8. Stress Magnification Factors using the V-Load Method and the Finite Element Method 16 
9. Code Limitation of Horizontally Curved Bridges to Treat them as a Straight Bridge

9.1 Guide Specifications for Horizontally Curved Highway Bridges (AASHTO 1993)

9.2 Guide Specifications for Horizontally Curved I Steel Girder Highway Bridges (AASHTO 2003)

9.3 Canadian Highway Bridge Design Code (CHBDC)

9.4 Curvature Limitations in North American Bridge Codes and the V-Load Method

10. Examination of the Equation for Curvature Limitation proposed by Khalafalla (2009)

11. Effect of Warping Stress

11.1 Effect of Depth of I-Girder on Warping Stress

11.2 Bottom Flange Width Effect on Warping Stress

11.3 The effect of Number of Transverse Cross Bracing on Warping Stress

12. Correlation between the V-Load Method Results and Curvature Limitations

13. Conclusions

14. Recommendations for Future Research

APPENDIX 1: RESULTS OF STRESS MAGNIFICATION FACTOR SINGLE SPAN BRIDGES

APPENDIX 2: RESULTS OF STRESS MAGNIFICATION FACTOR FOR TWO-SPAN BRIDGES

APPENDIX 3: NUMBER OF BRACING EFFECT ON STRESS MAGNIFICATION FACTOR OF

SINGLE SPAN BRIDGES

APPENDIX 4: NUMBER OF BRACING EFFECT ON STRESS MAGNIFICATION FACTOR OF

TWO-SPAN BRIDGES

References 


\section{LIST OF TABLES}

$\underline{\text { Tables }}$

Page

Table 1. Value of $C$ as a Function of the number of girders, $\mathrm{N}_{\mathrm{g}}$

Table 2. Geometry of the studied bridges

Table 3. Comparison of the stress magnification factor obtained from the FEM and VLM for single span bridges of $15 \mathrm{~m}$ span and $8 \mathrm{~m}$ width

Table 4. Comparison of the stress magnification factor obtained from the FEM and VLM for single span bridges of $15 \mathrm{~m}$ span and $12 \mathrm{~m}$ width

Table 5. Comparison of the stress magnification factor obtained from the FEM and VLM for single span bridges of $15 \mathrm{~m}$ span and $16 \mathrm{~m}$ width

Table 6. Comparison of the stress magnification factor obtained from the FEM and VLM for single span bridges of $25 \mathrm{~m}$ span and $8 \mathrm{~m}$ width

Table 7. Comparison of the stress magnification factor obtained from the FEM and VLM for single span bridges of $25 \mathrm{~m}$ span and $12 \mathrm{~m}$ width

Table 8. Comparison of the stress magnification factor obtained from the FEM and VLM for single span bridges of $25 \mathrm{~m}$ span and $16 \mathrm{~m}$ width

Table 9. Comparison of the stress magnification factor obtained from the FEM and VLM for single span bridges of $35 \mathrm{~m}$ span and $8 \mathrm{~m}$ width

Table 10. Comparison of the stress magnification factor obtained from the FEM and VLM for single span bridges of $35 \mathrm{~m}$ span and $12 \mathrm{~m}$ width

Table 11. Comparison of the stress magnification factor obtained from the FEM and VLM for single span bridges of $35 \mathrm{~m}$ span and $16 \mathrm{~m}$ width

Table 12: Comparison of the stress magnification factor obtained from the FEM and VLM for two-span continuous bridges of $15 \mathrm{~m}$ span each and $8 \mathrm{~m}$ width

Table 13. Comparison of the stress magnification factor obtained from the FEM and VLM for two-span continuous bridges of $15 \mathrm{~m}$ span each and $12 \mathrm{~m}$ width

Table 14. Comparison of the stress magnification factor obtained from the FEM and VLM for two-span continuous bridges of $15 \mathrm{~m}$ span each and $16 \mathrm{~m}$ width

Table 15. Comparison of the stress magnification factor obtained from the FEM and VLM for two-span continuous bridges of $25 \mathrm{~m}$ span each and $8 \mathrm{~m}$ width

Table 16. Comparison of the stress magnification factor obtained from the FEM and VLM for two-span continuous bridges of $25 \mathrm{~m}$ span each and $12 \mathrm{~m}$ width 
Table 17. Comparison of the stress magnification factor obtained from the FEM and VLM for two-span continuous bridges of $25 \mathrm{~m}$ span each and $16 \mathrm{~m}$ width

Table 18. Comparison of the stress magnification factor obtained from the FEM and VLM for two-span continuous bridges of $35 \mathrm{~m}$ span each and $8 \mathrm{~m}$ width

Table 19. Comparison of the stress magnification factor obtained from the FEM and VLM for two-span continuous bridges of $35 \mathrm{~m}$ span each and $12 \mathrm{~m}$ width

Table 20. Comparison of the stress magnification factor obtained from the FEM and VLM for two-span continuous bridges of $35 \mathrm{~m}$ span each and $16 \mathrm{~m}$ width

Table 21. Limiting central angle for neglecting curvature in determining primary bending moment in a curved bridge

Table 22. Curvature limitations for single span bridges

Table 23. Curvature limitations for two-span bridges

Table 24. Code curvature limitations and corresponding stress magnification factor for single span bridges

Table 25. Code curvature limitations and corresponding stress magnification factor for single span bridges

Table 26. Effect of girder depth on warping stress and Stress Magnification Factor

Table 27: Effect of girder flange width on warping stress and Stress Magnification Factor

Table 28. Single-span bridge curvature limitations as obtained from the FEA modelling and V-Load method for a specific number of transverse $\mathrm{X}$ bracing

Table 29. Two-span continuous bridge curvature limitations as obtained from the FEA modelling and VLoad method for a specific number of transverse $\mathrm{X}$ bracing 


\section{LIST OF FIGURES}

Figure 1. Highfield Lane bridge

Figure 2. Braced Pair Girder

Figure 3. View of Underside of typical I-Girder Bridge

Figure 4. Lateral bending moment in girder flanges due to torsional effect

Figure 5. Longitudinal bending moment and flange forces

Figure 6. Horizontally curved two-girder bridge

Figure 7. Free-body diagram and cross-section of bridge showing diaphragm and girders

Figure 8. Cross section of a multi-girder bridge unit

Figure 9. The general I-girder normal stresses, which can occur in a curved I-shaped girder

Figure 10. The general I-girder shear stresses, which can occur in a curved I-shaped girder

Figure 11. Girder section twisted by a torque

Figure 12. Distribution of lateral loads on a girder flange

Figure 13. Bending and warping stress in girder cross section

Figure 14. General cross section of the studied bridges

Figure 15. Comparison of the stress magnification factor obtained from the FEM and VLM for single span bridges of $15 \mathrm{~m}$ span and $8 \mathrm{~m}$ width

Figure 16. Comparison of the stress magnification factor obtained from the FEM and VLM for single span bridges of $15 \mathrm{~m}$ span and $12 \mathrm{~m}$ width

Figure 17. Comparison of the stress magnification factor obtained from the FEM and VLM for single span bridges of $15 \mathrm{~m}$ span and $16 \mathrm{~m}$ width

Figure 18. Comparison of the stress magnification factor obtained from the FEM and VLM for single span bridges of $25 \mathrm{~m}$ span and $8 \mathrm{~m}$ width

Figure 19. Comparison of the stress magnification factor obtained from the FEM and VLM for single span bridges of $25 \mathrm{~m}$ span and $12 \mathrm{~m}$ width 
Figure 20. Comparison of the stress magnification factor obtained from the FEM and VLM for single span bridges of $25 \mathrm{~m}$ span and $16 \mathrm{~m}$ width

Figure 21. Comparison of the stress magnification factor obtained from the FEM and VLM for single span bridges of $35 \mathrm{~m}$ span and $8 \mathrm{~m}$ width

Figure 22. Comparison of the stress magnification factor obtained from the FEM and VLM for single span bridges of $35 \mathrm{~m}$ span and $12 \mathrm{~m}$ width

Figure 23. Comparison of the stress magnification factor obtained from the FEM and VLM for single span bridges of $35 \mathrm{~m}$ span and $16 \mathrm{~m}$ width

Figure 24. Comparison of the stress magnification factor obtained from the FEM and VLM for two-span continuous bridges of $15 \mathrm{~m}$ span each and $8 \mathrm{~m}$ width

Figure 25. Comparison of the stress magnification factor obtained from the FEM and VLM for two-span continuous bridges of $15 \mathrm{~m}$ span each and $12 \mathrm{~m}$ width

Figure 26. Comparison of the stress magnification factor obtained from the FEM and VLM for two-span continuous bridges of $15 \mathrm{~m}$ span each and $16 \mathrm{~m}$ width

Figure 27. Comparison of the stress magnification factor obtained from the FEM and VLM for two-span continuous bridges of $25 \mathrm{~m}$ span each and $8 \mathrm{~m}$ width

Figure 28. Comparison of the stress magnification factor obtained from the FEM and VLM for two-span continuous bridges of $25 \mathrm{~m}$ span each and $12 \mathrm{~m}$ width

Figure 29. Comparison of the stress magnification factor obtained from the FEM and VLM for two-span continuous bridges of $25 \mathrm{~m}$ span each and $16 \mathrm{~m}$ width

Figure 30. Comparison of the stress magnification factor obtained from the FEM and VLM for two-span continuous bridges of $35 \mathrm{~m}$ span each and $8 \mathrm{~m}$ width

Figure 31. Comparison of the stress magnification factor obtained from the FEM and VLM for two-span continuous bridges of $35 \mathrm{~m}$ span each and $12 \mathrm{~m}$ width

Figure 32. Comparison of the stress magnification factor obtained from the FEM and VLM for two-span continuous bridges of $35 \mathrm{~m}$ span each and $16 \mathrm{~m}$ width

Figure 33. Variation of stress magnification factor, SMF, with the change in girder depth and curvature for $25 \mathrm{~m}$ span bridge of $12 \mathrm{~m}$ width

Figure 34. Variation of warping-to-total bending stress ratio, WS/TS, with the change in girder depth and curvature for $25 \mathrm{~m}$ span bridge of $12 \mathrm{~m}$ width 
Figure 35. Variation of stress magnification factor, SMF, with the change in girder flange width and curvature for $25 \mathrm{~m}$ span bridge of $12 \mathrm{~m}$ width

Figure 36. Variation of stress magnification factor, SMF, with the change in girder flange width and curvature for $25 \mathrm{~m}$ span bridge of $12 \mathrm{~m}$ width 


\section{NOTATIONS}

b

$\mathrm{H}$ or $\mathrm{d}$ or $\mathrm{h}$ Depth of the bridge

$\mathrm{N}$

$\mathrm{R}$

W or B

$\mathrm{L}$

M

WS/TS

SMF

$L / R$

Radius of curvature

Width of the bridge
Half-width of the bridge

Number of transvers bracing

Centre line curved span length

Longitudinal bending moment

Warping Stress to Total Stress

Stress Magnification Factor in using the V-Load Method

Span-to-radius or curvature ratio 


\section{Introduction}

As a result of complicated geometrics, limited rights of way, and traffic mitigation, horizontally curved bridges are becoming the model type of highway interchanges and urban expressways. This type of superstructure has gained popularity since the early 1960s because it addresses the needs of transportation engineering.

The design of today's roadways has placed increasing demands on the engineer. The use of horizontally curved bridges has grown out of alignment requirements and constraints. The right of way available for the construction of a new roadway may be limited because of the expansion that many cities are experiencing. It may be impossible to use straight bridge girder in curved ramps, so a curved bridge is necessary with the alignment adapted to suit the site. In addition, the girder spans can be continuous which allows shallower girders. The aesthetics of a curved continuous bridge is also an advantage. There are, however, disadvantages which the engineer should be aware of when designing curved bridges. The fabrication costs are generally higher, and the curved bridge segments are produced in smaller pieces which increases the erection and transportation costs [1]. Analysis of curved bridges is different from that for a straight bridge because of the twisting of the unit due to its curvature.

Horizontally curved steel girder bridges are often used in our modern road systems. The curve in the bridge allows for a smoother transition for traffic, which creates better road travel. The disadvantage of horizontally curved bridges is that they are more difficult to analyze and design than the conventional straight bridges. The horizontal curvature in the girders adds torsional effects, which can increase or decrease the strains in the girders based on its location in the bridge cross-section. The methods used in steel bridge analysis can generally be classified in one of two categories: hand analysis, or computer-based numerical analysis using the finite element method. The finite element method is the most common numerical method in structure analysis and design [3, 4].

The V-Load method is a widely used as an approximate method for analyzing horizontally curved I-girder bridges. The method assumes that the internal torsional load on the bridge resulting from the curvature is resisted by self-equilibrating sets of shear responses (referred to as secondary) between adjacent girders. The final response in the curved girder is the sum of the secondary response and the respective straight girder primary response.

Due to the difficulty in analyzing these bridges, a variety of approaches may be used. The appropriateness and relative accuracy of these different approaches need to be determined. In bridges with light curvature, the curvature effects on bending, shear, and torsional stresses may be ignored if they are within an acceptable range [3]. Treating horizontally curved bridges as straight ones with certain limitations is one of the methods to simplify the design procedure.

Bridge design specifications and codes have specified certain limitations to treat horizontally curved bridges as straight bridges. However, these limitations do not differentiate between bridge cross section configurations, in addition to being inaccurate in estimating the structural response. Moreover, these specifications were developed primarily for the calculation of girder bending moments [2]. The purpose 
of this study is to investigate the applicability of those specified limitations of bridge curvature in North American Bridge Codes to treat a horizontally curved bridge as straight ones by the V-Load method and compare the results with those obtained using the finite element method [2].

\section{Overall Review, the Problem and Objectives of This Study}

Horizontally curved composite l-girder bridges, shown in Figure 1, are being increasingly used for highway interchanges and river crossings. Curved bridge girders offer several inherent advantages. They are more aesthetically pleasing than a series of straight girders along the chords of a roadway curve. Curved girders allow designers to use longer spans, thus eliminating much of the substructure. Curved bridges may also result in simpler and more uniform construction details because girder spacing and concrete slab overhang are generally constant along the length of the structure. However, curved bridge design has difficulty in mathematically analyzing the curved girders; curvature causes torsional loadings that complicate the stress analysis.

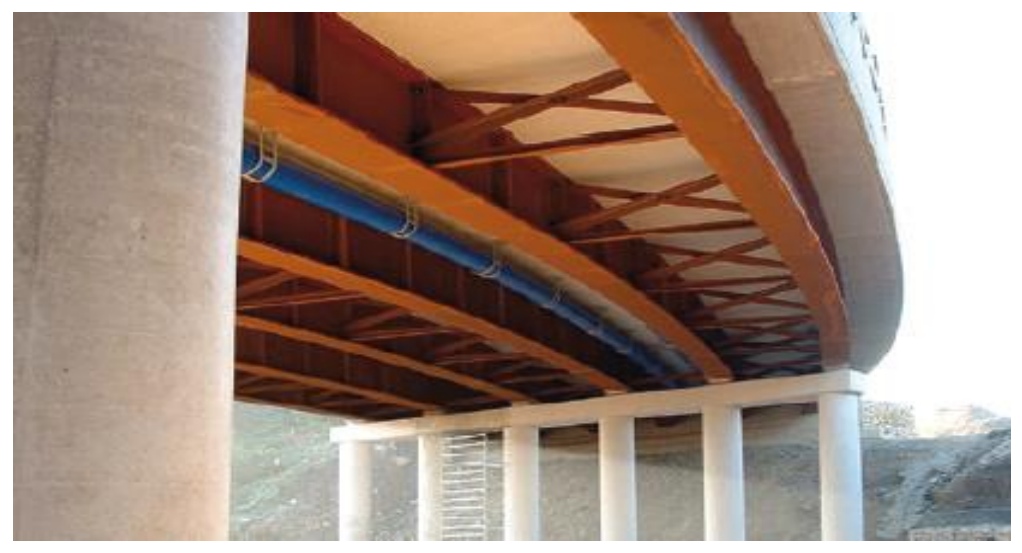

Figure 1. Highfield Lane bridge [5]

Different methods have been available for the structural analysis of curved bridges, but highway engineers generally prefer simplified techniques. Most recently, curved girders are widely used in bridge superstructures. However, due to the addition of curvature, the design and construction of bridges becomes greatly more complicated than that of straight bridges and their structural behavior still not well understood. While in straight bridges, the girders, stringers, and floor beams can be designed by systematically isolating each member and applying standard loads, curved bridges must be designed with careful consideration to system-wide behavior. In essence, the addition of curvature adds torsion to the system that results in significant warping and distortional stresses within the member cross-sections. Furthermore, "secondary members" such as cross frames and diaphragms that provide stability in straight bridges become primary load carrying members in curved bridges [6].

The V-Load method is a widely used as simplified method for the analysis of horizontally curved I-girder highway bridges as straight l-girder considering the effect of torsional due to curvature. This approximate method eventually became known as the $\mathrm{V}$-Load method because a large percentage of the torsional load on the girders is approximated by sets of vertical shears known as V-loads. 
The V-Load method has been widely used in consulting engineering offices. According to a 1969 survey, the method was used for the design of approximately 75 percent of the curved steel I-girder bridges in the United States. Current codes pertaining to analysis and design of horizontally curved bridges are mostly based on experimental and analytical research conducted over 30 years ago as part of project CURT (Consortium of University Research Teams, 1975) [6].

Treating the horizontally curved bridges as straight one with certain limitations is one of the methods to simplify the analysis and design procedure. Recently the Canadian Highway Bridge Design Code of 2014, CHBDC [7], the AASHTO Guide Specifications for Horizontally Curved Bridges of 2003 [8] and AASHTO LRFD Bridge Design Specifications of 2017 [9] have specified certain limitations to treat horizontally curved bridges as straight one. AASHTO Guide Specifications for Horizontally Curved Bridges accepted the use of V-Load Method (VLM) as one of the methods for the analysis of horizontally curved bridges. This current study is an attempt to realize the above mentioned need in Canada. The results and the equations provided in this study will help bridge engineers in predicting new and more reliable limitations in treating the horizontally curved bridges as straight ones. Therefore, the overall objectives of the research reported herein are:

- Study the applicability of the specified limitations of bridge curvature in North American Bridge Codes to treat a horizontally curved bridge as a straight one in structural analysis and design using the V-Load method.

- Compare the results with the provided information that complements existing data and that has been done with finite element method by Khalafalla (2009) [2].

- Develop empirical expressions for stress magnification factors and use them to develop curvature limitations to treat a horizontally curved bridge as straight one.

\section{Introduction of the V-Load Method}

In 1984, AISC Marketing Inc. published a report explaining the "V-Load Analysis" for the analysis of curved steel I-girder bridges [6]. This report presented an approximate simplified analysis method to determine moments and shears for horizontally curved I-girder bridges. Now, this method is known as the V-Load method because a large part of the torsion load on the girders is approximated by sets of vertical shears known as "V-Loads." The V-Load method is a two-step process. First, the bridge is straightened out so that the applied vertical load is assumed to induce only flexural stresses. Second, additional fictitious forces are applied to result in final stresses similar to the ones in a curved bridge. The additional fictitious forces are determined so that they result in no net vertical, longitudinal, or transverse forces on the bridge. With this method, the girders are assumed to be straight, but point loads are placed along each span at points where the diaphragm or transversal bracing connects to the girders (see Figure 2), simulating torsional loads imposed on the girder system. 


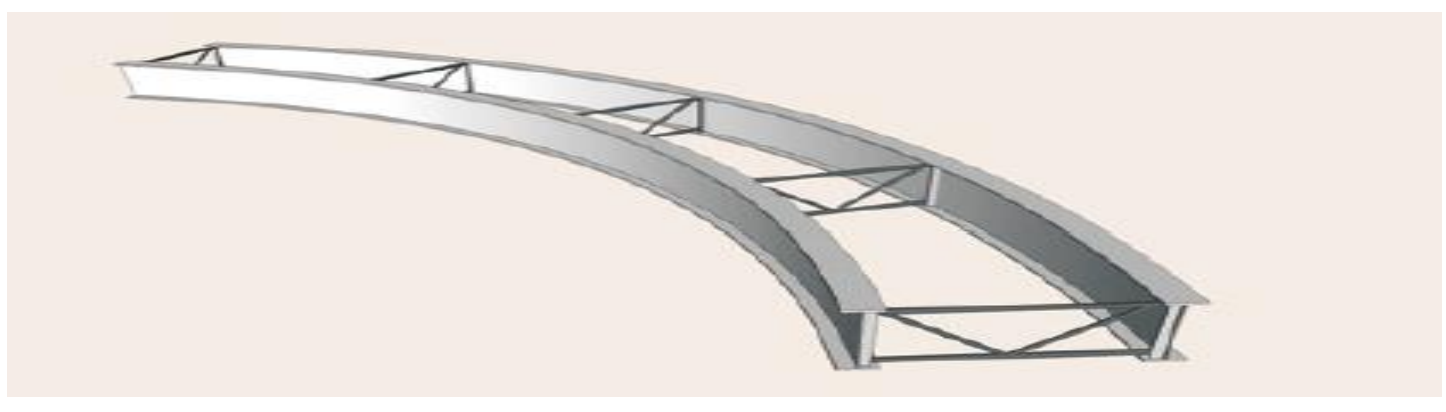

Figure 2. Braced Pair Girder [5]

In order to determine the magnitude of the extra point loads, the moments at critical sections (typically diaphragm or bracing locations) along the girders are determined, as if the bridge were a normal, straight span.

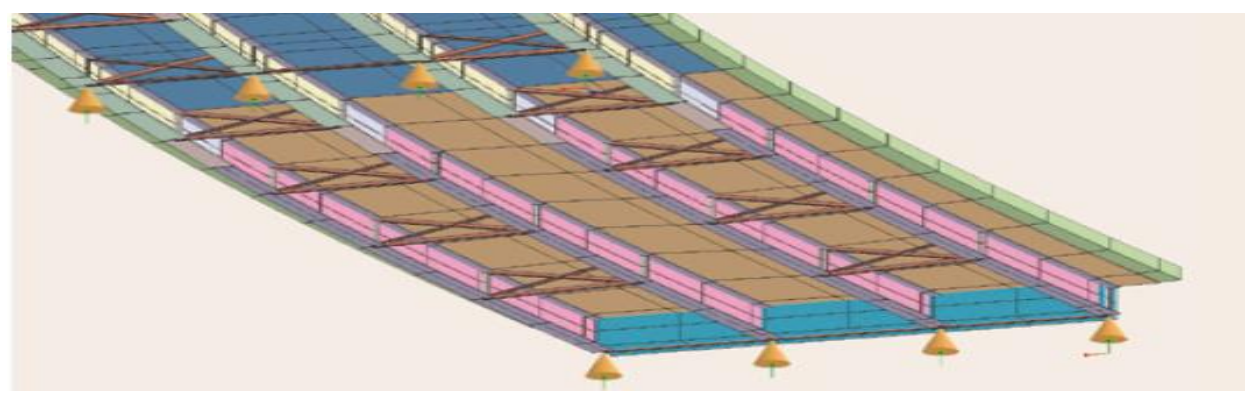

Figure 3. View of Underside of typical I-Girder Bridge [5]

Once the V-Load has been calculated, the extra loads are applied to each of the girders. The value of the loads applied depends on the position of the girder. The loads placed on the outside girder are equal to the V-Load and are acting down. The loads applied to the inside girder are also equal to the V-Load, but are acting up. The loads added to the middle girders are calculated by assuming a straight-line variation from one side of the bridge to the other. For example, if a girder is located at the center of the bridge no V-Load will be added to it. With the V-Load method, boundary conditions must be assumed which will allow evaluation by hand.

Recent efforts were made to extend the V-load method to composite curved open-framed bridges (no horizontal lateral bracing) with any general support configuration by comparing the V-load-method results to the results from several finite-element bridge models similar to that shown in Figure 3. Non-composite and composite bridges, with combinations of radial and skewed supports, were analyzed with both methods under the correct dead and live loading. The effect of horizontal lateral bracing was also studied for selected cases.

Another important consideration in the design of curved I-girder bridges is the warping stresses (lateral bending stresses) that develop in the girder flanges as depicted in Figure 4. These stresses arise from resistance to the out-of-plane warping of an I-girder cross section that is caused by the applied torsional loads. The approximate calculation of these warping stresses is also presented in this study. 


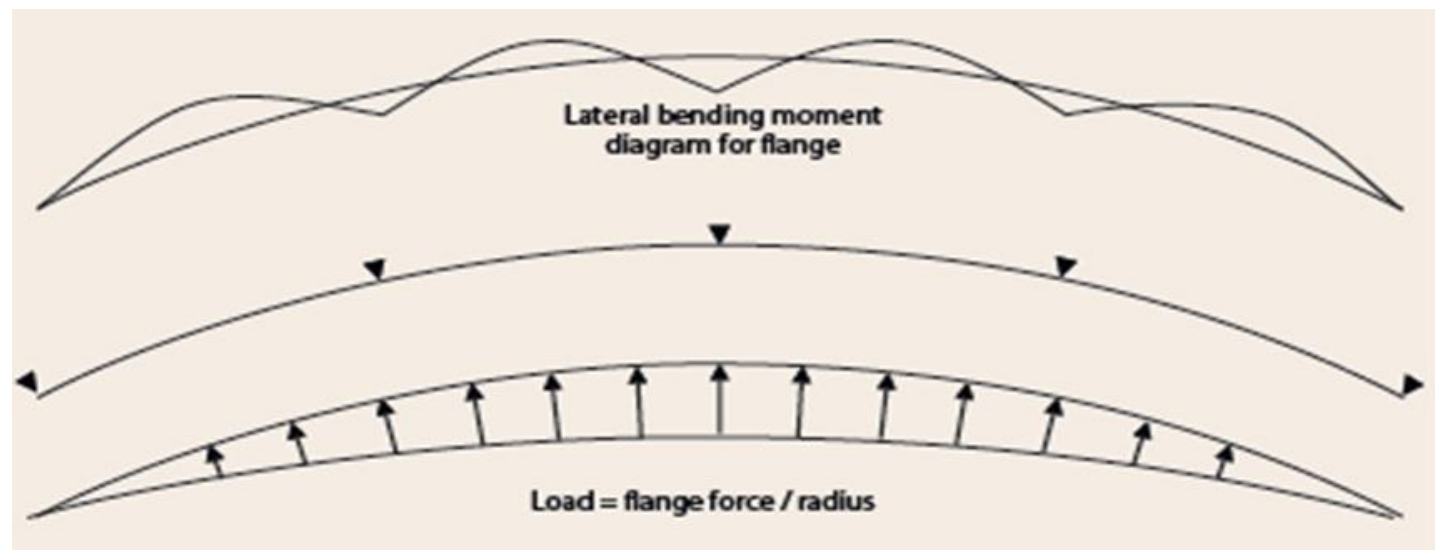

Figure 4. Lateral bending moment in girder flanges due to torsional effect [5]

For the bridge analyzed in this report there were 962 different load cases that had to be evaluated. This required repeating the $\mathrm{V}$-Load calculation process 962 times. This was not practical by hand, so a set of spread sheets was developed, using Microsoft Excel, that uses the V-Load method to calculate stress at the desired points along the span.

\section{V Load Method History and Review of Previous Work}

One of the first presentations of an approximate analysis of horizontally curved girders was by the United States Steel Corporation in 1963. The United States Steel approximate method became known as the Vload method and was extended to analyze multi-girder bridge units in 1965. A computer program implementing the V-Load method was developed in 1966 for multi-girder bridge units with radial supports [5]. About the same time, Dabrowski developed expressions for the warping moment in a curved girder using differential equations. Developments in curved girder analysis were also made by Gillespie and Ketchek. They used an approximate analysis method where it was found that the lateral bending stress was dependent on the lateral bending moment which is related to diaphragm spacing. Another method was developed by Ketchek who, in addition to allowing for the V-Loads used in earlier reports, allowed for the direct application of uniformly distributed torsional moments to the girders. In the 1970's, CURT, Consortium of University Research Teams, was established to develop methods for curved bridge analysis and design and determine bridge requirements. Also during this time, Weissman developed a method for analyzing curved girders using statically indeterminate analysis of plane grid systems with straight elements. The slope deflection technique was used by Heins and Siminou to determine various distribution factors to relate a single straight girder to a single curved girder and then to a system of curved girders. Culver, Brogan, and Bednar utilized the flexibility method to develop an approximate analysis using equivalent straight girders. They discovered that the maximum deflection of a curved girder is much larger than that of an equivalent straight girder. For small radii of curvature, a curved beam is more flexible than the equivalent straight girder, and the ratio of deflections between a curved and a straight girder increases as the radius of curvature decreases. They also found that the diaphragm spacing influenced the maximum warping stress but not the bending stress. The approximate method predicted the outer girder stress fairly well but underestimated the stress on the inner girder. 
In the 1980's, the V-Load method was revised to accommodate skewed bridges with the effort of US Steel Research and Richardson, Gordon, and Associates. Grubb found this approximate analysis method very accurate for the dead load condition. For live load, he found that the V-Load results were reasonable for the exterior girders but not for the interior girders. The accuracy was largely affected by the lateral distribution factors assumed in the V-Load method. In 1984, Heins and Jin [10] developed expressions for live load distribution factors for braced systems by the use of a three-dimensional space frame matrix formulation. Bottom bracing was added to their models to examine its effect on the load distribution. It was found that bottom bracing stiffens the system and the live load is distributed more uniformly to all the girders and the load to a given girder decreased.

\section{Approximate Analysis of Horizontally Curved Bridges using the V-Load Method}

Horizontally curved bridges respond to loads different from straight bridges because of the torsional forces induced by the curvature of the longitudinal axis. An approximate method of analysis for horizontally curved bridges can be developed using equivalent straight girders if the torque produced by the curvature is represented by self-equilibrating loads on the girders. These additional loads are called $\mathrm{V}$-loads because they are a set of vertical shears on the equivalent straight girders. The V-loads are developed from equilibrium requirements and are primarily a function of the radius of curvature, width of the bridge unit, and spacing of diaphragms (transverse bracing) between the girders [6]. This section presents the V-Load method for approximate analysis of horizontally curved bridge units. The method was first developed for a two-girder bridge unit and then for a multi-girder bridge unit.

\subsection{Two-Girder Bridge}

The approximate forces on two horizontally curved girders connected with radial diaphragms (transverse bracing) can be determined from equilibrium. Figure 5 shows a schematic diagram of the analysis of the longitudinal bending moment and resolved flange forces, while Figure 6 shows a horizontally curved bridge unit with two girders spaced a distance $D$. The angle of curvature of the bridge is $\theta$, the radius of the outside girder, girder 1, is R1 and the arc length is L1. The radius and arc length of girder 2 are R2 and L2, respectively. Radial diaphragms, spaced a distance D, connect girders 1 and 2 . Vertical loads on the bridge produce bending moments in both girders.

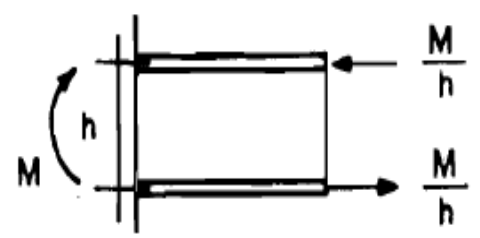

Figure 5. Longitudinal bending moment and flange forces [11]

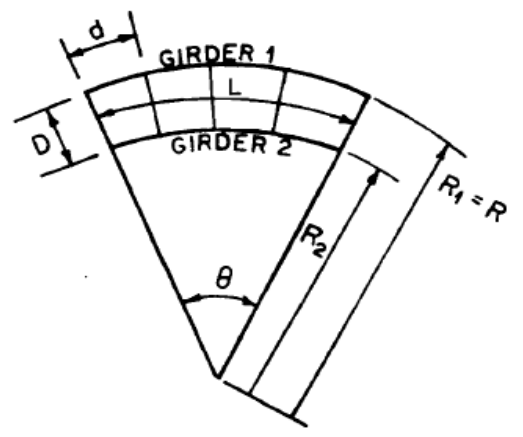

Figure 6. Horizontally curved two-girder bridge [11] 
Assuming that the plate girder sections resist the bending moment entirely by longitudinal forces in the flanges, as shown in Figure 7, the force in each flange of girder 1 is $M_{1} / h_{1}$ where $h_{1}$ is the depth of the girder and $M_{1}$ is the bending moment. In girder 2 , the bending moment is $M_{2}$ and the flange forces are $M_{2} / h_{2}$. However, because the flanges of the girder are horizontally curved, the longitudinal forces due to bending are not in equilibrium. To maintain radial equilibrium of the flange, the chord of the diaphragm must develop a force. Similar forces develop at the bottom cord of the diaphragm, for equilibrium of the bottom flange. Figure 7 shows a free body diagram of a diaphragm between the girders. The horizontal force, $\mathrm{H} 1$ and $\mathrm{H} 2$, and vertical shear force, $\mathrm{V}$, developed in the diaphragm are found as follows by equilibrium along a radial line at the diaphragm location.

$$
H_{1}=\frac{M_{1} \theta}{h_{1}}
$$

In which $\theta$ is central angle of curvature of the girder $\left(L_{1} / R_{1}\right.$ or $\left.L_{2} / R_{2}\right)$.
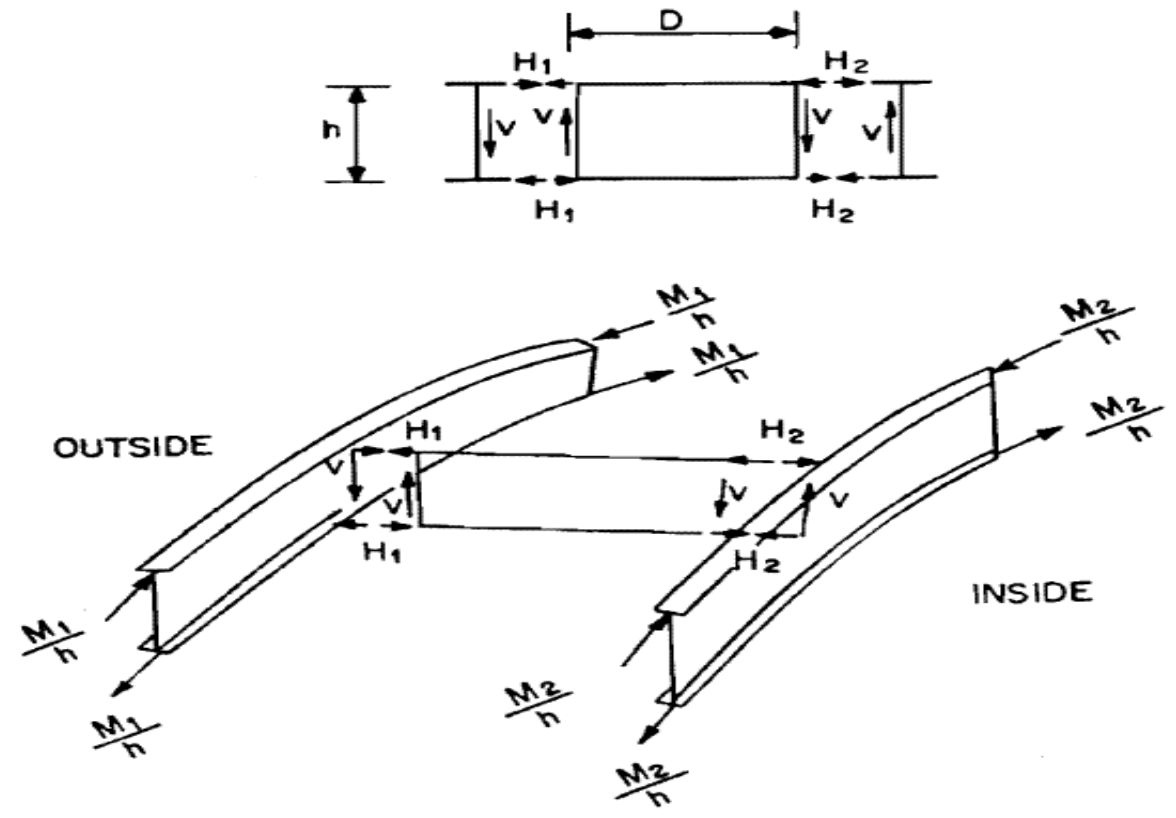

Figure 7. Free-body diagram and cross-section of bridge showing diaphragm and girders [11]

Substituting $\theta$ and $H_{1}$, repeating the same calculation for $H_{2}$ and using the equilibrium concept we have the shear force $\mathrm{V}$ :

$$
H_{1}=\frac{M_{1} d_{1}}{h_{1} R_{1}} \quad, \quad V=\left(H_{1}+H_{2}\right) \frac{h}{D} \quad, \quad V=\frac{M_{1} \frac{d_{1}}{R_{1}}+M_{2} \frac{d_{2}}{R_{2}}}{D}
$$

But from geometry, $d 1 / R 1=d 2 / R 2=d / R$ and the shear force in the diaphragm (transverse bracing) is:

$$
V=\frac{M_{1}+M_{2}}{R D / d}
$$


These shear forces in the diaphragm act in the opposite direction on girders 1 and 2 . The shear forces, known as V-loads, are self-equilibrating forces on the bridge unit that approximate the effects of the horizontal curvature of the girders. They must be self-equilibrating forces because they are not actual loads applied to the bridge unit.

The bending moments $M_{1}$ and $M_{2}$ are the moments in girders 1 and 2 due to the applied loads and the additional forces due to curvature, as represented by the V-loads. The two contributions to the totals moment can be separated as:

$$
\begin{aligned}
& M_{1}=M_{1 p}+M_{1 v} \\
& M_{2}=M_{2 p}+M_{2 v}
\end{aligned}
$$

The subscripts $\mathrm{p}$ and $\mathrm{v}$ denote responses due to the P-Loads, which are applied loads, and V-loads respectively. In common application of the V-Load method, the bending moments produced by the concentrated $V$-Load forces are assumed proportional to their respective girder lengths. Equation 5 gives the magnitude of the $V$-loads as a function of the P-Load moments only:

$$
V+\frac{M_{1 p}+M_{2 p}}{R D / d}
$$

Where the V-Load forces act on the girders at the diaphragm location.

In summary, the V-Load method involves analyzing the girders in the bridge unit as equivalent straight girders twice as follows.

- The first analysis gives the response to P-Loads, including $M_{1 p}$ and $M_{2 p}$.

- The second analysis gives the response to the self-equilibrating V-Load applied at the diaphragm or transverse bracing locations.

The total response on the girders is the sum of the responses to the P-Loads and V-Loads.

\subsection{Multi-Girder Bridge}

In a curved bridge unit with two girders, the outer girder experiences an increase in load due to the curvature while the inner one experiences a decrease in load. The same procedure can be applied in a bridge with more than two girders, but the effect of curvature must also be distributed to the inner girders. A general expression for the $\mathrm{V}$-Loads acting on multiple girder units can be developed using a similar procedure as for the two-girder bridge geometry.

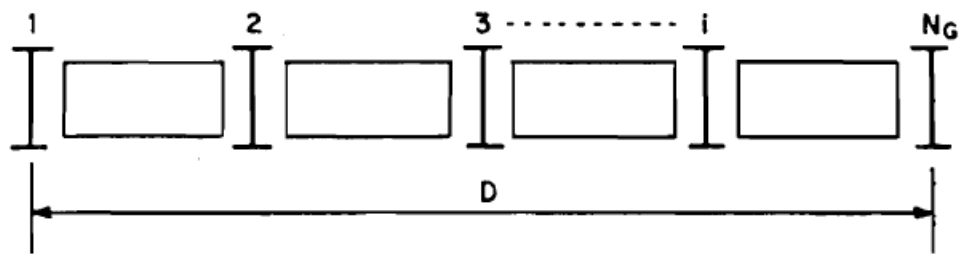

Figure 8. Cross section of a multi-girder bridge unit [11] 
Figure 8 shows a cross section of a bridge unit with $N$ girders, where $D$ is the distance between outer and inner girders. Due to curvature, the section is subjected to twisting. Lateral flange forces develop and produce forces in the diaphragms as described before. The V-Loads are derived using equilibrium between the girders and the diaphragms or transverse bracing. It can be shown that equilibrium of the diaphragm panels allows summation of the lateral flange forces and with repeating same approach, the equation for $\checkmark$ can be expressed as follows:

$$
V=\frac{\sum_{i=1}^{N_{g}} M_{p i}}{C(R D / d)}
$$

In which, $\mathrm{Ng}$ is the number of girders and $\mathrm{C}$ is equal to:

$$
C=\frac{1}{6} \frac{N_{g}\left(N_{g}+1\right)}{N_{g}}-1
$$

The other parameters are defined earlier.

\begin{tabular}{|c|c|}
\hline Number of Girdres, $\mathbf{~ N g}$ & $\mathbf{C}$ \\
\hline 2 & 1.0000 \\
\hline 3 & 1.0000 \\
\hline 4 & 1.1111 \\
\hline 5 & 1.2500 \\
\hline 6 & 1.4000 \\
\hline 7 & 1.5556 \\
\hline 8 & 1.7143 \\
\hline
\end{tabular}

Table 1. Value of $\mathrm{C}$ as a Function of the number of girders, $\mathrm{N}_{\mathrm{g}}[5]$

A check of this expression for a two-girder unit gives a value of $C$ equal to 1.0. This is the same coefficient as found in the derivation of the two girder unit. Table 1 lists the value of $C$ as a function of the number of girders. The summation of girder moments in $\mathrm{V}$ Equation can be approximately represented by the summation of primary girder moments as done for two-girder units. The V-Loads acting on the diaphragm or transverse bracing locations of the other girders are given by V-Load Equation that is based on the assumption of linearly varying diaphragm shear.

The first of the two analyses for each equivalent straight girder gives the P-Load moment, shear, and reaction responses, respectively. The second analysis gives the responses due to the V-Loads. The expression for the V-Load factor is dependent on the number of girders as derived above. The V-Loads are assumed to be distributed linearly between the outer and inner girders, Therefore, the V-Load on a girder is proportional to its distance from the bridge centerline. The magnitude of the V-Loads is observed to:

$\checkmark$ increase with decreasing radius of curvature,

$\checkmark$ increase with increase the curvature,

$\checkmark$ increase with decreasing bridge unit width, and 


\section{$\checkmark$ increase with increasing diaphragm (transverse bracing) spacing}

In summary, the V-Load method involves analyzing the girders in the bridge unit as equivalent straight girders twice as follows.

- The first analysis gives the response to P-Loads, including $M_{p i}$.

- The second analysis gives the response to the self-equilibrating V-Load applied at the diaphragm or transverse bracing locations.

The total response on the girders is the sum of the responses to the P-Loads and V-loads.

\subsection{Torsional Response of Girders}

In addition to the basic vertical shear and bending effects, a curved girder is also subjected to torsional effects. Because I-shaped girders have low St. Venant torsional stiffness, they carry torsion primarily by means of warping. The total state of normal stress in an I-shaped girder is a combination of any axial stress, major axis bending stress, lateral bending stress, and warping normal stress. The total state of shear stress in an I-shaped girder is a combination of vertical shear stress, horizontal shear stress, some St. Venant torsional shear stress (typically relatively small), and warping shear stress [4].

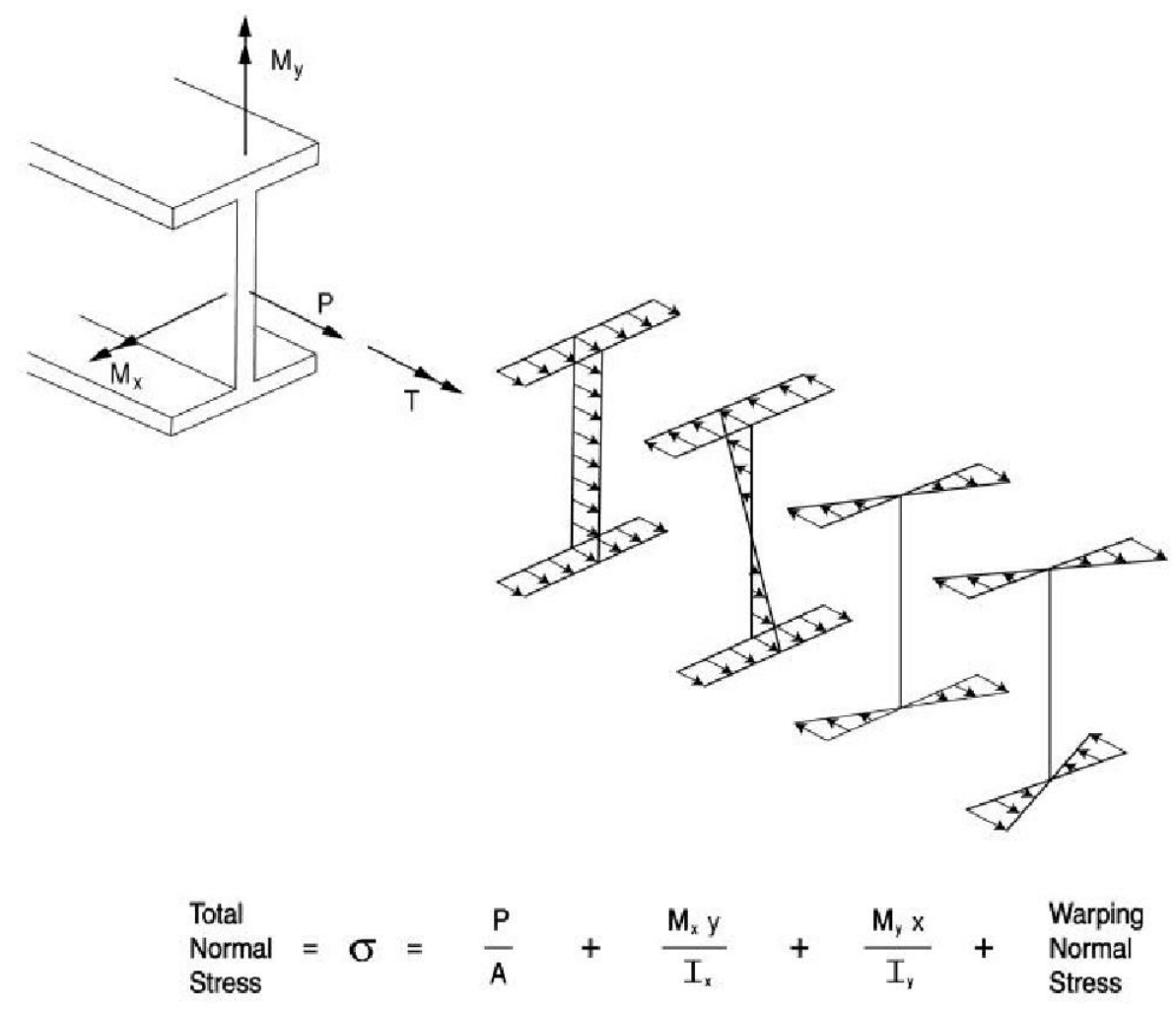

Figure 9. The general I-girder normal stresses, which can occur in a curved I-shaped girder 
The relatively low St. Venant torsional stiffness of I-shaped girders is a result of their open cross sectional geometry. The St. Venant torsional shear flow around the perimeter of the cross section can only develop relatively small force couples [12].

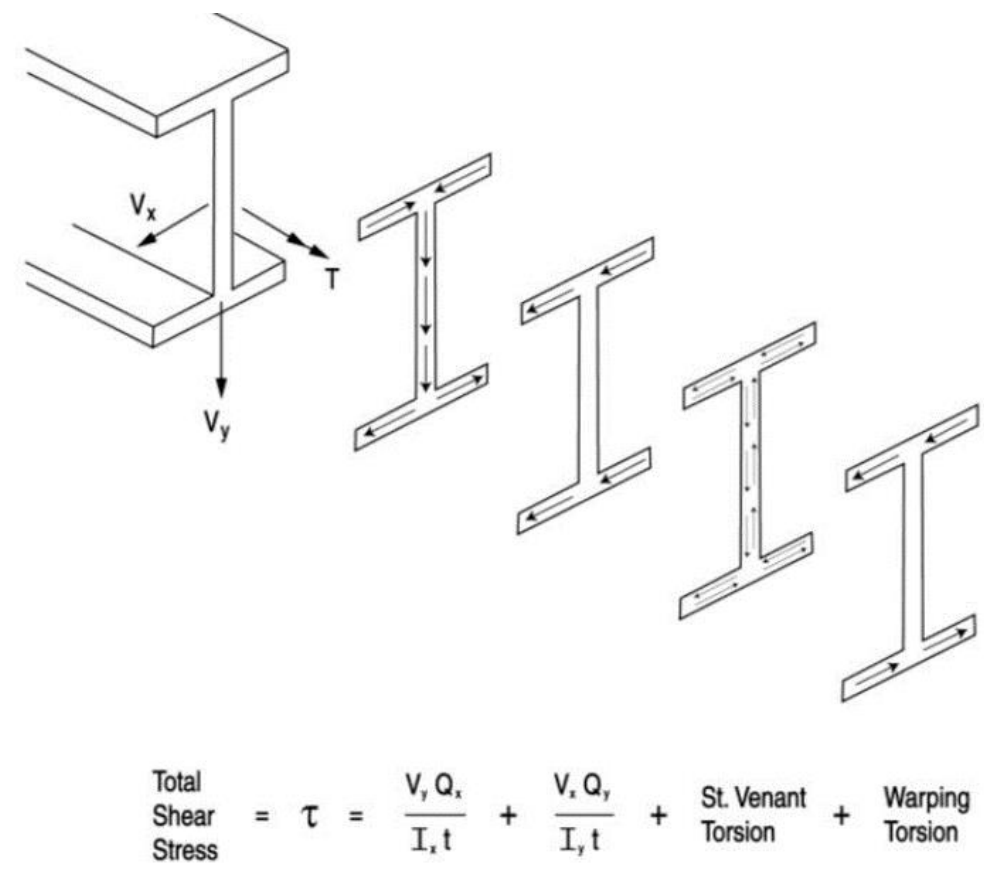

Figure 10. The general I-girder shear stresses, which can occur in a curved I-shaped girder [10]

Assuming no bracing in the plate of the bottom flange, the St. Venant's stiffness for wide flange girders is much less than its warping stiffness. So, the St. Venant's torsion is neglected in an approximate analysis of curved girder bridge without bracing in the plane of the bottom flanges. All of the torsion is assumed to be resisted by warping of the girders. The approximate torsional response analysis presented as follows.

The section of a girder twisted through an angle, $\phi$, and by a torque, $\mathrm{T}$, is shown in Figure 11 . The torque creates flange shear forces, $\mathrm{T} / \mathrm{h}$, in the direction of the torque, where $\mathrm{h}$ is the depth of the girder section. These flange shears cause lateral bending moments, $\mathrm{M}_{\mathrm{f}}$, in the flange. The effects of warping torsion can be approximated by applying lateral forces to a straight model of the bottom flange. Due to horizontal curvature, radial forces develop on the flanges to establish equilibrium.

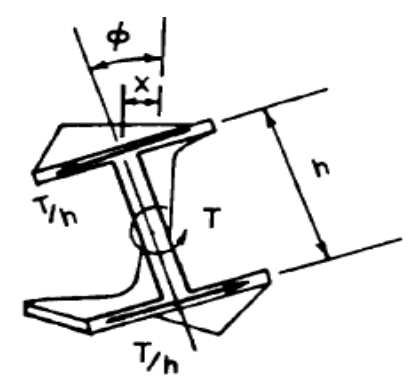

Figure 11. Girder section twisted by a torque [11] 
The lateral load on the flange, $W_{W}$, varies along its length and in proportion to the bending moment as required for radial equilibrium:

$$
W_{W}=M / R h
$$

Where $\mathrm{M}$ is the total bending moment on the girder, $\mathrm{h}$ is the distance between flanges, and $\mathrm{R}$ is the radius of the twisted by the girder. The distribution of these lateral flange loads is shown in Figure 12.

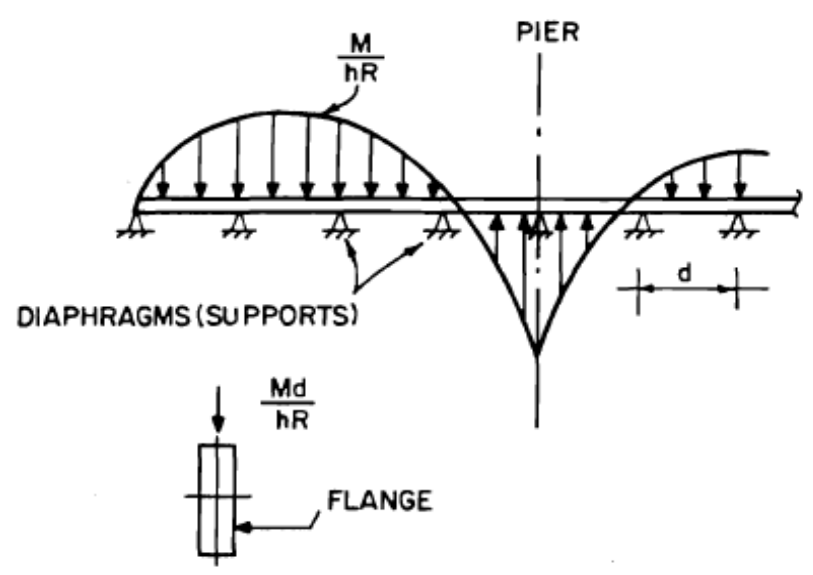

Figure 12. Distribution of lateral loads on a girder flange [11]

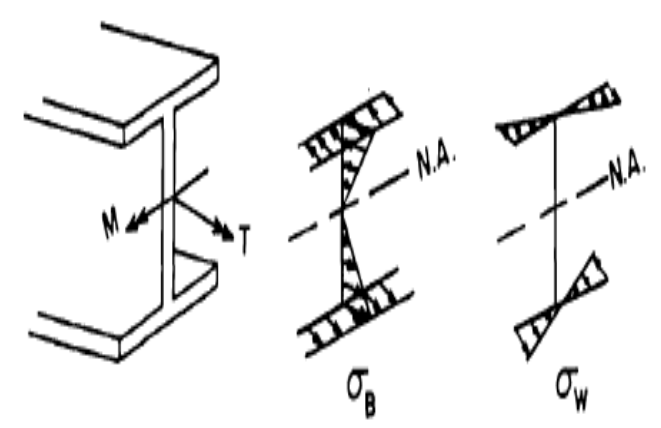

Figure 13. Bending and warping stress in girder cross section [11]

As shown in the above figure, diaphragms or transverse bracing restrain lateral bending of the girders, acting as lateral supports for the flanges. In the approximation, the diaphragms are assumed to provide rigid supports against lateral bending. The lateral bending moments in the flange resulting from this loading (flange warping), $M_{f}$, is illustrated in Figure (12). However, for simplicity, the transverse bending moment in girder flanges for cases with less than 3 intermediate cross frames (transverse bracing) or diaphragms may be determined as follows:

For other cases:

$$
\begin{aligned}
& M_{f}=1 / 8 W_{w} d^{2} \\
& M_{f}=1 / 10 W_{w} d^{2}
\end{aligned}
$$

The normal warping stress at the flange tip is then given by: 


$$
\sigma_{w}=\frac{M_{f}}{S_{f}}
$$

where $S_{f}$ is the section modulus of the bottom flange for lateral bending.

The longitudinal bending stress and warping stress distributions on a girder cross section are shown in Figure 13. The summation of the stress due to bending, $\sigma_{b}$, and that due to warping, $\sigma_{\mathrm{w}}$, gives the total stress at the tip of the flange, $\sigma_{\mathrm{t}}$.

\section{Analysis Procedure}

The procedures relevant to the analysis of curved bridge in this study involves computing the moments, shear forces, longitudinal and warping stresses, and reactions that develop due to dead load and specified positions of live loads. A direct analysis of the structure with the prescribed loads can be performed to compute the responses.

The approximate analysis procedure, based on the V-Load method, presented in this study, computes the response of multi-girder bridge units with variable radius of curvature. The girders may include composite behavior of the steel girders and concrete slab. The analysis procedure for horizontally curved bridges is based on the V-Load method described in Section 5. Two analyses of the equivalent straight girders are performed for each load case. The applied loads on the girder are called P-Loads, and analysis of the girders subjected to these loads results in P-Load responses such as $M_{p}, V_{p}$ and $R_{p}$ which are the bending moments, shears, and reactions, respectively. Because of the horizontal curvature of the unit, $\mathrm{V}$-Loads act on the girders.

The girders are analyzed a second time with the V-Loads applied at the diaphragm or transverse bracing locations. The response due to these V-Loads result in V-Load responses, namely: $M^{\prime \prime}, V^{\prime \prime \prime} R^{\prime \prime}$, representing the bending moments, shears, and reactions, respectively. The response of the girders in the curved unit is the sum of the P-Load and V-Load responses. Each equivalent straight girder in the unit is modeled by an arbitrary number of prismatic beam elements (constant properties for each element) connected at nodes. An important requirement of the analysis is to compute the response values along the entire length of the girders, not just at the nodes. The more the locations at which the response is computed, the better the resolution of the maximum and minimum response.

\section{Slab-On-Steel I-Girder Bridge Configurations}

A total of 462 single span and continuous two-span straight and curved concrete slab-on-steel l-girder bridge prototypes were considered for the V-Load analysis in the parametric study.

Major parameters were considered in two steps. The first steps involves comparing the results with the available results obtained from the finite element modelling performed by Khalafalla [2]. The second step 
involves changing the parameters such as curvature and number of cross bracing (to limit the ratio of warping stress to total stress to a prescribed value) and to reach reliable expression for curvature limitation to treat a curved bridges as a straight one in analysis.

\subsection{Parameters Considered to Compare the Result with the Finite Element Method}

The parameters considered for comparison with the results from the finite-element analysis are listed as follows.

- Span length (L): 15,25 , and $35 \mathrm{~m}$;

- Girder spacing (S): 2 m;

- Depth-to-span ratios (D/L): $1 / 25$ for single span, and 1/30 for two spans;

- Number of girders (N): 4 for $8 \mathrm{~m}$ bridge width; 6 for $12 \mathrm{~m}$ bridge width; 8 for $16 \mathrm{~m}$ bridge width;

- Span-to-radius of curvature ratio (L/R): 0.0, 0.1, 0.2, 0.3, 0.4, 0.5, \& 0.6;

- Number of X-bracing with top and bottom chord: 3 for $15 \mathrm{~m}$ span length; 5 for $25 \mathrm{~m}$ span length and 7 for $35 \mathrm{~m}$ span length;

- Deck slab thickness: $200 \mathrm{~mm}$;

- Girder web and flange thickness: $16 \mathrm{~mm}$;

- Overhang slab length: half the girder spacing;

- Bottom and top steel flange widths: $300 \mathrm{~mm}$.

\subsection{Parameters considered for limiting the warping stress}

The parameters considered to study warping stresses include those listed in listed in Section 7.1 in addition to the following:

- adding the span-to-radius of curvature ratio (L/R) as $0.02,0.04,0.06$ and 0.08

- considering a wide range of number of intermediate $X$ bracing as follows:

○ For $L=15 \mathrm{~m}, 5$, 4, 3, 2 for single span and 11, 9, 7, 5 for two-span (15-15) bridge

○ For $L=25 \mathrm{~m}, 7,5,4,3,2$ for single span and 15, 11, 9, 7, 5 for two-span (25-25) bridge

- For $L=35 \mathrm{~m}, 9,7,6,5$, 3 for single span and 19, 15, 13, 11, 7 for two-span (35-35) bridge

- Effect of depth with changing the overall depth

General cross section and geometric properties of the studied bridges are shown in Figure 14 and Table 2.

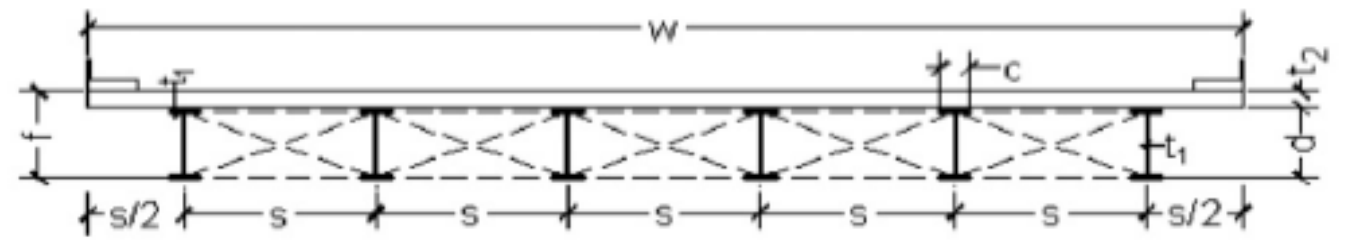

Figure 14. General cross section of the studied bridges [2] 
Table 2. Geometry of the studied bridges [2]

\begin{tabular}{cccccccccc} 
& & Number of & Bridge width & Number of & Girder spacing & \multicolumn{5}{c}{ Steel bridges } \\
\cline { 6 - 10 } Span $L(\mathrm{~m})$ & girders $(N)$ & $W(\mathrm{~m})$ & spans & $S(\mathrm{~m})$ & $C$ & $d$ & $f$ & $t_{1}$ & $t_{2}$ \\
\hline 15 & 4 & 8 & 1 & 2 & 300 & 700 & 900 & 16 & 200 \\
15 & 6 & 12 & 1 & 2 & 300 & 700 & 900 & 16 & 200 \\
15 & 8 & 16 & 1 & 2 & 300 & 700 & 900 & 16 & 200 \\
15 & 4 & 8 & 2 & 2 & 300 & 700 & 900 & 16 & 200 \\
15 & 6 & 12 & 2 & 2 & 300 & 700 & 900 & 16 & 200 \\
15 & 8 & 16 & 2 & 2 & 300 & 700 & 900 & 16 & 200 \\
25 & 4 & 8 & 1 & 2 & 300 & 1,000 & 1,200 & 16 & 200 \\
25 & 6 & 12 & 1 & 2 & 300 & 1,000 & 1,200 & 16 & 200 \\
25 & 8 & 16 & 1 & 2 & 300 & 1,000 & 1,200 & 16 & 200 \\
25 & 4 & 8 & 2 & 2 & 300 & 900 & 1,100 & 16 & 200 \\
25 & 6 & 12 & 2 & 2 & 300 & 900 & 1,100 & 16 & 200 \\
25 & 8 & 16 & 2 & 2 & 300 & 900 & 1,100 & 16 & 200 \\
35 & 4 & 8 & 1 & 2 & 300 & 1,400 & 1,600 & 16 & 200 \\
35 & 6 & 12 & 1 & 2 & 300 & 1,400 & 1,600 & 16 & 200 \\
35 & 8 & 16 & 1 & 2 & 300 & 1,400 & 1,600 & 16 & 200 \\
35 & 4 & 8 & 2 & 2 & 300 & 1,200 & 1,400 & 16 & 200 \\
35 & 6 & 12 & 2 & 2 & 300 & 1,200 & 1,400 & 16 & 200 \\
35 & 8 & 16 & 2 & 2 & 300 & 1,200 & 1,400 & 16 & 200 \\
\hline
\end{tabular}

\subsection{Assumptions of this study}

This study was based on the following assumptions:

1. Bridges were are analyzed as beam elements;

2. Bridges were single, and two spans;

3. Materials were elastic and homogenous; and

4. Bridges had constant radii of curvature between radial support lines.

\subsection{Loads}

For the purpose of comparing the results of a straight bridge with a curved one, bridges were analyzed for dead load only in this study.

\subsection{Stress Magnification Factor}

The stress magnification factor (SMF) for curved bridges was determined. From bridge analysis, the maximum vertical stresses were determined for straight ( $\left.\sigma_{\text {straight}}\right)$ and curved ( $\left.\sigma_{\text {curve }}\right)$ bridges due to a uniformly distributed dead load. Accordingly, the stress distribution factors, SMF, were calculated as follows: 
Based on research carried out using the finite element method [2], the stress magnification factors due to bending moment, including longitudinal and transverse bending moment (torsion effect in terms of warping stress) are considered for both single and two-span curved slab-on-steel l-girder bridges for the sake of comparison with the results obtained from the V-Load method. As such, results for the shear and deflection magnification factors obtained by Khalafalla [2] were not considered herein.

\section{Stress Magnification Factors obtained using the V-Load Method and the Finite Element Method}

A data base was generated from the parametric study using Microsoft Spread Sheet, Excel, to develop a comparison of the SMFs obtained using the finite element method and the V-Load method. Also, the results were used to examine the curvature limitation presented in CHBDC and AASHTO codes. Due to a large numbers of different bridges considered in this study, selected results are presented in this section.

Tables 3 through 11 present the stress magnification factors obtained using the finite-element method (FEM) and the V-Load method (VLM) for single span bridges with span ranging from 15 to $35 \mathrm{~m}$ and bridge widths ranging from 8 to $16 \mathrm{~m}$. The results are also presented in a graphical form in Figures 15 through 23. One In addition, Tables 12 through 20 present the stress magnification factors obtained using the finite-element method and the V-Load method for two-equal-span continuous bridges with span ranging from 15 to $35 \mathrm{~m}$ and bridge widths ranging from 8 to $16 \mathrm{~m}$. The results are also presented in a graphical form in Figures 24 through 32. Good correlation was observed between the results obtained from the finite-element modelling and the V-Load method. However, the results obtained from the V-Load method appear to overlap with those obtained from the finite element method in the range of span-to-radius of curvature ration, $L / R$, less than 0.2 , with differences between the two results generally increasing with increase in $L / R$ ratio. However, this conclusion is altered in very few bridges cases as shown in Figures 17 , $19,20,21,22$ and 23 on which the results from the finite element method and the V-Load methods are very close to each other all over the studied range of L/R (i.e. 0 to 0.6 ).

Analysis based on V Load Method including flexural stress and warping stress have been performed and the following observations were made:

1. Curvature is the most important parameter that affecting the structural behavior of horizontally curved bridges. Increase in the degree of curvature leads to significant increase in the stress, deflection, and reaction distribution factors, and decrease in the frequency distribution factor.

2. The stress magnification factor increased with increase in bridge curvature.

3. The stress magnification factor for single span bridges is about double that for two-span continuous bridges at the position moment region. 
4. The stress magnification factor at the negative moment region in two-span continuous bridges is significantly less than that at the position moment region. The ratio between then changes based on the studied bridge span, width and radius of curvature.

Table 3. Comparison of the stress magnification factor obtained from the FEM and VLM for single span bridges of $15 \mathrm{~m}$ span and $8 \mathrm{~m}$ width

\begin{tabular}{|c|c|c|c|c|c|}
\hline \multicolumn{3}{|c|}{ FINITE ELEMENT METHOD (FEM) -by Khalafalla 2009 } & \multicolumn{2}{c|}{ V LOAD METHOD (VLM) } \\
\hline L(m) & $\mathbf{W}(\mathbf{m})$ & Theta (L/R) & S11 Mid Span & WS/TS & SMF-Mid Span \\
\hline 15 & 8 & 0 & 1 & 0 & 1 \\
\hline 15 & 8 & 0.1 & 1.406804044 & 0.2392871335 & 1.4439581658 \\
\hline 15 & 8 & 0.2 & 1.827447166 & 0.3861689952 & 1.9498445855 \\
\hline 15 & 8 & 0.3 & 2.242315563 & 0.4855091940 & 2.5176593087 \\
\hline 15 & 8 & 0.4 & 2.636415213 & 0.5571744809 & 3.1474023353 \\
\hline 15 & 8 & 0.5 & 2.99981764 & 0.6113157212 & 3.8390736654 \\
\hline 15 & 8 & 0.6 & 3.328976962 & 0.6536603017 & 4.5926732989 \\
\hline
\end{tabular}

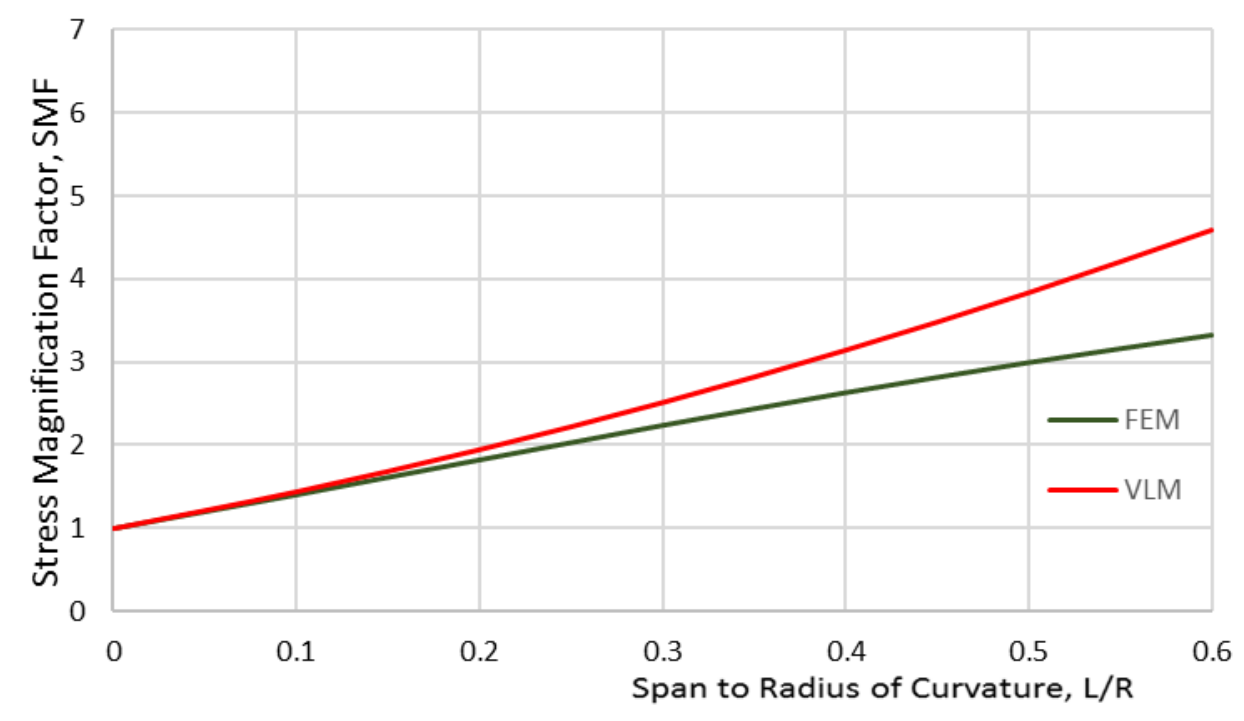

Figure 15. Comparison of the stress magnification factor obtained from the FEM and VLM for single span bridges of $15 \mathrm{~m}$ span and $8 \mathrm{~m}$ width 
Table 4. Comparison of the stress magnification factor obtained from the FEM and VLM for single span bridges of $15 \mathrm{~m}$ span and $12 \mathrm{~m}$ width

\begin{tabular}{|c|c|c|c|c|c|}
\hline \multicolumn{9}{|c|}{ FINITE ELEMENT METHOD (FEM) -by Khalafalla 2009 } & \multicolumn{2}{c|}{ V LOAD METHOD (VLM) } \\
\hline L(m) & $\mathbf{W}(\mathbf{m})$ & Theta (L/R) & S11 Mid Span & WS/TS & SMF-Mid Span \\
\hline 15 & 12 & 0 & 1 & 0 & 1 \\
\hline 15 & 12 & 0.1 & 1.42174074 & 0.239287134 & 1.406986263 \\
\hline 15 & 12 & 0.2 & 1.858776221 & 0.386168995 & 1.858206978 \\
\hline 15 & 12 & 0.3 & 2.293010833 & 0.485509194 & 2.353662195 \\
\hline 15 & 12 & 0.4 & 2.709740019 & 0.557174481 & 2.893351914 \\
\hline 15 & 12 & 0.5 & 3.098060399 & 0.611315721 & 3.477276136 \\
\hline 15 & 12 & 0.6 & 3.451169863 & 0.653660302 & 4.105434859 \\
\hline
\end{tabular}

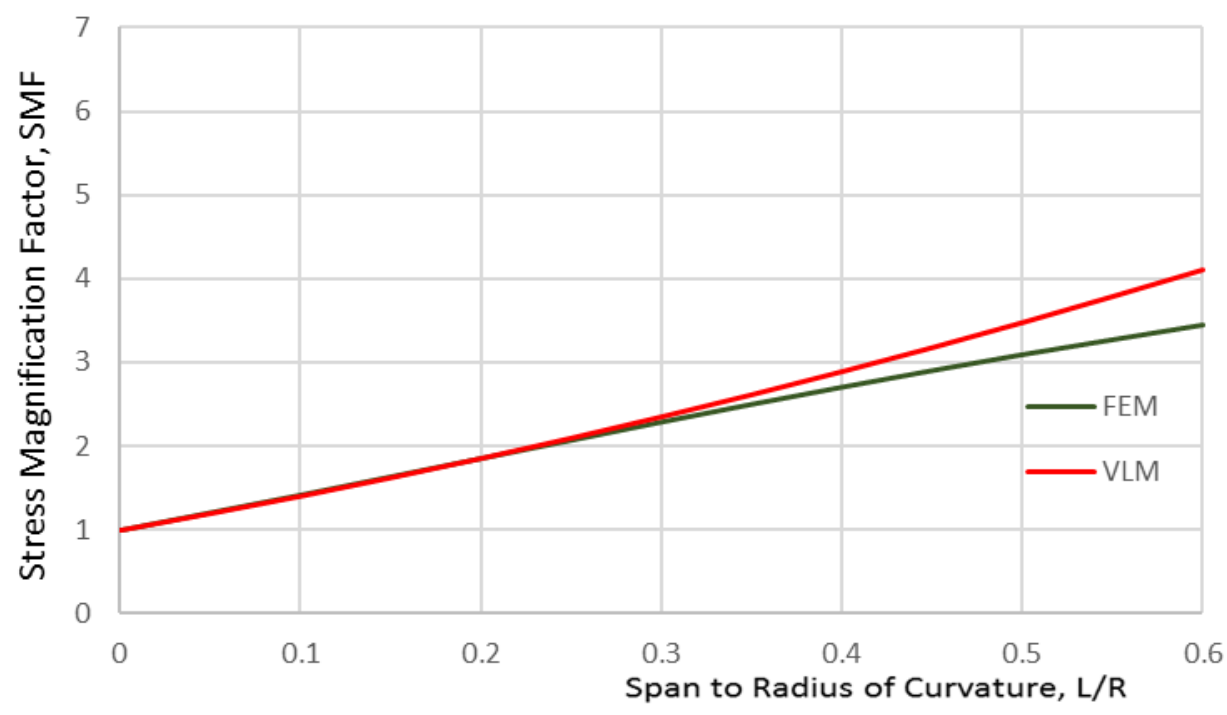

Figure 16. Comparison of the stress magnification factor obtained from the FEM and VLM for single span bridges of $15 \mathrm{~m}$ span and $12 \mathrm{~m}$ width 
Table 5. Comparison of the stress magnification factor obtained from the FEM and VLM for single span bridges of $15 \mathrm{~m}$ span and $16 \mathrm{~m}$ width

\begin{tabular}{|c|c|c|c|c|c|}
\hline \multicolumn{3}{|c|}{ FINITE ELEMENT METHOD (FEM) -by Khalafalla 2009 } & \multicolumn{2}{c|}{ V LOAD METHOD (VLM) } \\
\hline L(m) & $\mathbf{W}(\mathbf{m})$ & Theta (L/R) & S11 Mid Span & WS/TS & SMF-Mid Span \\
\hline 15 & 16 & 0 & 1 & 0 & 1 \\
\hline 15 & 16 & 0.1 & 1.445873206 & 0.239287134 & 1.386445718 \\
\hline 15 & 16 & 0.2 & 1.914174641 & 0.386168995 & 1.807295713 \\
\hline 15 & 16 & 0.3 & 2.386164274 & 0.485509194 & 2.262550034 \\
\hline 15 & 16 & 0.4 & 2.845893142 & 0.557174481 & 2.75220868 \\
\hline 15 & 16 & 0.5 & 3.280602073 & 0.611315721 & 3.276271653 \\
\hline 15 & 16 & 0.6 & 3.680821372 & 0.653660302 & 3.834738951 \\
\hline
\end{tabular}

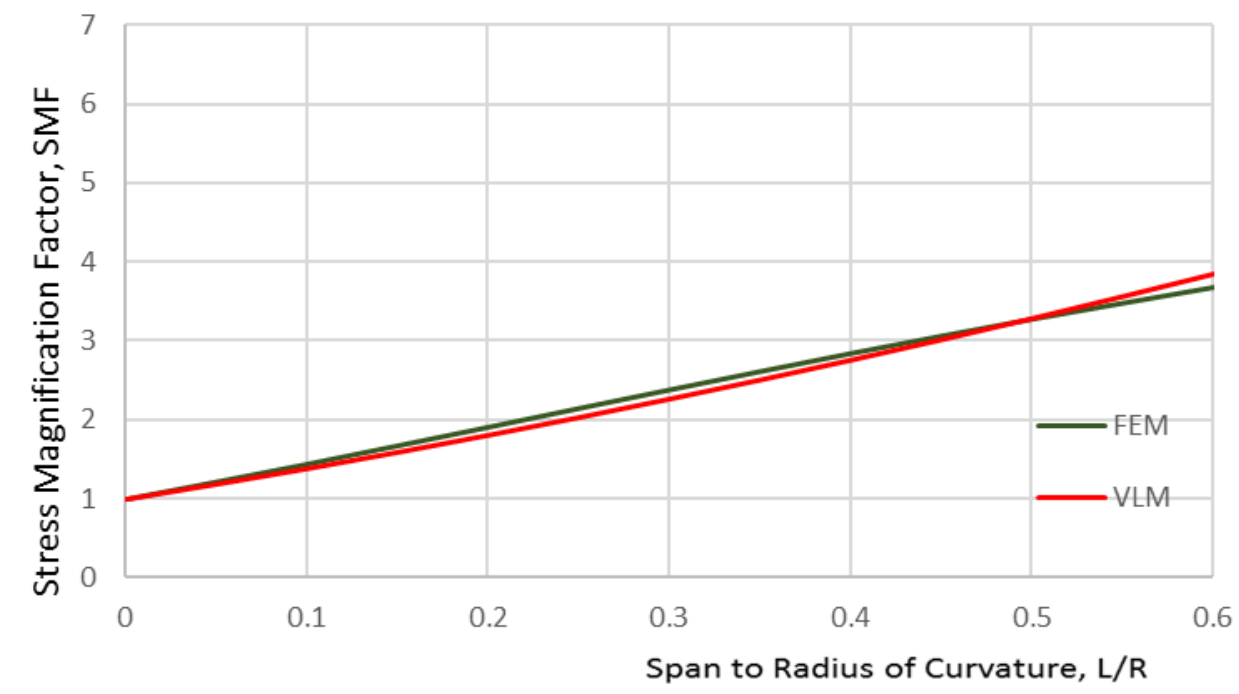

Figure 17. Comparison of the stress magnification factor obtained from the FEM and VLM for single span bridges of $15 \mathrm{~m}$ span and $16 \mathrm{~m}$ width 
Table 6. Comparison of the stress magnification factor obtained from the FEM and VLM for single span bridges of $25 \mathrm{~m}$ span and $8 \mathrm{~m}$ width

\begin{tabular}{|c|c|c|c|c|c|}
\hline \multicolumn{3}{|c|}{ FINITE ELEMENT METHOD (FEM) -by Khalafalla 2009 } & \multicolumn{2}{c|}{ V LOAD METHOD (VLM) } \\
\hline L(m) & W(m) & Theta (L/R) & S11 Mid Span & WS/TS & SMF-Mid Span \\
\hline 25 & 8 & 0 & 1 & 0 & 1 \\
\hline 25 & 8 & 0.1 & 1.473769411 & 0.213543666 & 1.474765844 \\
\hline 25 & 8 & 0.2 & 1.983512201 & 0.351934045 & 2.036332609 \\
\hline 25 & 8 & 0.3 & 2.500509623 & 0.448908054 & 2.684700338 \\
\hline 25 & 8 & 0.4 & 3.000539601 & 0.520637891 & 3.419869032 \\
\hline 25 & 8 & 0.5 & 3.468493315 & 0.575845604 & 4.24183869 \\
\hline 25 & 8 & 0.6 & 3.89771569 & 0.61965016 & 5.150609311 \\
\hline
\end{tabular}

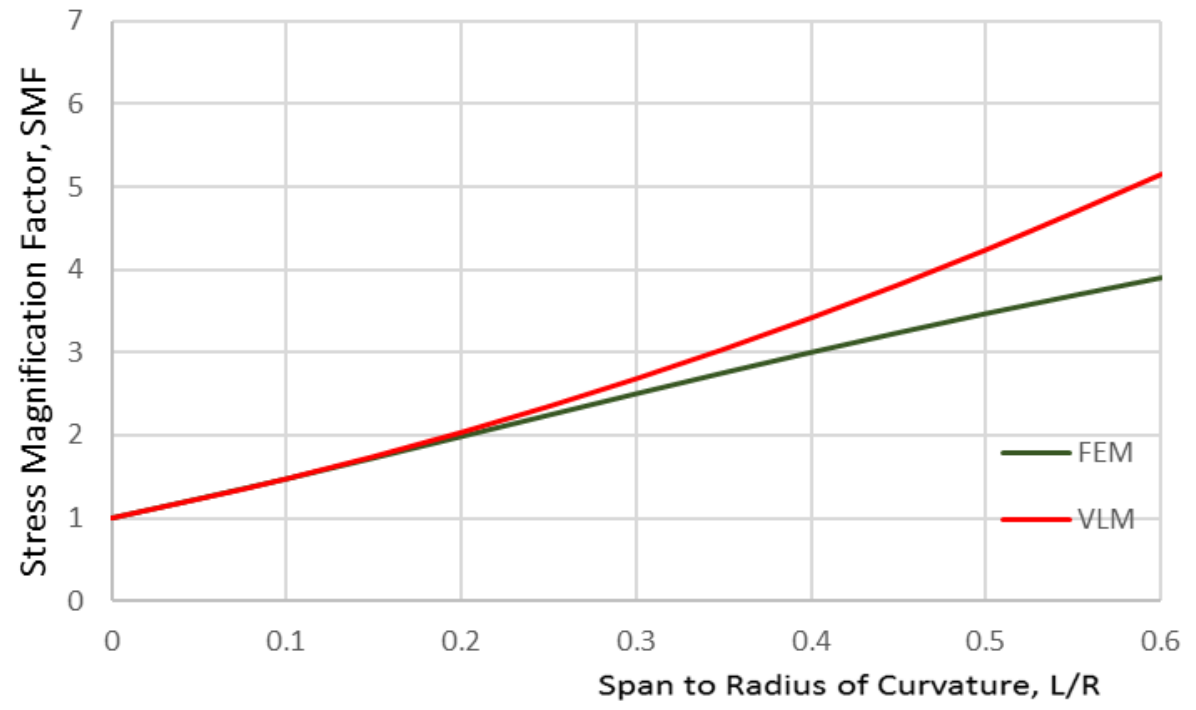

Figure 18. Comparison of the stress magnification factor obtained from the FEM and VLM for single span bridges of $25 \mathrm{~m}$ span and $8 \mathrm{~m}$ width 
Table 7. Comparison of the stress magnification factor obtained from the FEM and VLM for single span bridges of $25 \mathrm{~m}$ span and $12 \mathrm{~m}$ width

\begin{tabular}{|c|c|c|c|c|c|}
\hline \multicolumn{3}{|c|}{ FINITE ELEMENT METHOD (FEM) -by Khalafalla 2009 } & \multicolumn{2}{c|}{ V LOAD METHOD (VLM) } \\
\hline L(m) & $\mathbf{W}(\mathbf{m})$ & Theta (L/R) & S11 Mid Span & WS/TS & SMF-Mid Span \\
\hline 25 & 12 & 0 & 1 & 0 & 1 \\
\hline 25 & 12 & 0.1 & 1.468007857 & 0.197973884 & 1.389195015 \\
\hline 25 & 12 & 0.2 & 1.967918576 & 0.330514524 & 1.834754249 \\
\hline 25 & 12 & 0.3 & 2.478126302 & 0.425461228 & 2.336677745 \\
\hline 25 & 12 & 0.4 & 2.97988215 & 0.496822121 & 2.894965503 \\
\hline 25 & 12 & 0.5 & 3.459198857 & 0.552414692 & 3.509617523 \\
\hline 25 & 12 & 0.6 & 3.907267425 & 0.596945353 & 4.180633805 \\
\hline
\end{tabular}

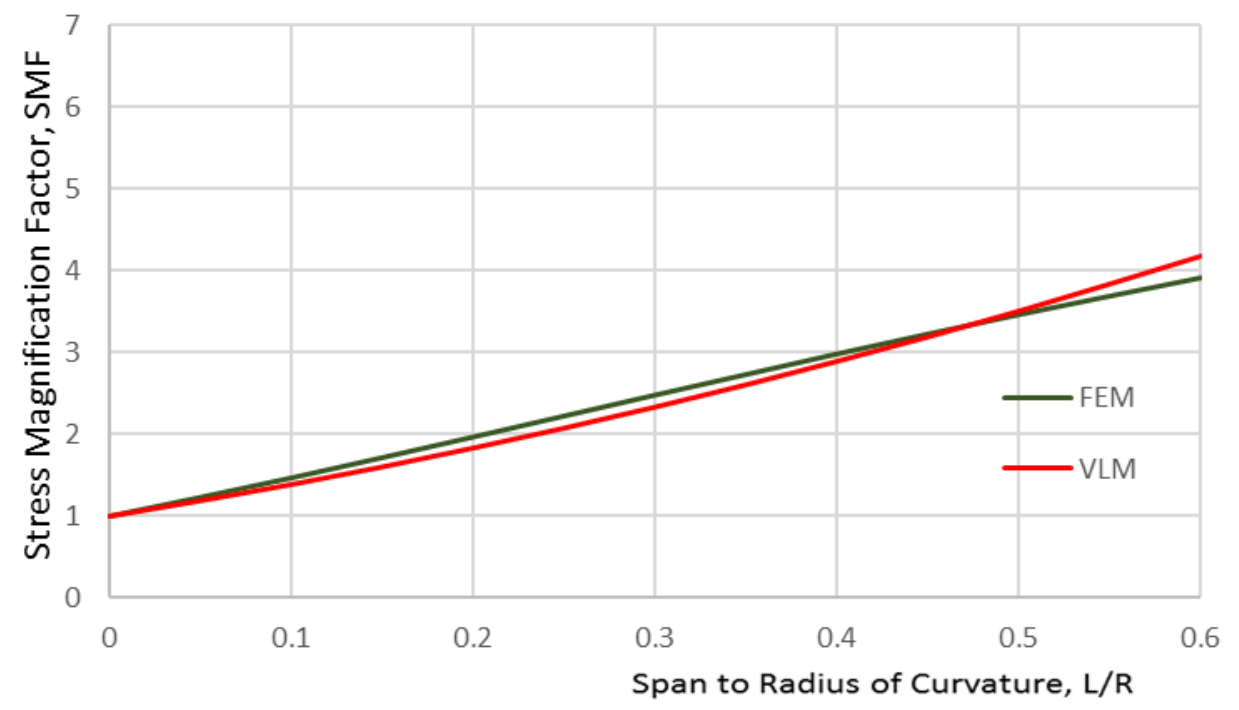

Figure 19. Comparison of the stress magnification factor obtained from the FEM and VLM for single span bridges of $25 \mathrm{~m}$ span and $12 \mathrm{~m}$ width 
Table 8. Comparison of the stress magnification factor obtained from the FEM and VLM for single span bridges of $25 \mathrm{~m}$ span and $16 \mathrm{~m}$ width

\begin{tabular}{|c|c|c|c|c|c|}
\hline \multicolumn{3}{|c|}{ FINITE ELEMENT METHOD (FEM) -IMAD WORK } & \multicolumn{2}{c|}{ V LOAD METHOD (VLM) } \\
\hline L(m) & $\mathbf{W}(\mathbf{m})$ & Theta (L/R) & S11 Mid Span & WS/TS & SMF-Mid Span \\
\hline 25 & 16 & 0 & 1 & 0 & 1 \\
\hline 25 & 16 & 0.1 & 1.467534004 & 0.213543666 & 1.384436289 \\
\hline 25 & 16 & 0.2 & 1.963867534 & 0.351934045 & 1.81709489 \\
\hline 25 & 16 & 0.3 & 2.469189829 & 0.448908054 & 2.297975848 \\
\hline 25 & 16 & 0.4 & 2.966706091 & 0.520637891 & 2.82707916 \\
\hline 25 & 16 & 0.5 & 3.443524542 & 0.575845604 & 3.404404828 \\
\hline 25 & 16 & 0.6 & 3.890656416 & 0.61965016 & 4.029952852 \\
\hline
\end{tabular}

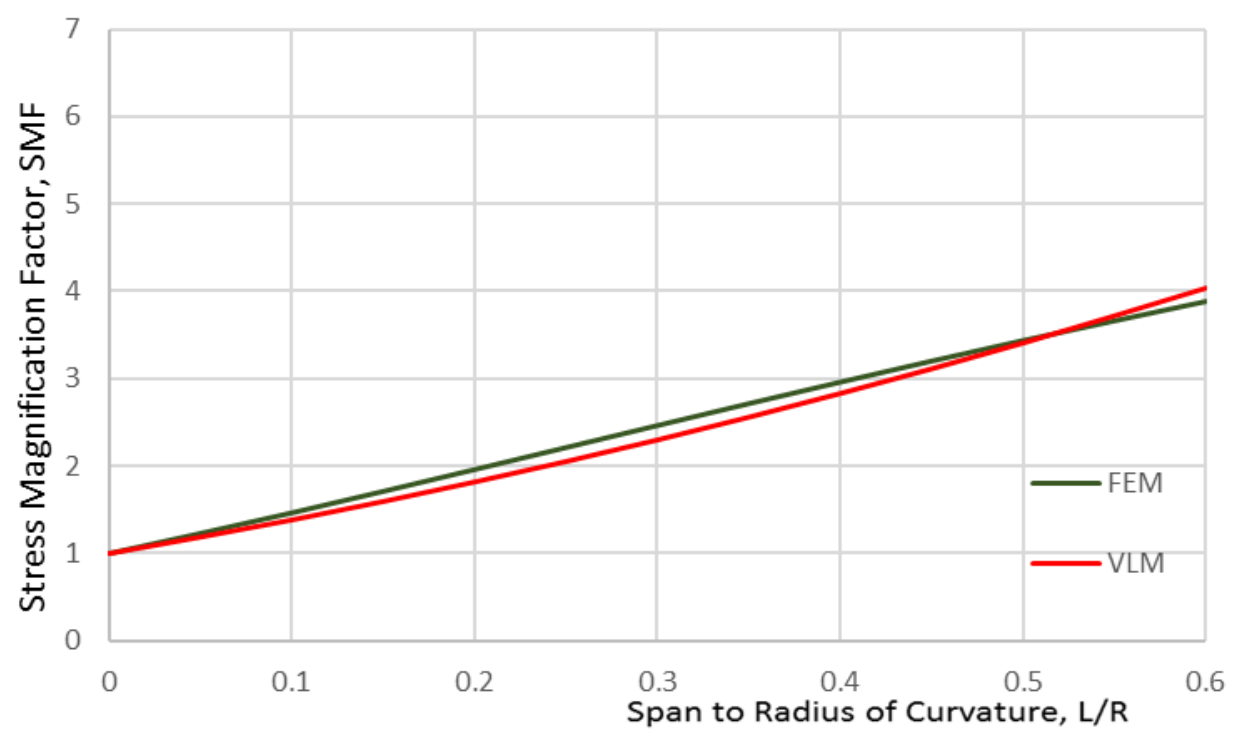

Figure 20. Comparison of the stress magnification factor obtained from the FEM and VLM for single span bridges of $25 \mathrm{~m}$ span and $16 \mathrm{~m}$ width 
Table 9. Comparison of the stress magnification factor obtained from the FEM and VLM for single span bridges of $35 \mathrm{~m}$ span and $8 \mathrm{~m}$ width

\begin{tabular}{|c|c|c|c|c|c|}
\hline \multicolumn{3}{|c|}{ FINITE ELEMENT METHOD (FEM) -IMAD WORK } & \multicolumn{2}{c|}{ V LOAD METHOD (VLM) } \\
\hline L(m) & $\mathbf{W}(\mathbf{m})$ & Theta (L/R) & S11 Mid Span & WS/TS & SMF-Mid Span \\
\hline 25 & 16 & 0 & 1 & 0 & 1 \\
\hline 25 & 16 & 0.1 & 1.467534004 & 0.213543666 & 1.384436289 \\
\hline 25 & 16 & 0.2 & 1.963867534 & 0.351934045 & 1.81709489 \\
\hline 25 & 16 & 0.3 & 2.469189829 & 0.448908054 & 2.297975848 \\
\hline 25 & 16 & 0.4 & 2.966706091 & 0.520637891 & 2.82707916 \\
\hline 25 & 16 & 0.5 & 3.443524542 & 0.575845604 & 3.404404828 \\
\hline 25 & 16 & 0.6 & 3.890656416 & 0.61965016 & 4.029952852 \\
\hline
\end{tabular}

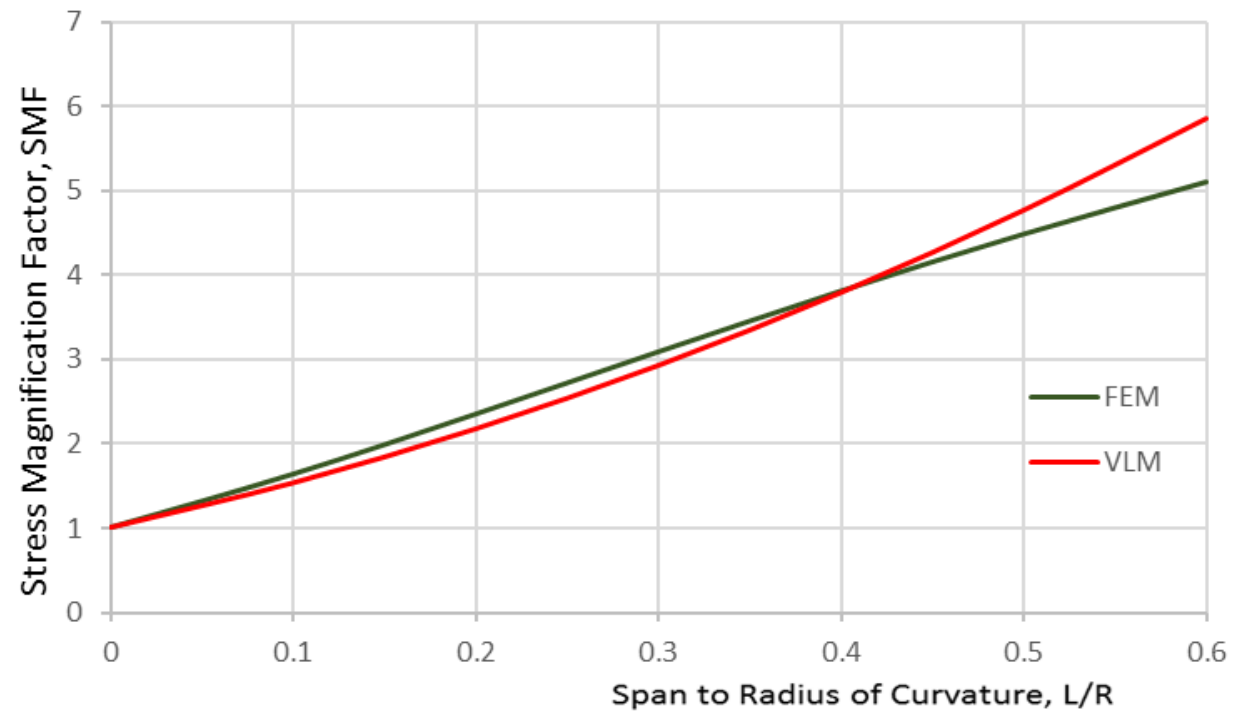

Figure 21. Comparison of the stress magnification factor obtained from the FEM and VLM for single span bridges of $35 \mathrm{~m}$ span and $8 \mathrm{~m}$ width 
Table 10. Comparison of the stress magnification factor obtained from the FEM and VLM for single span bridges of $35 \mathrm{~m}$ span and $12 \mathrm{~m}$ width

\begin{tabular}{|c|c|c|c|c|c|}
\multicolumn{3}{|c|}{ FINITE ELEMENT METHOD (FEM) -by Khalafalla 2009 } & \multicolumn{2}{c|}{ V LOAD METHOD (VLM) } \\
\hline L(m) & $\mathbf{W}(\mathbf{m})$ & Theta (L/R) & S11 Mid Span & WS/TS & SMF-Mid Span \\
\hline 35 & 12 & 0 & 1 & 0 & 1 \\
\hline 35 & 12 & 0.1 & 1.632154502 & 0.201386444 & 1.450267573 \\
\hline 35 & 12 & 0.2 & 2.344319037 & 0.335256728 & 1.980323161 \\
\hline 35 & 12 & 0.3 & 3.083019814 & 0.430689342 & 2.590166954 \\
\hline 35 & 12 & 0.4 & 3.803661901 & 0.502160702 & 3.279798952 \\
\hline 35 & 12 & 0.5 & 4.47830449 & 0.557688558 & 4.049219154 \\
\hline 35 & 12 & 0.6 & 5.096062202 & 0.602072483 & 4.89842756 \\
\hline
\end{tabular}

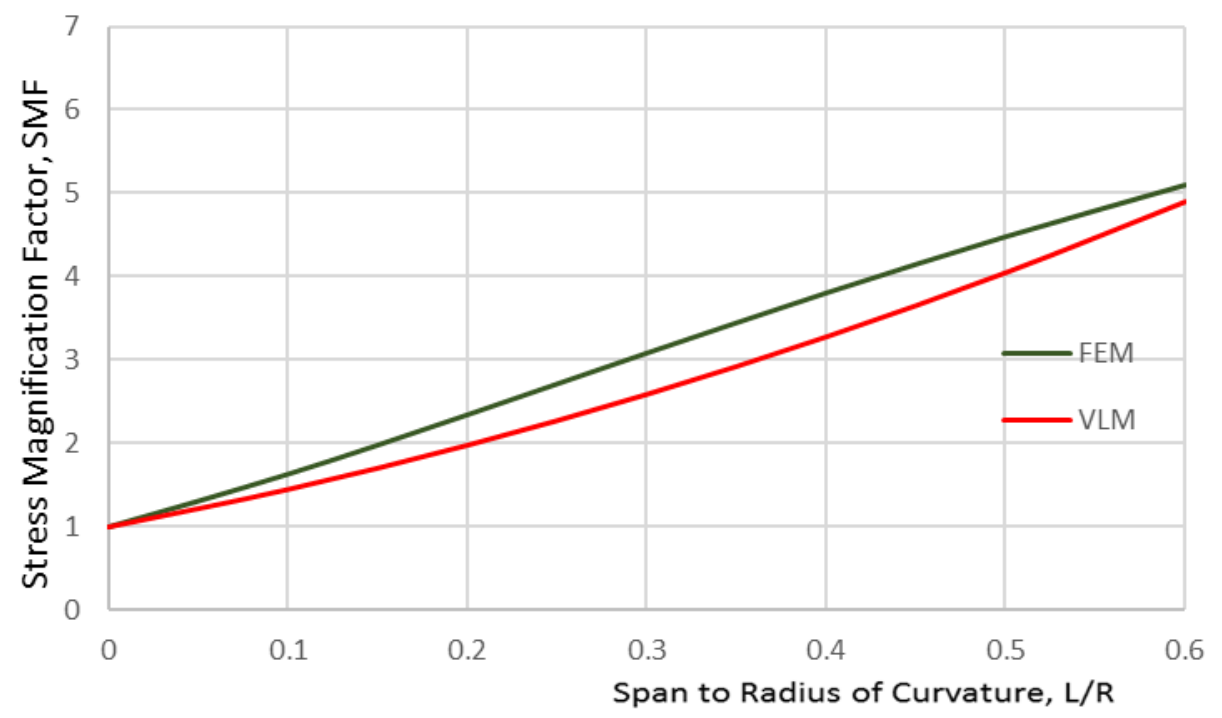

Figure 22. Comparison of the stress magnification factor obtained from the FEM and VLM for single span bridges of $35 \mathrm{~m}$ span and $12 \mathrm{~m}$ width 
Table 11. Comparison of the stress magnification factor obtained from the FEM and VLM for single span bridges of $35 \mathrm{~m}$ span and $16 \mathrm{~m}$ width

\begin{tabular}{|c|c|c|c|c|c|}
\hline \multicolumn{3}{|c|}{ FINITE ELEMENT METHOD (FEM) -by Khalafalla 2009 } & \multicolumn{2}{c|}{ V LOAD METHOD (VLM) } \\
\hline L(m) & $\mathbf{W}(\mathbf{m})$ & Theta (L/R) & S11 Mid Span & WS/TS & SMF-Mid Span \\
\hline 35 & 16 & 0 & 1 & 0 & 1 \\
\hline 35 & 16 & 0.1 & 1.593421381 & 0.201386444 & 1.406244676 \\
\hline 35 & 16 & 0.2 & 2.245601794 & 0.335256728 & 1.874546139 \\
\hline 35 & 16 & 0.3 & 2.926538749 & 0.430689342 & 2.404904577 \\
\hline 35 & 16 & 0.4 & 3.609718415 & 0.502160702 & 2.99731999 \\
\hline 35 & 16 & 0.5 & 4.274557688 & 0.557688558 & 3.651792379 \\
\hline 35 & 16 & 0.6 & 4.907600299 & 0.602072483 & 4.368321742 \\
\hline
\end{tabular}

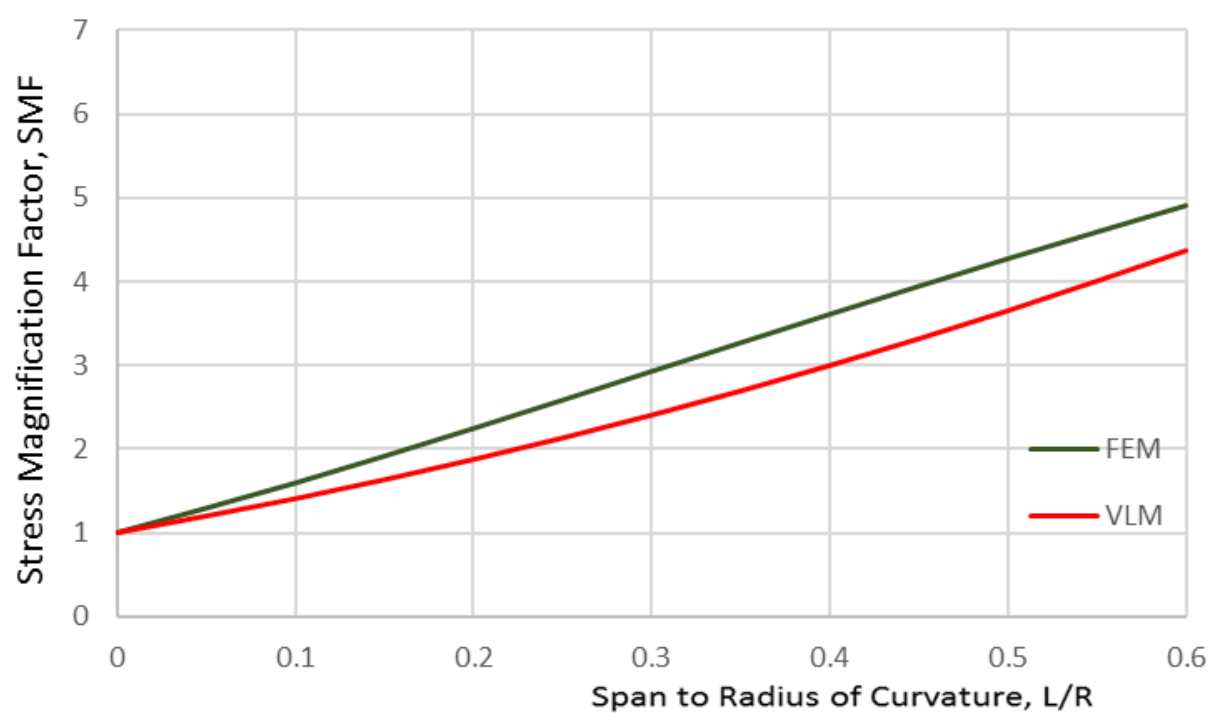

Figure 23. Comparison of the stress magnification factor obtained from the FEM and VLM for single span bridges of $35 \mathrm{~m}$ span and $16 \mathrm{~m}$ width 
Table 12: Comparison of the stress magnification factor obtained from the FEM and VLM for two-span continuous bridges of $15 \mathrm{~m}$ span each and $8 \mathrm{~m}$ width

\begin{tabular}{|c|c|c|c|c|c|c|c|}
\hline \multicolumn{6}{|c|}{ FINITE ELEMENT METHOD (FEM) -by Khalafalla 2009 } & \multicolumn{3}{c|}{ V LOAD METHOD (VLM) } \\
\hline $\mathbf{L}(\mathrm{m})$ & $\mathbf{W}(\mathrm{m})$ & Theta (L/R) & S11 Mid Span & S11 SUPPORT & WS/TS @MID & SMF Mid Span & SMF SUPPORT \\
\hline 15 & 8 & 0 & 1 & 1 & 0 & 1 & 1 \\
\hline 15 & 8 & 0.1 & 1.13976615 & 1.021919879 & 0.135903553 & 1.186266744 & 1.017138722 \\
\hline 15 & 8 & 0.2 & 1.276094472 & 1.045948204 & 0.239287134 & 1.380412709 & 1.034277395 \\
\hline 15 & 8 & 0.3 & 1.407275764 & 1.069698055 & 0.320575861 & 1.582437945 & 1.051416068 \\
\hline 15 & 8 & 0.4 & 1.532241774 & 1.091816844 & 0.386168995 & 1.792342451 & 1.068554741 \\
\hline 15 & 8 & 0.5 & 1.650351552 & 1.111349803 & 0.440212171 & 2.010126229 & 1.085693414 \\
\hline 15 & 8 & 0.6 & 1.761216641 & 1.127342165 & 0.485509194 & 2.235789277 & 1.102832087 \\
\hline
\end{tabular}

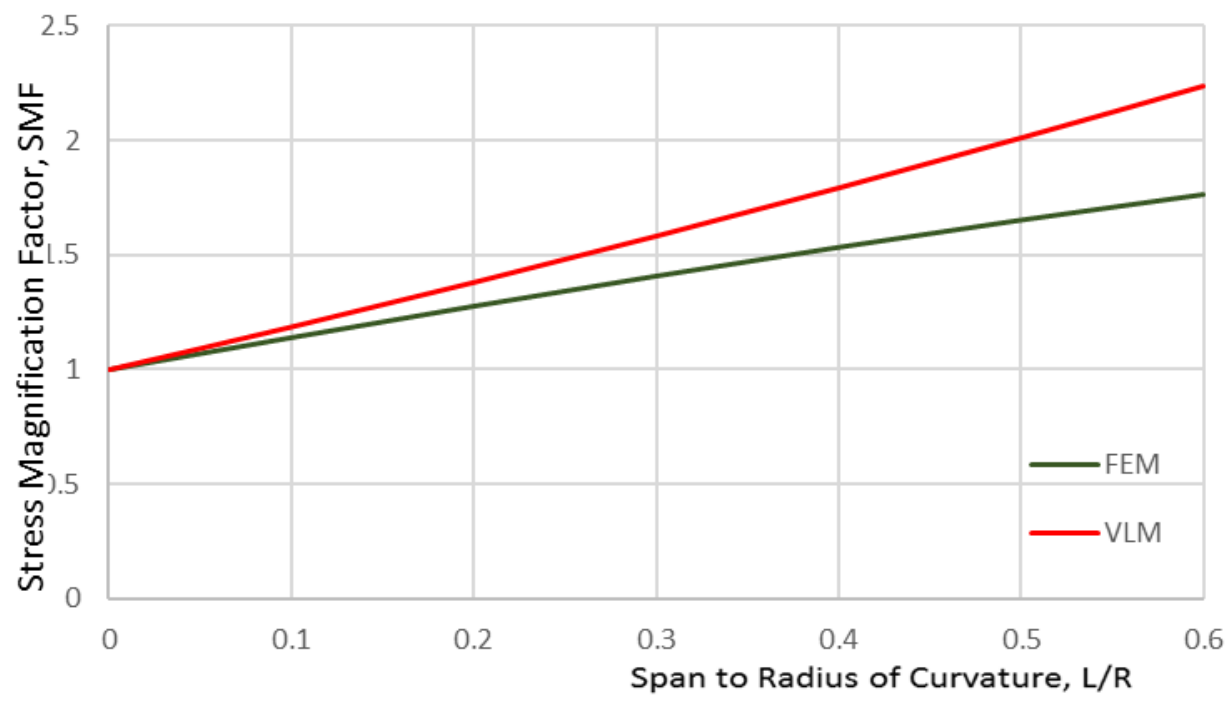

Figure 24. Comparison of the stress magnification factor obtained from the FEM and VLM for two-span continuous bridges of $15 \mathrm{~m}$ span each and $8 \mathrm{~m}$ width 
Table 13. Comparison of the stress magnification factor obtained from the FEM and VLM for two-span continuous bridges of $15 \mathrm{~m}$ span each and $12 \mathrm{~m}$ width

\begin{tabular}{|c|c|c|c|c|c|c|c|}
\hline \multicolumn{6}{|c|}{ FINITE ELEMENT METHOD (FEM) -by Khalafalla 2009 } & \multicolumn{3}{c|}{ V LOAD METHOD (VLM) } \\
\hline L(m) & W(m) & Theta (L/R) & S11 Mid Span & S11 SUPPORT & WS/TS @MID & SMF Mid Span & SMF SUPPORT \\
\hline 15 & 12 & 0 & 1 & 1 & 0 & 1 & 1 \\
\hline 15 & 12 & 0.1 & 1.150165525 & 1.03268576 & 0.135903553 & 1.177984325 & 1.012241959 \\
\hline 15 & 12 & 0.2 & 1.297751944 & 1.068215502 & 0.239287134 & 1.361596651 & 1.024483868 \\
\hline 15 & 12 & 0.3 & 1.440873046 & 1.103865412 & 0.320575861 & 1.550837028 & 1.036725777 \\
\hline 15 & 12 & 0.4 & 1.578566479 & 1.138513919 & 0.386168995 & 1.745705455 & 1.048967686 \\
\hline 15 & 12 & 0.5 & 1.710043113 & 1.171239736 & 0.440212171 & 1.946201932 & 1.061209595 \\
\hline 15 & 12 & 0.6 & 1.834744784 & 1.201361907 & 0.485509194 & 2.152326460 & 1.073451504 \\
\hline
\end{tabular}

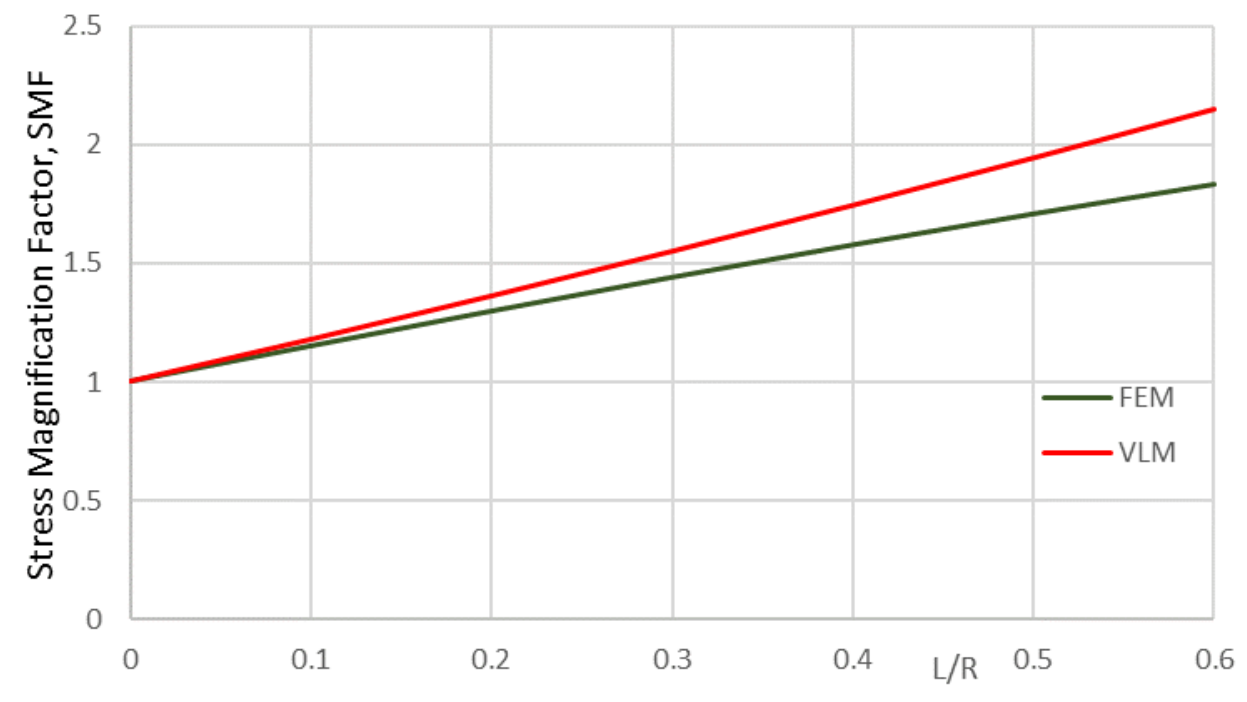

Figure 25. Comparison of the stress magnification factor obtained from the FEM and VLM for two-span continuous bridges of $15 \mathrm{~m}$ span each and $12 \mathrm{~m}$ width 
Table 14. Comparison of the stress magnification factor obtained from the FEM and VLM for two-span continuous bridges of $15 \mathrm{~m}$ span each and $16 \mathrm{~m}$ width

\begin{tabular}{|c|c|c|c|c|c|c|c|}
\hline \multicolumn{3}{|c|}{ FINITE ELEMENT METHOD (FEM) -by Khalafalla 2009 } & \multicolumn{3}{c|}{ V LOAD METHOD (VLM) } \\
\hline L(m) & $\mathbf{W}(\mathbf{m})$ & Theta (L/R) & S11 Mid Span & S11 SUPPORT & WS/TS @MID & SMF Mid Span & SMF SUPPORT \\
\hline 15 & 16 & 0 & 1 & 1 & 0 & 1 & 1 \\
\hline 15 & 16 & 0.1 & 1.163541767 & 1.044341335 & 0.135903553 & 1.173382847 & 1.009521455 \\
\hline 15 & 16 & 0.2 & 1.325850275 & 1.093120839 & 0.239287134 & 1.351142981 & 1.01904286 \\
\hline 15 & 16 & 0.3 & 1.485171982 & 1.142787977 & 0.320575861 & 1.533280451 & 1.028564266 \\
\hline 15 & 16 & 0.4 & 1.64021582 & 1.192334073 & 0.386168995 & 1.719795257 & 1.038085671 \\
\hline 15 & 16 & 0.5 & 1.790326621 & 1.240911842 & 0.440212171 & 1.9106874 & 1.047607077 \\
\hline 15 & 16 & 0.6 & 1.934675788 & 1.287875731 & 0.485509194 & 2.105956878 & 1.057128482 \\
\hline
\end{tabular}

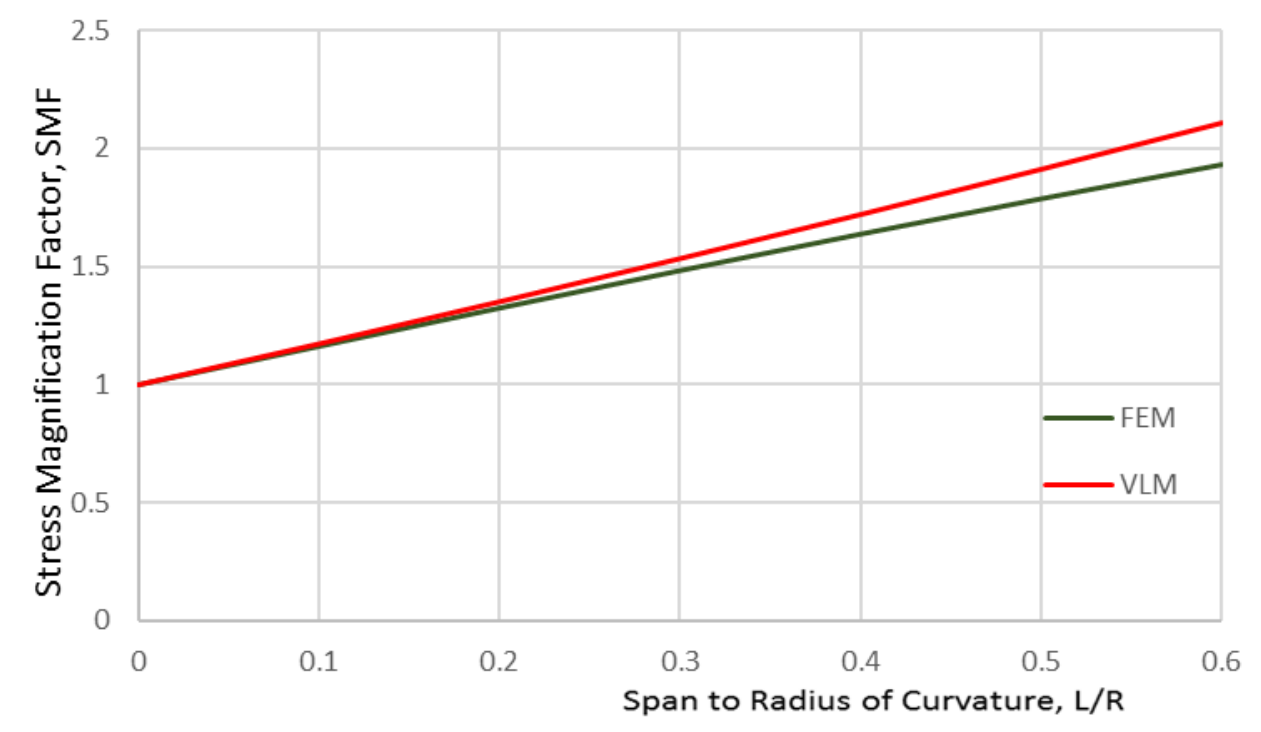

Figure 26. Comparison of the stress magnification factor obtained from the FEM and VLM for two-span continuous bridges of $15 \mathrm{~m}$ span each and $16 \mathrm{~m}$ width 
Table 15. Comparison of the stress magnification factor obtained from the FEM and VLM for two-span continuous bridges of $25 \mathrm{~m}$ span each and $8 \mathrm{~m}$ width

\begin{tabular}{|c|c|c|c|c|c|c|c|}
\hline \multicolumn{6}{|c|}{ FINITE ELEMENT METHOD (FEM) -by Khalafalla 2009 } & \multicolumn{3}{c|}{ V LOAD METHOD (VLM) } \\
\hline L(m) & W(m) & Theta (L/R) & S11 Mid Span & S11 SUPPORT & WS/TS @MID & SMF Mid Span & SMF SUPPORT \\
\hline 25 & 8 & 0 & 1 & 1 & 0 & 1 & 1 \\
\hline 25 & 8 & 0.1 & 1.122487751 & 1.009258283 & 0.113452024 & 1.175768397 & 1.026700427 \\
\hline 25 & 8 & 0.2 & 1.244475552 & 1.027795938 & 0.203784305 & 1.362382417 & 1.053400857 \\
\hline 25 & 8 & 0.3 & 1.364263574 & 1.048337094 & 0.277410505 & 1.559841983 & 1.080101287 \\
\hline 25 & 8 & 0.4 & 1.480551945 & 1.066811481 & 0.33857279 & 1.768147096 & 1.106801716 \\
\hline 25 & 8 & 0.5 & 1.592140786 & 1.082143535 & 0.390189132 & 1.987297755 & 1.133502146 \\
\hline 25 & 8 & 0.6 & 1.698130187 & 1.093468587 & 0.434332587 & 2.21729396 & 1.160202576 \\
\hline
\end{tabular}

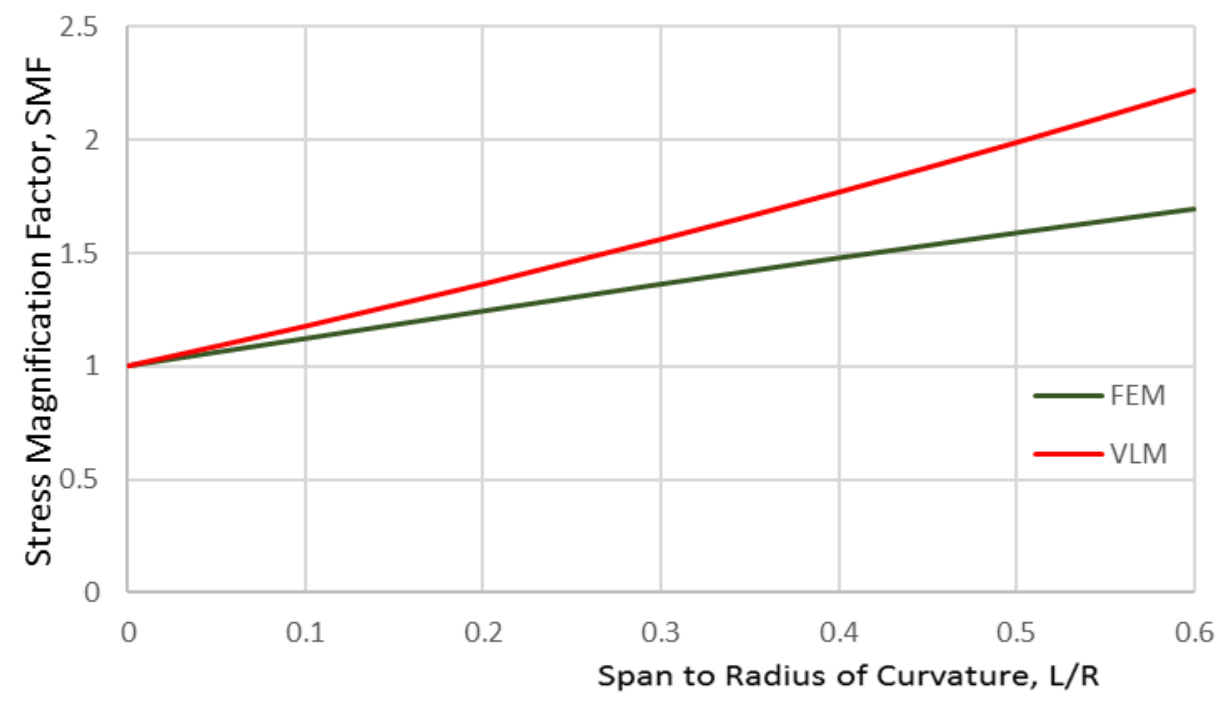

Figure 27. Comparison of the stress magnification factor obtained from the FEM and VLM for two-span continuous bridges of $25 \mathrm{~m}$ span each and $8 \mathrm{~m}$ width 
Table 16. Comparison of the stress magnification factor obtained from the FEM and VLM for two-span continuous bridges of $25 \mathrm{~m}$ span each and $12 \mathrm{~m}$ width

\begin{tabular}{|c|c|c|c|c|c|c|c|}
\hline \multicolumn{3}{|c|}{ FINITE ELEMENT METHOD (FEM) -by Khalafalla 2009 } & \multicolumn{3}{c|}{ V LOAD METHOD (VLM) } \\
\hline L(m) & W(m) & Theta (L/R) & S11 Mid Span & S11 SUPPORT & WS/TS @MID & SMF Mid Span & SMF SUPPORT \\
\hline 25 & 12 & 0 & 1 & 1 & 0 & 1 & 1 \\
\hline 25 & 12 & 0.1 & 1.124170053 & 1.014278171 & 0.113452024 & 1.162111842 & 1.019071733 \\
\hline 25 & 12 & 0.2 & 1.247844614 & 1.034047946 & 0.203784305 & 1.331970579 & 1.038143468 \\
\hline 25 & 12 & 0.3 & 1.369140819 & 1.054725948 & 0.277410505 & 1.509576134 & 1.057215203 \\
\hline 25 & 12 & 0.4 & 1.486968586 & 1.075615165 & 0.33857279 & 1.694928509 & 1.076286939 \\
\hline 25 & 12 & 0.5 & 1.600436032 & 1.095976344 & 0.390189132 & 1.888027702 & 1.095358674 \\
\hline 25 & 12 & 0.6 & 1.708750372 & 1.115196958 & 0.434332587 & 2.088873714 & 1.114430409 \\
\hline
\end{tabular}

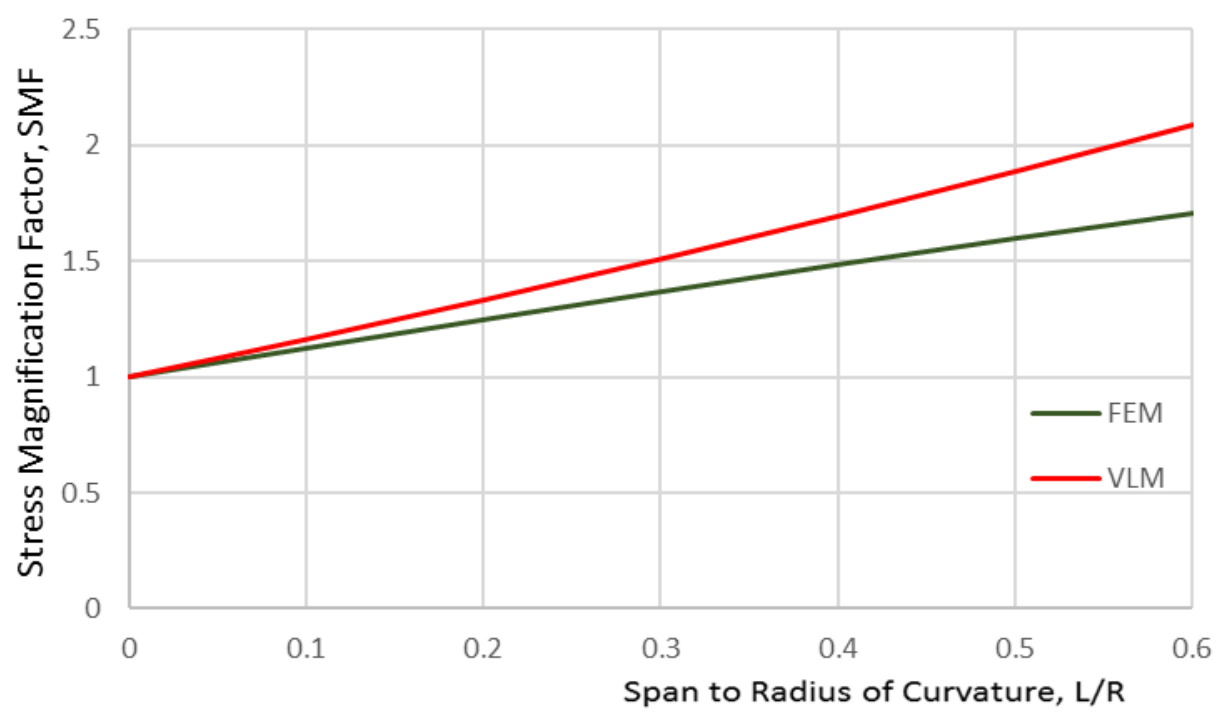

Figure 28. Comparison of the stress magnification factor obtained from the FEM and VLM for two-span continuous bridges of $25 \mathrm{~m}$ span each and $12 \mathrm{~m}$ width 
Table 17. Comparison of the stress magnification factor obtained from the FEM and VLM for two-span continuous bridges of $25 \mathrm{~m}$ span each and $16 \mathrm{~m}$ width

\begin{tabular}{|c|c|c|c|c|c|c|c|}
\hline \multicolumn{6}{|c|}{ FINITE ELEMENT METHOD (FEM) -by Khalafalla 2009 } & \multicolumn{3}{c|}{ V LOAD METHOD (VLM) } \\
\hline L(m) & $\mathbf{W}(\mathrm{m})$ & Theta (L/R) & S11 Mid Span & S11 SUPPORT & WS/TS @MID & SMF Mid Span & SMF SUPPORT \\
\hline 25 & 16 & 0 & 1 & 1 & 0 & 1 & 1 \\
\hline 25 & 16 & 0.1 & 1.129267811 & 1.01939856 & 0.113452024 & 1.154524646 & 1.014833446 \\
\hline 25 & 16 & 0.2 & 1.257943556 & 1.046272766 & 0.203784305 & 1.315074621 & 1.029666894 \\
\hline 25 & 16 & 0.3 & 1.384448392 & 1.074015248 & 0.277410505 & 1.481649849 & 1.044500342 \\
\hline 25 & 16 & 0.4 & 1.507696862 & 1.102011859 & 0.33857279 & 1.654250331 & 1.059333791 \\
\hline 25 & 16 & 0.5 & 1.626702191 & 1.129606099 & 0.390189132 & 1.832876066 & 1.074167239 \\
\hline 25 & 16 & 0.6 & 1.740674956 & 1.156247353 & 0.434332587 & 2.017527054 & 1.089000687 \\
\hline
\end{tabular}

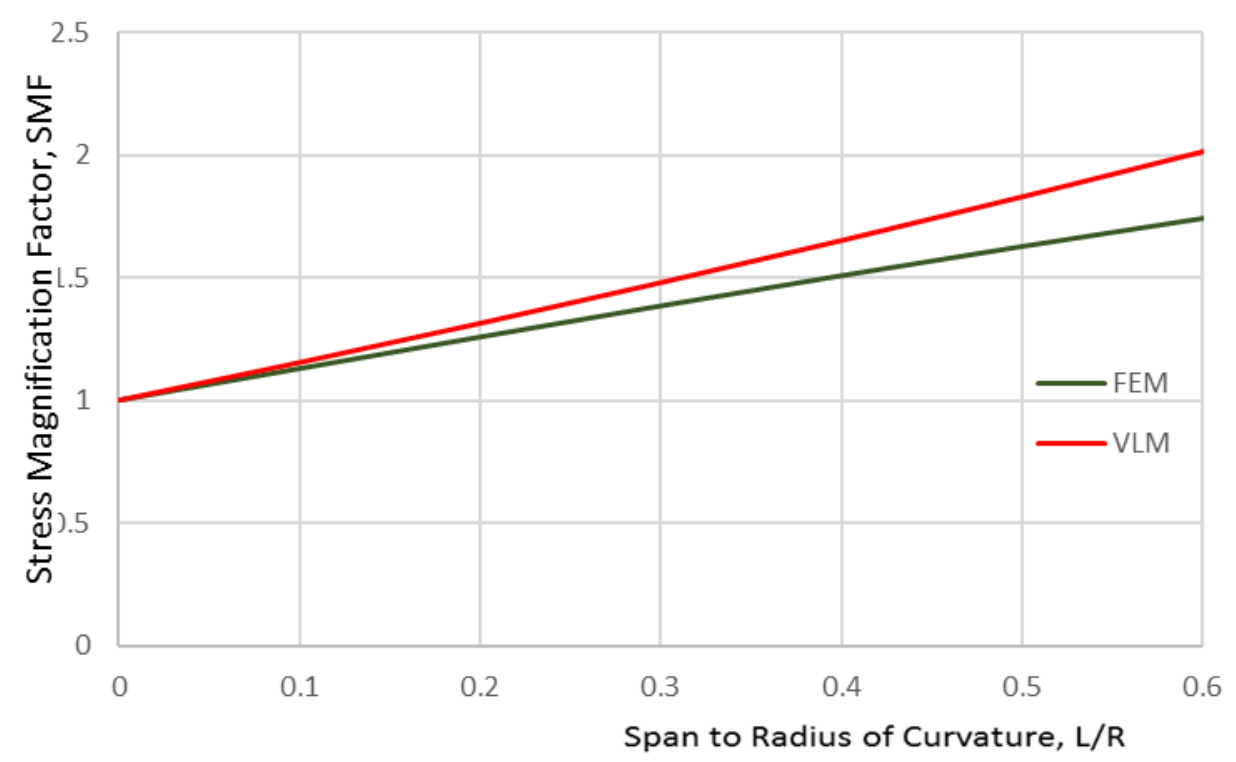

Figure 29. Comparison of the stress magnification factor obtained from the FEM and VLM for two-span continuous bridges of $25 \mathrm{~m}$ span each and $16 \mathrm{~m}$ width 
Table 18. Comparison of the stress magnification factor obtained from the FEM and VLM for two-span continuous bridges of $35 \mathrm{~m}$ span each and $8 \mathrm{~m}$ width

\begin{tabular}{|c|c|c|c|c|c|c|c|}
\hline \multicolumn{3}{|c|}{ FINITE ELEMENT METHOD (FEM) -by Khalafalla 2009 } & \multicolumn{3}{c|}{ V LOAD METHOD (VLM) } \\
\hline L(m) & $\mathbf{W}(\mathrm{m})$ & Theta (L/R) & S11 Mid Span & S11 SUPPORT & WS/TS @MID & SMF Mid Span & SMF SUPPORT \\
\hline 35 & 8 & 0 & 1 & 1 & 0 & 1 & 1 \\
\hline 35 & 8 & 0.1 & 1.1443283 & 1.011463639 & 0.104351033 & 1.181050193 & 1.036337261 \\
\hline 35 & 8 & 0.2 & 1.289740612 & 1.039266078 & 0.188981637 & 1.375570311 & 1.072674541 \\
\hline 35 & 8 & 0.3 & 1.433991483 & 1.067006215 & 0.258999391 & 1.583560343 & 1.109011821 \\
\hline 35 & 8 & 0.4 & 1.574680604 & 1.092378861 & 0.317888235 & 1.805020289 & 1.145349101 \\
\hline 35 & 8 & 0.5 & 1.7100271 & 1.114060091 & 0.368106141 & 2.039950148 & 1.181686381 \\
\hline 35 & 8 & 0.6 & 1.838172667 & 1.130866159 & 0.411436881 & 2.288349921 & 1.218023661 \\
\hline
\end{tabular}

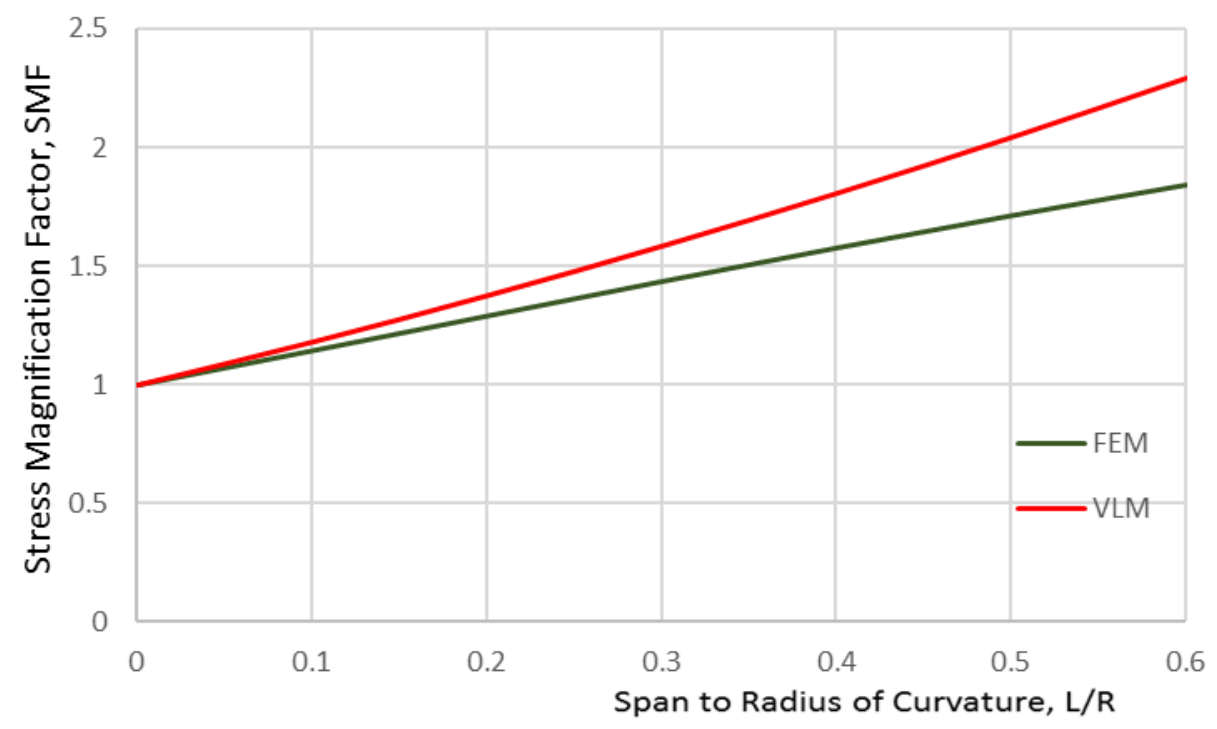

Figure 30. Comparison of the stress magnification factor obtained from the FEM and VLM for two-span continuous bridges of $35 \mathrm{~m}$ span each and $8 \mathrm{~m}$ width 
Table 19. Comparison of the stress magnification factor obtained from the FEM and VLM for two-span continuous bridges of $35 \mathrm{~m}$ span each and $12 \mathrm{~m}$ width

\begin{tabular}{|c|c|c|c|c|c|c|c|}
\hline \multicolumn{6}{|c|}{ FINITE ELEMENT METHOD (FEM) -by Khalafalla 2009 } & \multicolumn{3}{c|}{ V LOAD METHOD (VLM) } \\
\hline L(m) & $\mathbf{W}(\mathbf{m})$ & Theta (L/R) & S11 Mid Span & S11 SUPPORT & WS/TS @MID & SMF Mid Span & SMF SUPPORT \\
\hline 35 & 12 & 0 & 1 & 1 & 0 & 1 & 1 \\
\hline 35 & 12 & 0.1 & 1.140778941 & 1.011815369 & 0.104351033 & 1.162609806 & 1.025955181 \\
\hline 35 & 12 & 0.2 & 1.282481527 & 1.031948137 & 0.188981637 & 1.33484099 & 1.051910381 \\
\hline 35 & 12 & 0.3 & 1.423106527 & 1.052702766 & 0.258999391 & 1.516693541 & 1.077865581 \\
\hline 35 & 12 & 0.4 & 1.561037562 & 1.073177557 & 0.317888235 & 1.708167459 & 1.10382078 \\
\hline 35 & 12 & 0.5 & 1.694735222 & 1.092548544 & 0.368106141 & 1.909262743 & 1.12977598 \\
\hline 35 & 12 & 0.6 & 1.823044951 & 1.110007307 & 0.411436881 & 2.119979395 & 1.15573118 \\
\hline
\end{tabular}

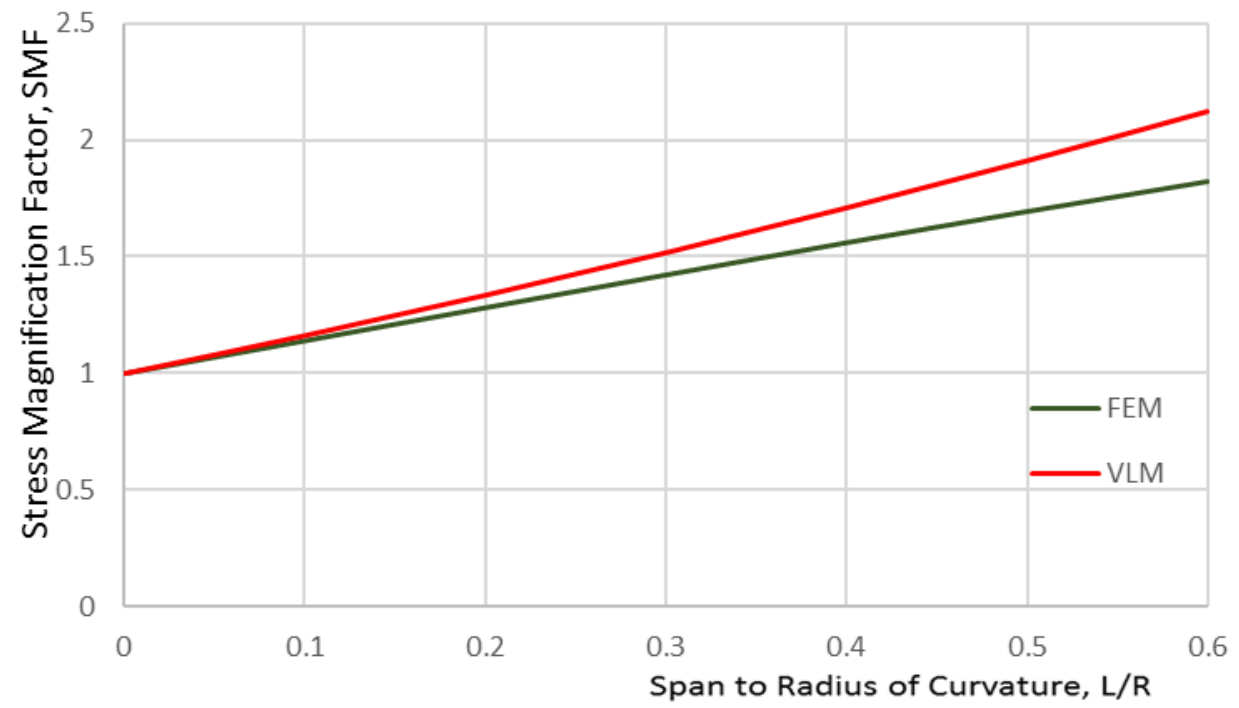

Figure 31. Comparison of the stress magnification factor obtained from the FEM and VLM for two-span continuous bridges of $35 \mathrm{~m}$ span each and $12 \mathrm{~m}$ width 
Table 20. Comparison of the stress magnification factor obtained from the FEM and VLM for two-span continuous bridges of $35 \mathrm{~m}$ span each and $16 \mathrm{~m}$ width

\begin{tabular}{|c|c|c|c|c|c|c|c|}
\hline \multicolumn{3}{|c|}{ FINITE ELEMENT METHOD (FEM) -by Khalafalla 2009 } & \multicolumn{3}{c|}{ V LOAD METHOD (VLM) } \\
\hline L(m) & $\mathbf{W}(\mathbf{m})$ & Theta (L/R) & S11 Mid Span & S11 SUPPORT & WS/TS @MID & SMF Mid Span & SMF SUPPORT \\
\hline 35 & 16 & 0 & 1 & 1 & 0 & 1 & 1 \\
\hline 35 & 16 & 0.1 & 1.140635772 & 1.010933976 & 0.104351033 & 1.152364848 & 1.020187191 \\
\hline 35 & 16 & 0.2 & 1.281731137 & 1.034559453 & 0.188981637 & 1.31221293 & 1.0403744 \\
\hline 35 & 16 & 0.3 & 1.421294523 & 1.058635975 & 0.258999391 & 1.479544235 & 1.060561609 \\
\hline 35 & 16 & 0.4 & 1.558023746 & 1.082074811 & 0.317888235 & 1.654358764 & 1.080748819 \\
\hline 35 & 16 & 0.5 & 1.690540023 & 1.104051637 & 0.368106141 & 1.836656515 & 1.100936028 \\
\hline 35 & 16 & 0.6 & 1.81769437 & 1.123882106 & 0.411436881 & 2.026437489 & 1.121123237 \\
\hline
\end{tabular}

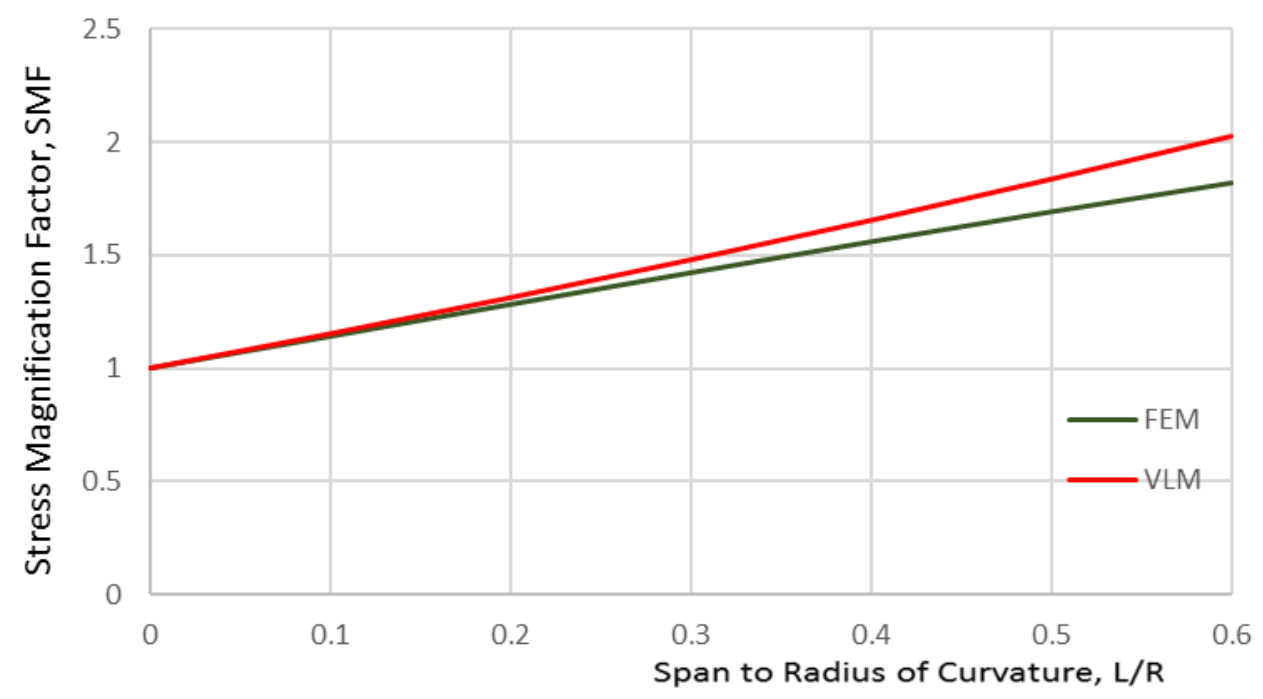

Figure 32. Comparison of the stress magnification factor obtained from the FEM and VLM for two-span continuous bridges of $35 \mathrm{~m}$ span each and $16 \mathrm{~m}$ width 


\section{Curvature Limitation to Treat a Horizontally Curved Bridge as a Straight Bridge}

Canadian Highway Bridge Design Code CHBDC of 2014 [7] and the AASHTO Guide Specifications for Horizontally Curved Bridges of 2003 [8] and 1993 [13] specified certain limitations to treat horizontally curved bridges as straight ones. These limitations can be summarized in the following subsections.

\subsection{Guide Specifications for Horizontally Curved Highway Bridges of 1993}

For the Curved I-Girder bridges, the effects of curvature may be neglected in determining the primary bending moments in the longitudinal girders when the central angle subtended by each span is less than the values given in Table 21.

Table 21. Limiting central angle for neglecting curvature in determining primary bending moment in a curved bridge [13]

\begin{tabular}{|c|c|c|}
\hline Numbers of Girders & Angle for one Span & Angle for two or More Spans \\
\hline 2 & $2^{\circ}$ & $3^{\circ}$ \\
\hline 3 or 4 & $3^{\circ}$ & $4^{\circ}$ \\
\hline 5 or more & $4^{\circ}$ & $5^{\circ}$ \\
\hline
\end{tabular}

\subsection{Guide Specifications for Horizontally Curved I Steel Girder Highway Bridges of 2003}

In the I-girder bridges, the effect of curvature may be ignored in the determination of vertical moment, when the following three conditions are met:

I. Girders are concentric.

II. Bearing lines are not skewed more than 10 degrees from radial, and

III. The arc span divided by the girder radius is less than 0.06 radians.

\subsection{Canadian Highway Bridge Design Code of 2014}

For bridges that are curved in plan and that are built with shored construction, the simplified method of analysis specified in CHBDC for straight slab-on-girder bridges can be applied to a curved bridges by treating it as a straight provided that:

a) There are at least two intermediate diaphragms per span.

b) $L^{2} /(B R) \leq 0.5$

where $B=$ bridge width, $L=$ centerline curved span length, and $R=$ radius of curvature. 
Assuming all conditions for curvature limitations are met per CHBDC and AASHTO, the span-to-radius of curvature, L/R, limits are summarized in Tables 22 and 23 for single and two-span bridges, respectively. As shown in the tables, the L/R limit specified in CHBDC for the studied bridge geometries are higher than those specified in AASHTO Guides of 1993 and 2003. This means that CHBDC underestimates the response of curved bridges in the range of L/R between those obtained using CHBDC and AASHTO Guides.

Table 22. Curvature limitations for single span bridges

\begin{tabular}{|c|c|c|c|c|c|}
\hline \multicolumn{6}{|c|}{ Single Span I- Girder Bridge Horizontal Curvature Limitation(L/R) in CHBDC and AASHTO } \\
\hline \multirow{2}{*}{$\mathbf{L}(\mathbf{m})$} & \multirow{2}{*}{ No. of Girder } & $\begin{array}{r}\text { Width } \\
\text { B or W (m) }\end{array}$ & CHBDC & \multirow{2}{*}{ AASHTO 1993 } & AASHTO 2003 \\
\hline \multirow{3}{*}{15} & 4 & 8 & 0.267 & 0.052 & 0.060 \\
\cline { 2 - 6 } & 6 & 12 & 0.400 & 0.070 & 0.060 \\
\cline { 2 - 6 } & 8 & 16 & 0.533 & 0.070 & 0.060 \\
\hline \multirow{3}{*}{25} & 4 & 8 & 0.160 & 0.052 & 0.060 \\
\cline { 2 - 6 } & 6 & 12 & 0.240 & 0.070 & 0.060 \\
\hline \multirow{3}{*}{35} & 8 & 16 & 0.320 & 0.070 & 0.060 \\
\cline { 2 - 6 } & 4 & 8 & 0.114 & 0.052 & 0.060 \\
\cline { 2 - 6 } & 6 & 12 & 0.171 & 0.070 & 0.060 \\
\hline
\end{tabular}

Table 23. Curvature limitations for two-span bridges

\begin{tabular}{|c|c|c|c|c|c|}
\hline \multicolumn{6}{|c|}{ Two Span I- Girder Bridge Horizontal Curvature Limitation(L/R) in CHBDC and AASHTO } \\
\hline \multirow{2}{*}{$L(\mathbf{m})$} & \multirow{2}{*}{ No. of Girder } & Width & \multirow{2}{*}{ CHBDC } & \multirow{2}{*}{ AASHTO 1993} & \multirow{2}{*}{ AASHTO 2003} \\
\hline & & B or $W(m)$ & & & \\
\hline \multirow{3}{*}{$15 \times 2$} & 4 & 8 & 0.133 & 0.070 & 0.060 \\
\hline & 6 & 12 & 0.200 & 0.087 & 0.060 \\
\hline & 8 & 16 & 0.267 & 0.087 & 0.060 \\
\hline \multirow{3}{*}{$25 \times 2$} & 4 & 8 & 0.080 & 0.070 & 0.060 \\
\hline & 6 & 12 & 0.120 & 0.087 & 0.060 \\
\hline & 8 & 16 & 0.160 & 0.087 & 0.060 \\
\hline \multirow{3}{*}{$35 \times 2$} & 4 & 8 & 0.057 & 0.070 & 0.060 \\
\hline & 6 & 12 & 0.086 & 0.087 & 0.060 \\
\hline & 8 & 16 & 0.114 & 0.087 & 0.060 \\
\hline
\end{tabular}

\subsection{Curvature Limitations in North American Bridge Codes and Corresponding Stress Magnification Factor using the V-Load Method}

Tables 24 and 25 presents the values of the stress magnification factors corresponding to the $L / R$ limit to treat a curved bridges as a straight one for single span and two-span continuous bridges, respectively. As expected, the SMFs associated with the L/R limit specified per CHBDC is very much greater than those associated with L/R limits specified in AASHTO Guides of 1993 and 2003. 
Table 24. Code curvature limitations and corresponding stress magnification factor for single span bridges

\begin{tabular}{|c|c|c|c|c|c|}
\hline \multicolumn{6}{|c|}{ Single Span I - Girder Bridge (L/R) Limitation and Corresponding SMF in CHBDC and AASHTO } \\
\hline \multirow{3}{*}{$L(m)$} & \multirow{3}{*}{ No. of Girder } & \multirow{2}{*}{ Width } & CHBDC & AASHTO 1993 & AASHTO 2003 \\
\hline & & & L/R & L/R & L/R \\
\hline & & B or $W(m)$ & SMF & SMF & SMF \\
\hline \multirow{6}{*}{15} & \multirow{2}{*}{4} & \multirow{2}{*}{8} & 0.267 & 0.052 & 0.060 \\
\hline & & & 2.518 & 1.215 & 1.259 \\
\hline & \multirow{2}{*}{6} & \multirow{2}{*}{12} & 0.400 & 0.070 & 0.060 \\
\hline & & & 2.893 & 1.281 & 1.239 \\
\hline & \multirow{2}{*}{8} & \multirow{2}{*}{16} & 0.533 & 0.070 & 0.060 \\
\hline & & & 3.276 & 1.267 & 1.228 \\
\hline \multirow{6}{*}{25} & \multirow{2}{*}{4} & \multirow{2}{*}{8} & 0.160 & 0.052 & 0.060 \\
\hline & & & 1.812 & 1.227 & 1.274 \\
\hline & \multirow{2}{*}{6} & \multirow{2}{*}{12} & 0.240 & 0.070 & 0.060 \\
\hline & & & 2.036 & 1.267 & 1.227 \\
\hline & \multirow{2}{*}{8} & \multirow{2}{*}{16} & 0.320 & 0.070 & 0.060 \\
\hline & & & 2.404 & 1.265 & 1.225 \\
\hline \multirow{6}{*}{35} & \multirow{2}{*}{4} & \multirow{2}{*}{8} & 0.114 & 0.052 & 0.060 \\
\hline & & & 1.594 & 1.251 & 1.304 \\
\hline & \multirow{2}{*}{6} & \multirow{2}{*}{12} & 0.171 & 0.070 & 0.060 \\
\hline & & & 1.821 & 1.308 & 1.261 \\
\hline & \multirow{2}{*}{8} & \multirow{2}{*}{16} & 0.228 & 0.070 & 0.060 \\
\hline & & & 2.034 & 1.278 & 1.236 \\
\hline
\end{tabular}

Table 25. Code curvature limitations and corresponding stress magnification factor for single span bridges

\begin{tabular}{|c|c|c|c|c|c|}
\hline Two & oan I - Girder Br & dge (L/R) Lim & and Corre & g SMF in CHBDC & AASHTO \\
\hline \multirow{3}{*}{$L(m)$} & \multirow{3}{*}{ No. of Girder } & \multirow{2}{*}{ Width } & CHBDC & AASHTO 1993 & AASHTO 2003 \\
\hline & & & L/R & L/R & L/R \\
\hline & & B or W (m) & SMF & SMF & SMF \\
\hline \multirow{6}{*}{$15 \times 2$} & \multirow{2}{*}{4} & \multirow{2}{*}{8} & 0.133 & 0.070 & 0.060 \\
\hline & & & 1.244 & 1.130 & 1.111 \\
\hline & \multirow{2}{*}{6} & \multirow{2}{*}{12} & 0.200 & 0.087 & 0.060 \\
\hline & & & 1.362 & 1.160 & 1.106 \\
\hline & \multirow{2}{*}{8} & \multirow{2}{*}{16} & 0.267 & 0.087 & 0.060 \\
\hline & & & 1.478 & 1.156 & 1.104 \\
\hline \multirow{6}{*}{$25 \times 2$} & \multirow{2}{*}{4} & \multirow{2}{*}{8} & 0.080 & 0.070 & 0.060 \\
\hline & & & 1.140 & 1.122 & 1.104 \\
\hline & \multirow{2}{*}{6} & \multirow{2}{*}{12} & 0.120 & 0.087 & 0.060 \\
\hline & & & 1.196 & 1.113 & 1.096 \\
\hline & \multirow{2}{*}{8} & \multirow{2}{*}{16} & 0.160 & 0.087 & 0.060 \\
\hline & & & 1.251 & 1.139 & 1.092 \\
\hline \multirow{6}{*}{$35 \times 2$} & \multirow{2}{*}{4} & \multirow{2}{*}{8} & 0.057 & 0.070 & 0.060 \\
\hline & & & 1.107 & 1.125 & 1.107 \\
\hline & \multirow{2}{*}{6} & \multirow{2}{*}{12} & 0.086 & 0.087 & 0.060 \\
\hline & & & 1.146 & 1.146 & 1.096 \\
\hline & \multirow{2}{*}{8} & \multirow{2}{*}{16} & 0.114 & 0.087 & 0.060 \\
\hline & & & 1.168 & 1.137 & 1.091 \\
\hline
\end{tabular}




\section{Examination of the Equation for Curvature Limitation proposed by Khalafalla (2009)}

Recently, Khalafalla [2] investigated the curvature limitations of composite steel I-girder bridges that let to proposing the following two equations for single span and two-equal-span continuous bridges, followed by the scope of applicability of these equations with respect to bridge curved span and width. The limiting values to ignore curvature effect were determined based on $5 \%$ underestimation in design parameters.

\section{Single Span Bridge}

$(L / R)^{0.92}(L)^{0.5}(B)^{0.04} \leq 0.054$

$15 \leq \mathrm{L} \leq 35 \mathrm{~m}$

$8 \leq \mathrm{B} \leq 16 \mathrm{~m}$

\section{Two Span Bridge}

$(L / R)^{0.81}(L)^{-0.06}(B)^{0.08} \leq 0.0235$

$15 \leq L \leq 35 \mathrm{~m}$ ( $\mathrm{L}$ for each span)

$8 \leq \mathrm{B} \leq 16 \mathrm{~m}$

Where $L$ is the bridge span arc length in meters, $R$ is the radius of curvature in meters, and $B$ is the bridge width in meters.

Results presented earlier in this project report for the V-Load method showed insignificant difference between the finite element analysis results reported by Khalafalla [2] in the range of L/R between 0 and 0.2. The above-mentioned developed equations lead to a $L / R$ limit of less than 0.1 for bridge spans between 15 and $35 \mathrm{~m}$ and bridge widths between 8 and $16 \mathrm{~m}$. As such, one may conclude that the V-Load method will yield similar equations to those developed earlier by Khalafalla in 2009.

\section{Effect of Warping Stress}

One of the most important factor that affect the total bending stress in curved girders is the contribution of warping stress. As described, the flanges of the girders are subjected to warping due to the torsion induced by the horizontal curvature of the bridge unit. In composite girders, the concrete slab acts together with the top flange to resist the warping moment. The section modulus for lateral bending of the top flange and slab is much larger than that for the bottom flange, resulting in smaller warping stresses in the former. As such, only the warping of the bottom flange is important in composite systems.

In the V-Load approximate analysis procedure, the bottom flanges of the girders are straightened and modeled as individual flange elements supported at each diaphragm (or transvers $\mathrm{X}$ bracing) location. The curvature of the flanges is the same as that of the girders. Using the model of the bottom flanges, an analysis of the lateral bending can be performed after the $\mathrm{V}$-Loads are specified. As described earlier, the lateral bending of the flanges is caused by the radial flange forces which develop due to the horizontal curvature. As described, the warping stress combined with the longitudinal bending stress gives the total stress at the tip of the bottom flange. In the V-Load method, large warping stress exists at the diaphragm locations because the diaphragms are assumed to be infinitely stiff and provide rigid supports for the flange. This assumption is not the same in the finite element modelling, so the flanges can deflect laterally at the diaphragm locations. Based on Equations 16 and 17, the warping stress can be calculated as: 


$$
\begin{gathered}
\sigma_{w}=\frac{M_{f}}{S_{f}} \\
\sigma_{\omega}=6 M_{f} / b_{f}^{2} t_{f}
\end{gathered}
$$

One may consider decreasing the warping stress in curved girders by considering the following changes:

1) Decreasing intermediate diaphragm or transverse bracing spacing.

2) Increasing girder depth.

3) Increasing flange width.

Recent study by Davidson et al. in 1996 [14] concluded that the change in warping stress with an increase in girder depth is not a significant. The reduction of warping stress again arises from the increase in the torsional warping constant, which is directly proportional to the moment of inertia of the flange, $l_{f}$, and therefore related to the width of the flange squared. Davidson et al. [14] recommended that for a preliminary design purposes, a warping-to-bending stress ratio of 0.25 should be targeted resulting in the following equation for the maximum spacing between the radial diaphragms or $\mathrm{X}$ bracings between the radial supporting lines:

$$
S_{\max }=L\left[-\ln \left(\frac{R b_{f}}{2000 L^{2}}\right)\right]^{-1.52}
$$

In which $\mathrm{S}_{\text {max }}$ is the maximum spacing of intermediate diaphragm or transverse bracing, $\mathrm{L}$ is the arc length of the bridge in $\mathrm{m}, \mathrm{R}$ is the radius of curvature in $\mathrm{m}$, and $\mathrm{b}_{\mathrm{f}}$ is the bottom flange $\mathrm{I}$-Girder in $\mathrm{mm}$.

It is important to note that the magnitude of bending stress is not sensitive to the diaphragm spacing. The spacing of diaphragms has little effect on the longitudinal bending stresses but does affect the warping stresses. Furthermore, in the V-Loads analysis, the diaphragms do not contribute to the torsional stiffness of the bridge unit. The finite element analysis recognizes the contribution of the diaphragms to the torsional stiffness of the bridge unit. The larger the distance between diaphragms, the greater the warping stresses at the diaphragm locations. Decreasing the diaphragm spacing decreases the magnitudes of the warping stresses and also decreases their influence on the warping plus bending stress values.

In this study, the following parameters were considered in investigating the warping stress magnitude in curved composite l-girders as presented in the following subsections.

1) Curvature of bridge with $L / R \leq 0.1$,

2) Depth I-girders,

3) Bottom flange width, and

4) Number of $X$ bracings. 


\subsection{Effect of depth of I-Girder on warping stress}

Using the V-Load meth, Table 26 presents the change in the stress magnification factor, SMF, and the ratio of warping to total bending stress, WS/TS, in the outer girder of a $25 \mathrm{~m}$ span, 6-girder, bridge of $12 \mathrm{~m}$ width with the change in girder depth from $1 \mathrm{~m}$ to $1.2 \mathrm{ad} 1.4 \mathrm{~m}$ and change in L/R ratio from 0 to 0.1 . Results for SMF and WS/TS are presented in graphical form in Figures 33 and 34, respectively. In this analysis, the. It can be observed that the change in girder depth has insignificant effect on SMF of the studied bridges irrespective of the L/R value. Also, changing the depth of the girder has insignificant effect on warping stress-total stress ratio, while the warping stress increases with increase in curvature.

Table 26. Effect of girder depth on warping stress and Stress Magnification Factor

\begin{tabular}{|c|c|c|c|c|c|c|c|}
\hline \multicolumn{8}{|c|}{ DEPTH EFFECT, L=25, No. of GIRDER $6, \mathrm{~W}=12(\mathrm{~m})$} \\
\hline \multirow{2}{*}{ L/R } & \multirow{2}{*}{$L(m)$} & \multicolumn{2}{|c|}{$\mathrm{H}=1(\mathrm{~m})$} & \multicolumn{2}{|c|}{$\mathrm{H}=1.2(\mathrm{~m})$} & \multicolumn{2}{|c|}{$\mathrm{H}=1.40(\mathrm{~m})$} \\
\hline & & WS/TS & SMF & WS/TS & SMF & WS/TS & SMF \\
\hline 0 & 25 & 0.00 & 1.00 & 0.00 & 1.00 & 0.00 & 1.00 \\
\hline 0.02 & 25 & 0.03 & 1.05 & 0.03 & 1.06 & 0.03 & 1.06 \\
\hline 0.04 & 25 & 0.06 & 1.11 & 0.06 & 1.11 & 0.07 & 1.12 \\
\hline 0.06 & 25 & 0.08 & 1.17 & 0.09 & 1.17 & 0.10 & 1.18 \\
\hline 0.08 & 25 & 0.11 & 1.22 & 0.12 & 1.24 & 0.13 & 1.25 \\
\hline 0.1 & 25 & 0.13 & 1.28 & 0.14 & 1.30 & 0.15 & 1.31 \\
\hline
\end{tabular}

Note: WS/TS: warping stress/total stress, SMF: stress magnification factor, H: girder depth

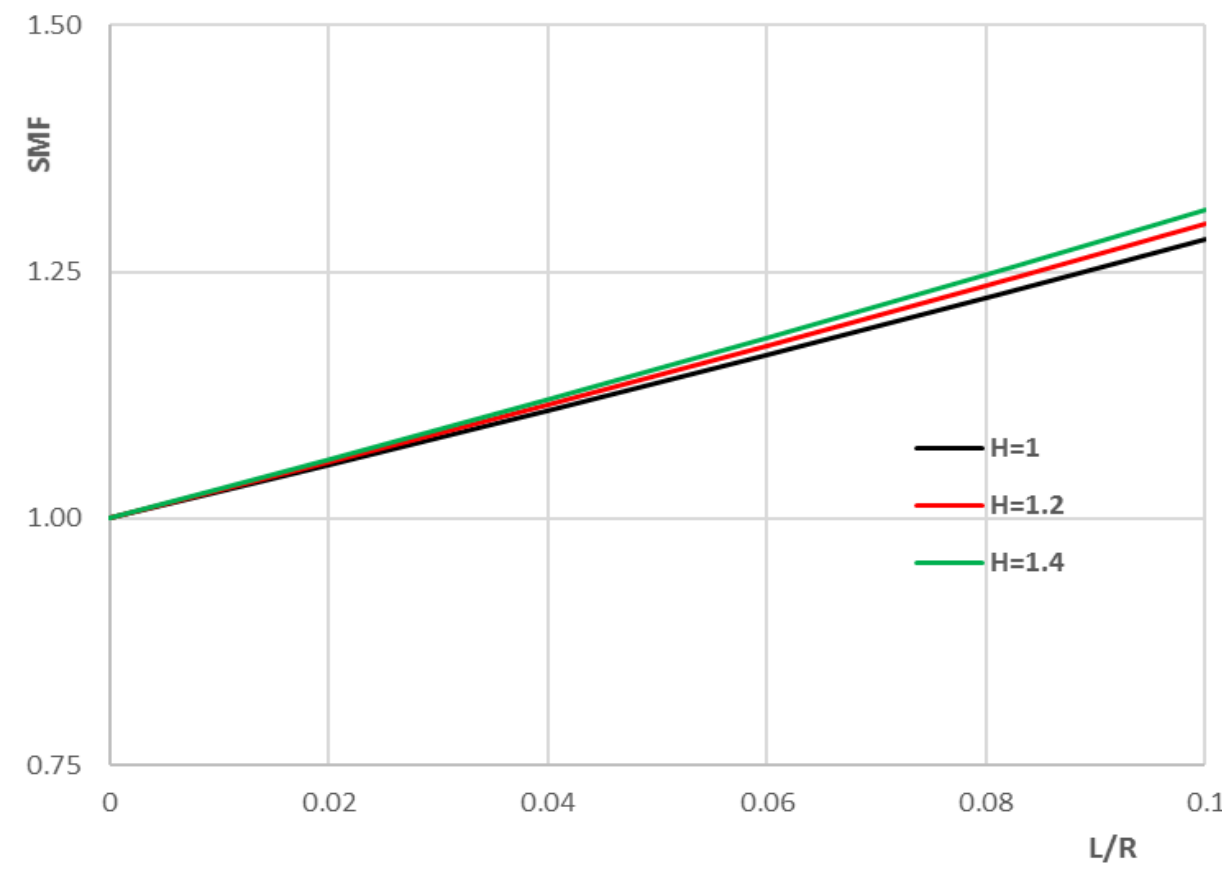

Figure 33. Variation of stress magnitication tactor, SMF, with the change in girder depth and curvature for $25 \mathrm{~m}$ span bridge of $12 \mathrm{~m}$ width 


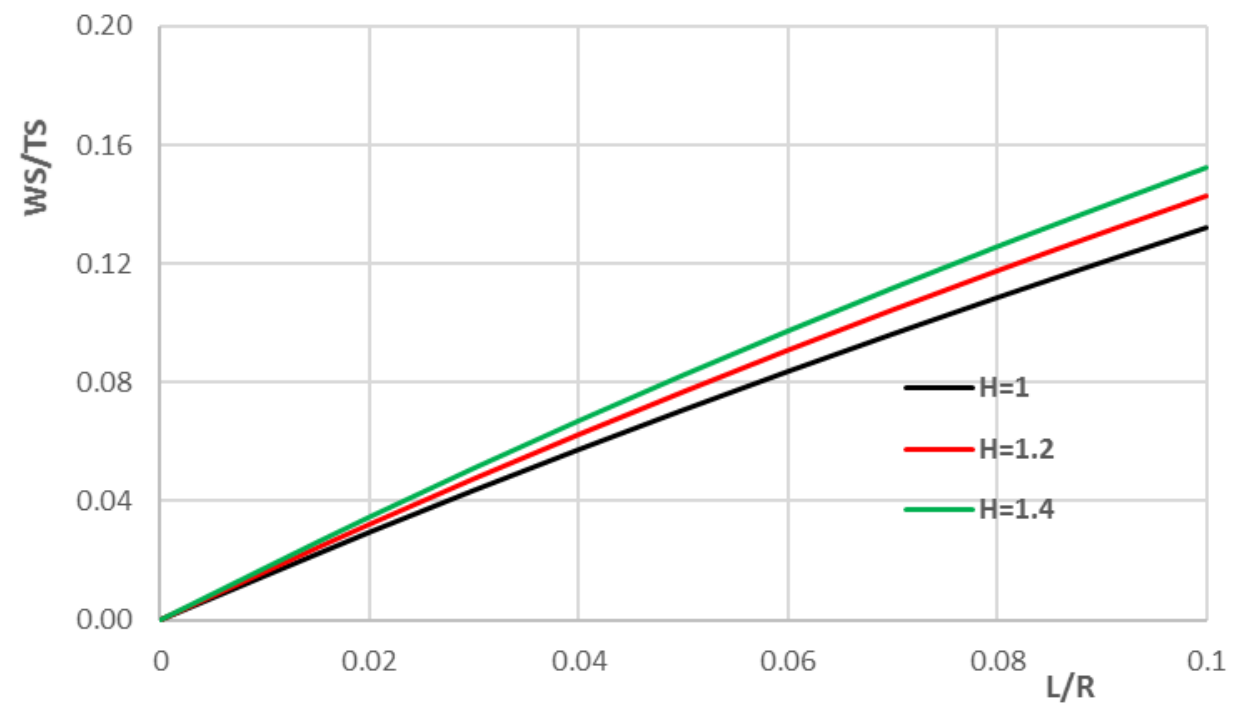

Figure 34. Variation of warping-to-total bending stress ratio, WS/TS, with the change in girder depth and curvature for $25 \mathrm{~m}$ span bridge of $12 \mathrm{~m}$ width

\subsection{Bottom flange width effect on warping stress}

Using the V-Load method, Table 27 presents the change in the stress magnification factor, SMF, and the ratio of warping to total bending stress, WS/TS, in the outer girder of a $25 \mathrm{~m}$ span, 6-girder, bridge of 12 $\mathrm{m}$ width With the change in bottom flange width from $200 \mathrm{~mm}$ to 300 and $400 \mathrm{~mm}$ and change in L/R ratio from 0 to 0.1 . Results for SMF and WS/TS are presented in graphical form in Figures 35 and 36, respectively. In this analysis, the. It can be observed that the SMF decrease with increase in flange width, with the rate of decrease significantly increasing with increase in L/R ratio. Similar behavior to SMF is observed for the WS/TS ratios. As such, one may conclude that the flange width has an effect on the warping stress and thus the SMF of the I-girder design.

Table 27: Effect of girder flange width on warping stress and Stress Magnification Factor

\begin{tabular}{|c|c|c|c|c|c|c|c|}
\hline \multicolumn{8}{|c|}{ I GIRDER FLANGE WIDTF EFFECT, L=25, No. of GIRDER 6, W=12 (m) } \\
\hline \multirow{2}{*}{ L/R } & \multirow{2}{*}{$\mathbf{L}(\mathbf{m})$} & \multicolumn{2}{|c|}{$\mathbf{b}=\mathbf{0 . 2}(\mathbf{m})$} & \multicolumn{2}{|c|}{$\mathbf{b}=\mathbf{0 . 3}(\mathbf{m})$} & \multicolumn{2}{|c|}{$\mathbf{b}=\mathbf{0 . 4}(\mathbf{m})$} \\
\cline { 3 - 8 } & & WS/TS & SMF & WS/TS & SMF & WS/TS & SMF \\
\hline 0 & 25 & 0.00 & 1.00 & 0.00 & 1.00 & 0.00 & 1.00 \\
\hline 0.02 & 25 & 0.05 & 1.08 & 0.03 & 1.05 & 0.02 & 1.04 \\
\hline 0.04 & 25 & 0.10 & 1.16 & 0.06 & 1.11 & 0.04 & 1.09 \\
\hline 0.06 & 25 & 0.15 & 1.25 & 0.08 & 1.17 & 0.06 & 1.13 \\
\hline 0.08 & 25 & 0.19 & 1.34 & 0.11 & 1.22 & 0.07 & 1.18 \\
0.1 & 25 & 0.22 & 1.43 & 0.13 & 1.28 & 0.09 & 1.22 \\
\hline
\end{tabular}

Note: WS/TS: Warping Stress/Total Stress, SMF: Stress Magnification Factor, b: Girder Flange Width. 


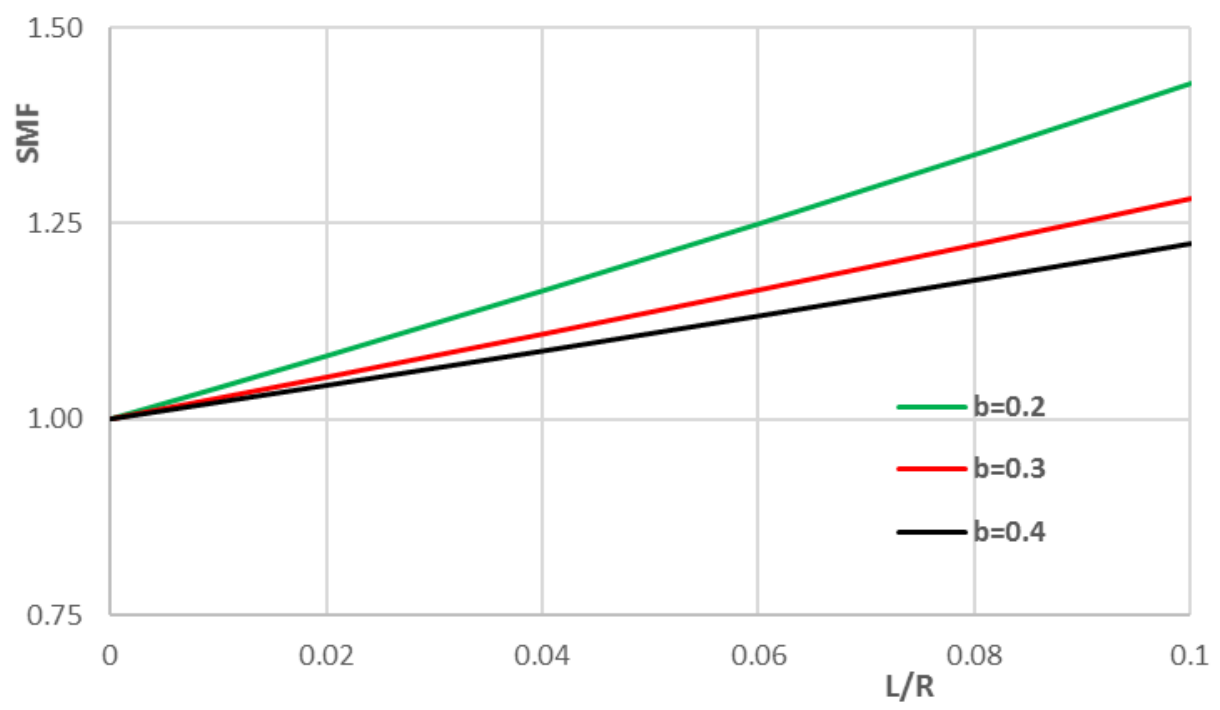

Figure 35. Variation of stress magnification factor, SMF, with the change in girder flange width and curvature for $25 \mathrm{~m}$ span bridge of $12 \mathrm{~m}$ width

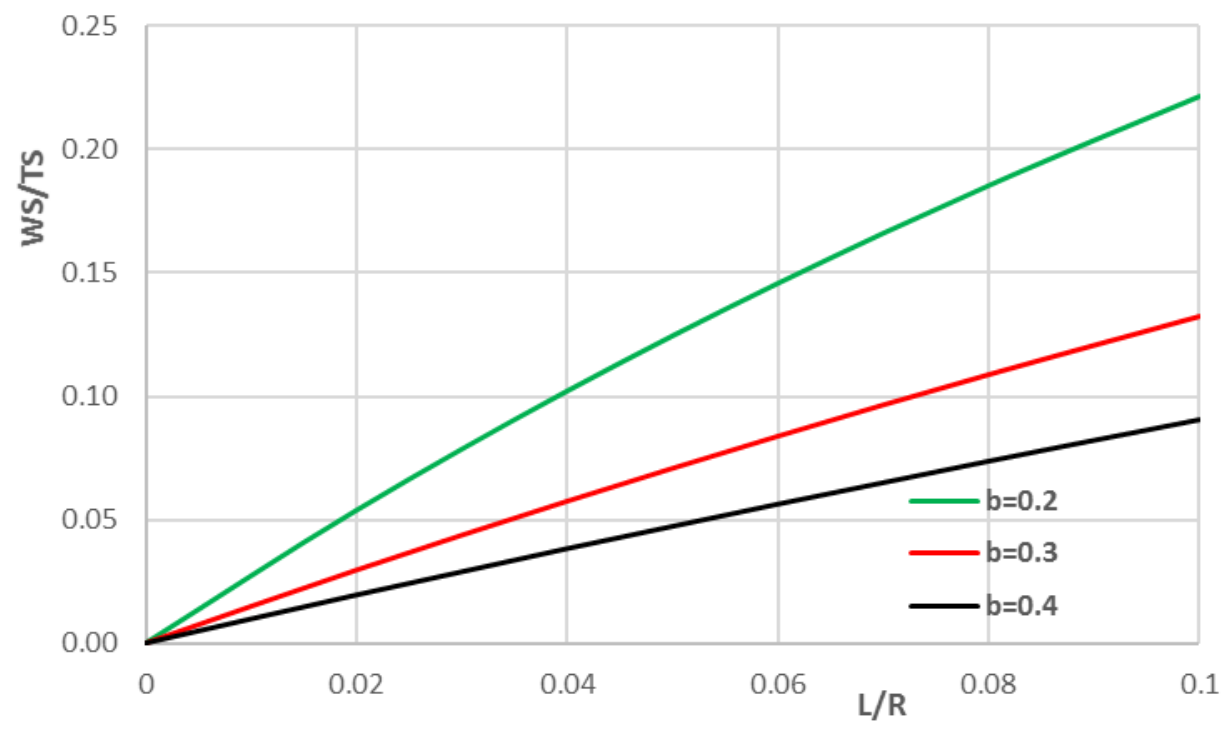

Figure 36. Variation of stress magnification factor, SMF, with the change in girder flange width and curvature for $25 \mathrm{~m}$ span bridge of $12 \mathrm{~m}$ width

\subsection{The effect of Number of Transverse Bracing on Warping Stress}

As mentioned earlier, Davidson et al. recommended, for a preliminary design purposes, a warping-tobending stress ratio of 0.25 and the corresponding maximum spacing between bracings as shown in equation (18). Results using the V-Load method are summarized in Appendices 3 and 4 considering the following parameters in addition to bridge configurations in Section 7: 
- L/R ratio: $0.0,0.02,0.04,0.06,0.08$ and 0.1 ;

- Number of intermediate $X$ bracing:

○ For $L=15 \mathrm{~m}: 5,4,3,2$ per span

○ For $L=25 \mathrm{~m}: 7,5,4,3,2$ per span

- For $L=35 \mathrm{~m}: 9,7,6,5,3$ per span

Results showed that the transverse bracing numbers or spacing has a great effect on warping stress, the warping-to-bending stress ratio and stress magnification factor (SMF). Also, it was observed that decreasing the number of transverse bracing at a certain curvature $(L / R)$ causes an increase in warping stress. Moreover, it was observed that the effect of number of transverse bracing on warping stress in a two-span bridge is less significant than that in a single span bridge of the same width, curved span, cross section configuration and radius of curvature.

\section{Correlation between the V-Load Method Results and Curvature Limitations}

One the objectives of this study is to examine the available equations for a curvature limitation for curved bridge that can be treated as a straight bridge in structural design. For this task, the data generated from the parametric V-Load analysis were correlated with those presented by Khalafalla [2] and Khalafalla and Sennah [15] (i.e. equation 15). If should be noted that Khalafalla used the following general equation form in developing those in equation 15.

$$
(L / R)^{\alpha}(L)^{\beta}(B)^{\gamma} \leq \phi
$$

In the finite element analysis conducted by Khalafalla [2], the number of bracing spacing obtained from equation 18 was considered in the studied bridges to determine curvature limitations. However, in the current study by the V-Load method, the number of cross-bracing spacing, N, was considered and the following modified form of equation 19 was considered to develop new equation for bridge curvature limitations.

$$
(L / R)^{\alpha}(L)^{\beta}(B)^{\gamma}(N)^{\rho} \leq \phi^{\prime}
$$

Following the same procedure presented by Khalafalla [2], the following two equations were developed as a modification to equation (15) for single- and two-span bridges to account the effect of number of transverse bracing on the stress magnification factor.

$\begin{array}{ll}\text { For single-span bridge: } & \text { Modification factor }=1.124 \mathrm{~N}^{-0.050} \\ \text { For two-span bridge: } & \text { Modification factor }=1.070 \mathrm{~N}^{-0.047}\end{array}$

Equations 21 and 22 can be simplified by considering them as $1.10 \mathrm{~N}^{-0.050}$ for the effect of number of transverse bracing to Equation 15. As such, equation 15 can be rewritten as follows, considering the same scope of applicability. 
For single-span bridges:

$$
\left.(L / R)^{0.92} X(L)^{0.5} X(B)\right)^{0.04} X(N)^{-0.05} \leq 0.0491
$$

For two-span bridges:

$$
(L / R)^{0.81} X(L)^{-0.06} \times(B)^{0.08} \times(N)^{-0.05} \leq 0.0214
$$

Tables 28 and 29 summarize the curvature limitation derived from equation (15) and equations 23 and 24. Good correlations were observed.

Table 28. Single-span bridge curvature limitations as obtained from the FEA modelling and V-Load method for a specific number of transverse $\mathrm{X}$ bracing

\begin{tabular}{|c|c|c|c|c|}
\hline \multicolumn{5}{|c|}{ Single Span Bridge } \\
\hline \multicolumn{5}{|c|}{ CURVATURE (L/R) Limitation with Khalafalla, 2009 Equation and V Load Method } \\
\hline L (m) & $\mathbf{W}(\mathrm{m})$ & No. of Bracing & L/R (Khalafalla, 2009) & L/R (V Load Method) \\
\hline 15 & 8 & 3 & 0.0088 & 0.0084 \\
\hline 15 & 12 & 3 & 0.0086 & 0.0083 \\
\hline 15 & 16 & 3 & 0.0085 & 0.0082 \\
\hline 25 & 8 & 5 & 0.0067 & 0.0065 \\
\hline 25 & 12 & 5 & 0.0065 & 0.0064 \\
\hline 25 & 16 & 5 & 0.0065 & 0.0064 \\
\hline 35 & 8 & 7 & 0.0055 & 0.0056 \\
\hline 35 & 12 & 7 & 0.0054 & 0.0055 \\
\hline 35 & 16 & 7 & 0.0054 & 0.0054 \\
\hline
\end{tabular}

Table 29. Two-span continuous bridge curvature limitations as obtained from the FEA modelling and VLoad method for a specific number of transverse $\mathrm{X}$ bracing

\begin{tabular}{|c|c|c|c|c|}
\hline \multicolumn{5}{|c|}{ Two Span Bridge Span } \\
\hline \multicolumn{5}{|c|}{ CURVATURE (L/R) Limitation with Khalafalla, 2009 Equation and V Load Method } \\
\hline L (m) & W (m) & No. of Bracing & L/R (Khalafalla, 2009) & L/R (V Load Method) \\
\hline 15 & 8 & 3 & 0.0097 & 0.0093 \\
\hline 15 & 12 & 3 & 0.0093 & 0.0089 \\
\hline 15 & 16 & 3 & 0.0091 & 0.0086 \\
\hline 25 & 8 & 5 & 0.0101 & 0.0099 \\
\hline 25 & 12 & 5 & 0.0097 & 0.0095 \\
\hline 25 & 16 & 5 & 0.0094 & 0.0093 \\
\hline 35 & 8 & 7 & 0.0103 & 0.0104 \\
\hline 35 & 12 & 7 & 0.0099 & 0.0100 \\
\hline 35 & 16 & 7 & 0.0096 & 0.0097 \\
\hline
\end{tabular}




\section{Conclusions}

The purpose of this study is to investigate the applicability of those specified limitations of bridge curvature in North American Bridge Codes to treat a horizontally curved bridge as straight one by the VLoad method and compare the results with the results obtained from the finite element modelling by others. Based on the data generated form this study, the following conclusions are drawn.

1- The stress magnification factor is the governing factor to design on whether single- and two-span curved slab on steel I-girder bridges can be treated as a straight one per the outcome from the VLoad method.

2- In general, good correlation between the finite element results and the results from the V-Load method for bridges of shallow curvature, while the V-Load method provides conservative values for the bending moment and warping stresses for bridges of high curvature. This conclusion is dependent of the bridge configuration, including span length, bridge width and number of crossbracing spacing.

3- The developed equations for curvature limitations by Khalafalla in 2009 correlate well with the results from the $\mathrm{V}$-Load method, given the limiting values of the span-to-radius of curvature ration, $L / R$, are generally less than 0.1 .

4- A modification to the curvature limitations by Khalafalla in 2009 was proposed using the data generated from the V-Load method to consider the effect of number of bracing spacing on the total bending moment on the girder.

\section{Recommendations for Future Research}

Further research is recommended in the following areas:

1) Study of curvature limitations for the truck loading conditions.

2) Study of curvature limitations for the bare steel girders for un-shored construction.

3) Study of the presence of concrete barrier wall, built integrally with the concrete deck slab, on the results from the finite element method and the V-Load method. 


\section{APPENDIX 1.}

\section{RESULTS OF STRESS MAGNIFICATION FACTOR SINGLE SPAN BRIDGES}

Table A.1. Results of stress magnification factors and

Warping-bending stress ratios for single span bridges

\begin{tabular}{|c|c|c|c|c|c|}
\hline $\mathbf{L}(\mathbf{m})$ & $\mathbf{W}(\mathbf{m})$ & Theta(L/R) & No. of Bracing & WS/TS & SMF \\
\hline 15 & 8 & 0 & 5 & 0 & 1 \\
\hline 15 & 8 & 0.02 & 5 & 0.027200 & 1.047663202 \\
\hline 15 & 8 & 0.04 & 5 & 0.052959585 & 1.096398177 \\
\hline 15 & 8 & 0.06 & 5 & 0.077390103 & 1.146204974 \\
\hline 15 & 8 & 0.08 & 5 & 0.100591866 & 1.197083593 \\
\hline 15 & 8 & 0.1 & 5 & 0.122655301 & 1.249034034 \\
\hline 15 & 8 & 0.2 & 5 & 0.218509281 & 1.52486357 \\
\hline 15 & 8 & 0.3 & 5 & 0.295481226 & 1.827488655 \\
\hline 15 & 8 & 0.4 & 5 & 0.358650171 & 2.156909291 \\
\hline 15 & 8 & 0.5 & 5 & 0.411423442 & 2.513125478 \\
\hline 15 & 8 & 0.6 & 5 & 0.456172147 & 2.896137215 \\
\hline 15 & 8 & 0 & 4 & 0 & 1 \\
\hline 15 & 8 & 0.02 & 4 & 0.038704843 & 1.059437409 \\
\hline 15 & 8 & 0.04 & 4 & 0.0745252 & 1.120359032 \\
\hline 15 & 8 & 0.06 & 4 & 0.107771937 & 1.182764919 \\
\hline 15 & 8 & 0.08 & 4 & 0.1387128 & 1.24665507 \\
\hline 15 & 8 & 0.1 & 4 & 0.16757964 & 1.312029484 \\
\hline 15 & 8 & 0.2 & 4 & 0.287054749 & 1.661165508 \\
\hline 15 & 8 & 0.3 & 4 & 0.376538536 & 2.047408122 \\
\hline 15 & 8 & 0.4 & 4 & 0.44606455 & 2.470757327 \\
\hline 15 & 8 & 0.5 & 4 & 0.501639759 & 2.931213121 \\
\hline 15 & 8 & 0.6 & 4 & 0.547080268 & 3.428775506 \\
\hline 15 & 8 & 0 & 3 & 0 & 1 \\
\hline 15 & 8 & 0.02 & 3 & 0.059187713 & 1.083837408 \\
\hline 15 & 8 & 0.04 & 3 & 0.111760574 & 1.1701519 \\
\hline 15 & 8 & 0.06 & 3 & 0.158768814 & 1.258943523 \\
\hline 15 & 8 & 0.08 & 3 & 0.201051515 & 1.350212278 \\
\hline 15 & 8 & 0.1 & 3 & 0.239287134 & 1.443958166 \\
\hline 15 & 8 & 0.2 & 3 & 0.386168995 & 1.949844586 \\
\hline 15 & 8 & 0.3 & 3 & 0.485509194 & 2.517659309 \\
\hline 15 & 8 & 0.4 & 3 & 0.557174481 & 3.147402335 \\
\hline 15 & 8 & 0.5 & 3 & 0.611315721 & 3.839073665 \\
\hline
\end{tabular}




\begin{tabular}{|c|c|c|c|c|c|}
\hline 15 & 8 & 0.6 & 3 & 0.653660302 & 4.592673299 \\
\hline 15 & 8 & 0 & 2 & 0 & 1 \\
\hline 15 & 8 & 0.02 & 2 & 0.100591866 & 1.141491475 \\
\hline 15 & 8 & 0.04 & 2 & 0.182795947 & 1.288947824 \\
\hline 15 & 8 & 0.06 & 2 & 0.251231839 & 1.442369095 \\
\hline 15 & 8 & 0.08 & 2 & 0.309091264 & 1.601755289 \\
\hline 15 & 8 & 0.1 & 2 & 0.358650171 & 1.767106405 \\
\hline 15 & 8 & 0.2 & 2 & 0.527950724 & 2.683335823 \\
\hline 15 & 8 & 0.3 & 2 & 0.626536015 & 3.748688305 \\
\hline 15 & 8 & 0.4 & 2 & 0.691057265 & 4.963163851 \\
\hline 15 & 8 & 0.5 & 2 & 0.73656878 & 6.326762459 \\
\hline 15 & 8 & 0.6 & 2 & 0.770393043 & 7.839484132 \\
\hline 15 & 12 & 0 & 5 & 0 & 1 \\
\hline 15 & 12 & 0.02 & 5 & 0.027200044 & 1.042033894 \\
\hline 15 & 12 & 0.04 & 5 & 0.052959585 & 1.084833326 \\
\hline 15 & 12 & 0.06 & 5 & 0.077390103 & 1.128398345 \\
\hline 15 & 12 & 0.08 & 5 & 0.100591866 & 1.172728951 \\
\hline 15 & 12 & 0.1 & 5 & 0.122655301 & 1.217825144 \\
\hline 15 & 12 & 0.2 & 5 & 0.218509281 & 1.454789917 \\
\hline 15 & 12 & 0.3 & 5 & 0.295481226 & 1.710894368 \\
\hline 15 & 12 & 0.4 & 5 & 0.358650171 & 1.986138499 \\
\hline 15 & 12 & 0.5 & 5 & 0.411423442 & 2.280522308 \\
\hline 15 & 12 & 0.6 & 5 & 0.456172147 & 2.594045796 \\
\hline 15 & 12 & 0 & 4 & 0 & 1 \\
\hline 15 & 12 & 0.02 & 4 & 0.038704843 & 1.056520729 \\
\hline 15 & 12 & 0.04 & 4 & 0.0745252 & 1.114306356 \\
\hline 15 & 12 & 0.06 & 4 & 0.107771937 & 1.17335095 \\
\hline 15 & 12 & 0.08 & 4 & 0.1387128 & 1.23365451 \\
\hline 15 & 12 & 0.1 & 4 & 0.16757964 & 1.295217036 \\
\hline 15 & 12 & 0.2 & 4 & 0.287054749 & 1.621914157 \\
\hline 15 & 12 & 0.3 & 4 & 0.376538536 & 1.980085429 \\
\hline 15 & 12 & 0.4 & 4 & 0.44606455 & 2.369730852 \\
\hline 15 & 12 & 0.5 & 4 & 0.501639759 & 2.790850427 \\
\hline 15 & 12 & 0.6 & 4 & 0.547080268 & 3.243444152 \\
\hline 15 & 12 & 0 & 3 & 0 & 1 \\
\hline 15 & 12 & 0.02 & 3 & 0.059187713 & 1.077858532 \\
\hline 15 & 12 & 0.04 & 3 & 0.111760574 & 1.157486395 \\
\hline 15 & 12 & 0.06 & 3 & 0.158768814 & 1.238883637 \\
\hline 15 & 12 & 0.08 & 3 & 0.201051515 & 1.32205026 \\
\hline 15 & 12 & 0.1 & 3 & 0.239287134 & 1.406986263 \\
\hline
\end{tabular}




\begin{tabular}{|c|c|c|c|c|c|}
\hline 15 & 12 & 0.2 & 3 & 0.386168995 & 1.858206978 \\
\hline 15 & 12 & 0.3 & 3 & 0.485509194 & 2.353662195 \\
\hline 15 & 12 & 0.4 & 3 & 0.557174481 & 2.893351914 \\
\hline 15 & 12 & 0.5 & 3 & 0.611315721 & 3.477276136 \\
\hline 15 & 12 & 0.6 & 3 & 0.653660302 & 4.105434859 \\
\hline 15 & 12 & 0 & 2 & 0 & 1 \\
\hline 15 & 12 & 0.02 & 2 & 0.100591866 & 1.125960979 \\
\hline 15 & 12 & 0.04 & 2 & 0.182795947 & 1.254762348 \\
\hline 15 & 12 & 0.06 & 2 & 0.251231839 & 1.386404156 \\
\hline 15 & 12 & 0.08 & 2 & 0.309091264 & 1.520886403 \\
\hline 15 & 12 & 0.1 & 2 & 0.358650171 & 1.658209089 \\
\hline 15 & 12 & 0.2 & 2 & 0.527950724 & 2.387429111 \\
\hline 15 & 12 & 0.3 & 2 & 0.626536015 & 3.187660114 \\
\hline 15 & 12 & 0.4 & 2 & 0.691057265 & 4.0589021 \\
\hline 15 & 12 & 0.5 & 2 & 0.73656878 & 5.001155067 \\
\hline 15 & 12 & 0.6 & 2 & 0.770393043 & 6.014419016 \\
\hline 15 & 16 & 0 & 5 & 0 & 1 \\
\hline 15 & 16 & 0.02 & 5 & 0.027200044 & 1.038906409 \\
\hline 15 & 16 & 0.04 & 5 & 0.052959585 & 1.078408221 \\
\hline 15 & 16 & 0.06 & 5 & 0.077390103 & 1.118505484 \\
\hline 15 & 16 & 0.08 & 5 & 0.100591866 & 1.159198199 \\
\hline 15 & 16 & 0.1 & 5 & 0.122655301 & 1.200486366 \\
\hline 15 & 16 & 0.2 & 5 & 0.218509281 & 1.415858975 \\
\hline 15 & 16 & 0.3 & 5 & 0.295481226 & 1.646117877 \\
\hline 15 & 16 & 0.4 & 5 & 0.358650171 & 1.891263072 \\
\hline 15 & 16 & 0.5 & 5 & 0.411423442 & 2.15129456 \\
\hline 15 & 16 & 0.6 & 5 & 0.456172147 & 2.42621234 \\
\hline 15 & 16 & 0 & 4 & 0 & 1 \\
\hline 15 & 16 & 0.02 & 4 & 0.038704843 & 1.050915483 \\
\hline 15 & 16 & 0.04 & 4 & 0.0745252 & 1.102655501 \\
\hline 15 & 16 & 0.06 & 4 & 0.107771937 & 1.155220103 \\
\hline 15 & 16 & 0.08 & 4 & 0.1387128 & 1.208609289 \\
\hline 15 & 16 & 0.1 & 4 & 0.16757964 & 1.262823059 \\
\hline 15 & 16 & 0.2 & 4 & 0.287054749 & 1.546260669 \\
\hline 15 & 16 & 0.3 & 4 & 0.376538536 & 1.850312879 \\
\hline 15 & 16 & 0.4 & 4 & 0.44606455 & 2.17497969 \\
\hline 15 & 16 & 0.5 & 4 & 0.501639759 & 2.5202611 \\
\hline 15 & 16 & 0.6 & 4 & 0.547080268 & 2.886157112 \\
\hline 15 & 16 & 0 & 3 & 0 & 1 \\
\hline 15 & 16 & 0.02 & 3 & 0.059187713 & 1.074536837 \\
\hline
\end{tabular}




\begin{tabular}{|c|c|c|c|c|c|}
\hline 15 & 16 & 0.04 & 3 & 0.111760574 & 1.150449798 \\
\hline 15 & 16 & 0.06 & 3 & 0.158768814 & 1.227738932 \\
\hline 15 & 16 & 0.08 & 3 & 0.201051515 & 1.306404238 \\
\hline 15 & 16 & 0.1 & 3 & 0.239287134 & 1.386445718 \\
\hline 15 & 16 & 0.2 & 3 & 0.386168995 & 1.807295713 \\
\hline 15 & 16 & 0.3 & 3 & 0.485509194 & 2.262550034 \\
\hline 15 & 16 & 0.4 & 3 & 0.557174481 & 2.75220868 \\
\hline 15 & 16 & 0.5 & 3 & 0.611315721 & 3.276271653 \\
\hline 15 & 16 & 0.6 & 3 & 0.653660302 & 3.834738951 \\
\hline 15 & 16 & 0 & 2 & 0 & 1 \\
\hline 15 & 16 & 0.02 & 2 & 0.100591866 & 1.122823413 \\
\hline 15 & 16 & 0.04 & 2 & 0.182795947 & 1.247855989 \\
\hline 15 & 16 & 0.06 & 2 & 0.251231839 & 1.375097778 \\
\hline 15 & 16 & 0.08 & 2 & 0.309091264 & 1.504548778 \\
\hline 15 & 16 & 0.1 & 2 & 0.358650171 & 1.63620899 \\
\hline 15 & 16 & 0.2 & 2 & 0.527950724 & 2.327648235 \\
\hline 15 & 16 & 0.3 & 2 & 0.626536015 & 3.074317782 \\
\hline 15 & 16 & 0.4 & 2 & 0.691057265 & 3.876217634 \\
\hline 15 & 16 & 0.5 & 2 & 0.73656878 & 4.733347788 \\
\hline 15 & 16 & 0.6 & 2 & 0.770393043 & 5.645708246 \\
\hline 25 & 8 & 0 & 7 & 0 & 1 \\
\hline 25 & 8 & 0.02 & 7 & 0.02959531 & 1.063103548 \\
\hline 25 & 8 & 0.04 & 7 & 0.057489209 & 1.128137 \\
\hline 25 & 8 & 0.06 & 7 & 0.083824317 & 1.195100397 \\
\hline 25 & 8 & 0.08 & 7 & 0.108727746 & 1.263993739 \\
\hline 25 & 8 & 0.1 & 7 & 0.132313155 & 1.334817028 \\
\hline 25 & 8 & 0.2 & 7 & 0.233704173 & 1.717882655 \\
\hline 25 & 8 & 0.3 & 7 & 0.31387886 & 2.149196923 \\
\hline 25 & 8 & 0.4 & 7 & 0.378865823 & 2.628759832 \\
\hline 25 & 8 & 0.5 & 7 & 0.432607253 & 3.156571383 \\
\hline 25 & 8 & 0.6 & 7 & 0.47778965 & 3.732631575 \\
\hline 25 & 8 & 0 & 5 & 0 & 1 \\
\hline 25 & 8 & 0.02 & 5 & 0.051508119 & 1.088009126 \\
\hline 25 & 8 & 0.04 & 5 & 0.097969988 & 1.179490247 \\
\hline 25 & 8 & 0.06 & 5 & 0.14009255 & 1.274443407 \\
\hline 25 & 8 & 0.08 & 5 & 0.178456587 & 1.372868606 \\
\hline 25 & 8 & 0.1 & 5 & 0.213543666 & 1.474765844 \\
\hline 25 & 8 & 0.2 & 5 & 0.351934045 & 2.036332609 \\
\hline 25 & 8 & 0.3 & 5 & 0.448908054 & 2.684700338 \\
\hline 25 & 8 & 0.4 & 5 & 0.520637891 & 3.419869032 \\
\hline
\end{tabular}




\begin{tabular}{|c|c|c|c|c|c|}
\hline 25 & 8 & 0.5 & 5 & 0.575845604 & 4.24183869 \\
\hline 25 & 8 & 0.6 & 5 & 0.61965016 & 5.150609311 \\
\hline 25 & 8 & 0 & 4 & 0 & 1 \\
\hline 25 & 8 & 0.02 & 4 & 0.072420437 & 1.127364257 \\
\hline 25 & 8 & 0.04 & 4 & 0.135059786 & 1.261867618 \\
\hline 25 & 8 & 0.06 & 4 & 0.189774245 & 1.403510123 \\
\hline 25 & 8 & 0.08 & 4 & 0.237978277 & 1.552291774 \\
\hline 25 & 8 & 0.1 & 4 & 0.280768637 & 1.70821257 \\
\hline 25 & 8 & 0.2 & 4 & 0.438437715 & 2.594903726 \\
\hline 25 & 8 & 0.3 & 4 & 0.539408137 & 3.660073512 \\
\hline 25 & 8 & 0.4 & 4 & 0.609602641 & 4.903721926 \\
\hline 25 & 8 & 0.5 & 4 & 0.661231226 & 6.32584897 \\
\hline 25 & 8 & 0.6 & 4 & 0.700799384 & 7.926454643 \\
\hline 25 & 8 & 0 & 3 & 0 & 1 \\
\hline 25 & 8 & 0.02 & 3 & 0.108727746 & 1.15880702 \\
\hline 25 & 8 & 0.04 & 3 & 0.196130649 & 1.325619697 \\
\hline 25 & 8 & 0.06 & 3 & 0.267922105 & 1.500438075 \\
\hline 25 & 8 & 0.08 & 3 & 0.32794185 & 1.683262154 \\
\hline 25 & 8 & 0.1 & 3 & 0.378865823 & 1.874091933 \\
\hline 25 & 8 & 0.2 & 3 & 0.549532546 & 2.948326336 \\
\hline 25 & 8 & 0.3 & 3 & 0.646627414 & 4.222703251 \\
\hline 25 & 8 & 0.4 & 3 & 0.709288162 & 5.697222678 \\
\hline 25 & 8 & 0.5 & 3 & 0.753073647 & 7.371884618 \\
\hline 25 & 8 & 0.6 & 3 & 0.785396148 & 9.246689069 \\
\hline 25 & 8 & 0 & 2 & 0 & 1 \\
\hline 25 & 8 & 0.02 & 2 & 0.178105065 & 1.252714924 \\
\hline 25 & 8 & 0.04 & 2 & 0.302358543 & 1.518258481 \\
\hline 25 & 8 & 0.06 & 2 & 0.393976703 & 1.796630713 \\
\hline 25 & 8 & 0.08 & 2 & 0.464324581 & 2.08783162 \\
\hline 25 & 8 & 0.1 & 2 & 0.520039004 & 2.391861202 \\
\hline 25 & 8 & 0.2 & 2 & 0.684244289 & 4.104439235 \\
\hline 25 & 8 & 0.3 & 2 & 0.764733998 & 6.137734141 \\
\hline 25 & 8 & 0.4 & 2 & 0.812523805 & 8.491745921 \\
\hline 25 & 8 & 0.5 & 2 & 0.844176401 & 11.16647457 \\
\hline 25 & 8 & 0.6 & 2 & 0.866684723 & 14.1619201 \\
\hline 25 & 12 & 0 & 7 & 0 & 1 \\
\hline 25 & 12 & 0.02 & 7 & 0.02959531 & 1.053787662 \\
\hline 25 & 12 & 0.04 & 7 & 0.057489209 & 1.108953815 \\
\hline 25 & 12 & 0.06 & 7 & 0.083824317 & 1.1654985 \\
\hline 25 & 12 & 0.08 & 7 & 0.108727746 & 1.223421718 \\
\hline
\end{tabular}




\begin{tabular}{|c|c|c|c|c|c|}
\hline 25 & 12 & 0.1 & 7 & 0.132313155 & 1.282723468 \\
\hline 25 & 12 & 0.2 & 7 & 0.233704173 & 1.599910209 \\
\hline 25 & 12 & 0.3 & 7 & 0.31387886 & 1.951560265 \\
\hline 25 & 12 & 0.4 & 7 & 0.378865823 & 2.337673635 \\
\hline 25 & 12 & 0.5 & 7 & 0.432607253 & 2.758250321 \\
\hline 25 & 12 & 0.6 & 7 & 0.47778965 & 3.213290321 \\
\hline 25 & 12 & 0 & 5 & 0 & 1 \\
\hline 25 & 12 & 0.02 & 5 & 0.047045858 & 1.073329896 \\
\hline 25 & 12 & 0.04 & 5 & 0.089863987 & 1.14891432 \\
\hline 25 & 12 & 0.06 & 5 & 0.128999764 & 1.226753314 \\
\hline 25 & 12 & 0.08 & 5 & 0.164908627 & 1.306846879 \\
\hline 25 & 12 & 0.1 & 5 & 0.197973884 & 1.389195015 \\
\hline 25 & 12 & 0.2 & 5 & 0.330514524 & 1.834754249 \\
\hline 25 & 12 & 0.3 & 5 & 0.425461228 & 2.336677745 \\
\hline 25 & 12 & 0.4 & 5 & 0.496822121 & 2.894965503 \\
\hline 25 & 12 & 0.5 & 5 & 0.552414692 & 3.509617523 \\
\hline 25 & 12 & 0.6 & 5 & 0.596945353 & 4.180633805 \\
\hline 25 & 12 & 0 & 4 & 0 & 1 \\
\hline 25 & 12 & 0.02 & 4 & 0.072420437 & 1.113281521 \\
\hline 25 & 12 & 0.04 & 4 & 0.135059786 & 1.23166239 \\
\hline 25 & 12 & 0.06 & 4 & 0.189774245 & 1.355142648 \\
\hline 25 & 12 & 0.08 & 4 & 0.237978277 & 1.483722295 \\
\hline 25 & 12 & 0.1 & 4 & 0.280768637 & 1.617401331 \\
\hline 25 & 12 & 0.2 & 4 & 0.438437715 & 2.362287354 \\
\hline 25 & 12 & 0.3 & 4 & 0.539408137 & 3.23465811 \\
\hline 25 & 12 & 0.4 & 4 & 0.609602641 & 4.234513601 \\
\hline 25 & 12 & 0.5 & 4 & 0.661231226 & 5.361853825 \\
\hline 25 & 12 & 0.6 & 4 & 0.700799384 & 6.616678783 \\
\hline 25 & 12 & 0 & 3 & 0 & 1 \\
\hline 25 & 12 & 0.02 & 3 & 0.099830161 & 1.136938274 \\
\hline 25 & 12 & 0.04 & 3 & 0.181537413 & 1.279075013 \\
\hline 25 & 12 & 0.06 & 3 & 0.249646068 & 1.426410258 \\
\hline 25 & 12 & 0.08 & 3 & 0.307290164 & 1.57894401 \\
\hline 25 & 12 & 0.1 & 3 & 0.356709384 & 1.736676269 \\
\hline 25 & 12 & 0.2 & 3 & 0.525844942 & 2.603315165 \\
\hline 25 & 12 & 0.3 & 3 & 0.624557272 & 3.59991673 \\
\hline 25 & 12 & 0.4 & 3 & 0.689250825 & 4.726480963 \\
\hline 25 & 12 & 0.5 & 3 & 0.734926378 & 5.983007866 \\
\hline 25 & 12 & 0.6 & 3 & 0.768895357 & 7.369497437 \\
\hline 25 & 12 & 0 & 2 & 0 & 1 \\
\hline
\end{tabular}




\begin{tabular}{|c|c|c|c|c|c|}
\hline 25 & 12 & 0.02 & 2 & 0.178105065 & 1.242425111 \\
\hline 25 & 12 & 0.04 & 2 & 0.302358543 & 1.494013519 \\
\hline 25 & 12 & 0.06 & 2 & 0.393976703 & 1.754765266 \\
\hline 25 & 12 & 0.08 & 2 & 0.464324581 & 2.024680352 \\
\hline 25 & 12 & 0.1 & 2 & 0.520039004 & 2.303758777 \\
\hline 25 & 12 & 0.2 & 2 & 0.684244289 & 3.83660099 \\
\hline 25 & 12 & 0.3 & 2 & 0.764733998 & 5.598526682 \\
\hline 25 & 12 & 0.4 & 2 & 0.812523805 & 7.589535852 \\
\hline 25 & 12 & 0.5 & 2 & 0.844176401 & 9.809628502 \\
\hline 25 & 12 & 0.6 & 2 & 0.866684723 & 12.25880463 \\
\hline 25 & 16 & 0 & 7 & 0 & 1 \\
\hline 25 & 16 & 0.02 & 7 & 0.02697741 & 1.045790747 \\
\hline 25 & 16 & 0.04 & 7 & 0.052537494 & 1.092556163 \\
\hline 25 & 16 & 0.06 & 7 & 0.076789087 & 1.140296292 \\
\hline 25 & 16 & 0.08 & 7 & 0.099830161 & 1.189011132 \\
\hline 25 & 16 & 0.1 & 7 & 0.121749142 & 1.238700684 \\
\hline 25 & 16 & 0.2 & 7 & 0.217070176 & 1.501769123 \\
\hline 25 & 16 & 0.3 & 7 & 0.293725718 & 1.78920536 \\
\hline 25 & 16 & 0.4 & 7 & 0.356709384 & 2.101009394 \\
\hline 25 & 16 & 0.5 & 7 & 0.409379365 & 2.437181225 \\
\hline 25 & 16 & 0.6 & 7 & 0.454077265 & 2.797720854 \\
\hline 25 & 16 & 0 & 5 & 0 & 1 \\
\hline 25 & 16 & 0.02 & 5 & 0.051508119 & 1.073029503 \\
\hline 25 & 16 & 0.04 & 5 & 0.097969988 & 1.147987858 \\
\hline 25 & 16 & 0.06 & 5 & 0.14009255 & 1.224875107 \\
\hline 25 & 16 & 0.08 & 5 & 0.178456587 & 1.303691251 \\
\hline 25 & 16 & 0.1 & 5 & 0.213543666 & 1.384436289 \\
\hline 25 & 16 & 0.2 & 5 & 0.351934045 & 1.81709489 \\
\hline 25 & 16 & 0.3 & 5 & 0.448908054 & 2.297975848 \\
\hline 25 & 16 & 0.4 & 5 & 0.520637891 & 2.82707916 \\
\hline 25 & 16 & 0.5 & 5 & 0.575845604 & 3.404404828 \\
\hline 25 & 16 & 0.6 & 5 & 0.61965016 & 4.029952852 \\
\hline 25 & 16 & 0 & 4 & 0 & 1 \\
\hline 25 & 16 & 0.02 & 4 & 0.072420437 & 1.105457551 \\
\hline 25 & 16 & 0.04 & 4 & 0.135059786 & 1.214881219 \\
\hline 25 & 16 & 0.06 & 4 & 0.189774245 & 1.328271045 \\
\hline 25 & 16 & 0.08 & 4 & 0.237978277 & 1.44562703 \\
\hline 25 & 16 & 0.1 & 4 & 0.280768637 & 1.566949174 \\
\hline 25 & 16 & 0.2 & 4 & 0.438437715 & 2.233052271 \\
\hline 25 & 16 & 0.3 & 4 & 0.539408137 & 2.998309336 \\
\hline
\end{tabular}




\begin{tabular}{|c|c|c|c|c|c|}
\hline 25 & 16 & 0.4 & 4 & 0.609602641 & 3.862720367 \\
\hline 25 & 16 & 0.5 & 4 & 0.661231226 & 4.826285365 \\
\hline 25 & 16 & 0.6 & 4 & 0.700799384 & 5.88900433 \\
\hline 25 & 16 & 0 & 3 & 0 & 1 \\
\hline 25 & 16 & 0.02 & 3 & 0.108727746 & 1.14244447 \\
\hline 25 & 16 & 0.04 & 3 & 0.196130649 & 1.289336472 \\
\hline 25 & 16 & 0.06 & 3 & 0.267922105 & 1.440676049 \\
\hline 25 & 16 & 0.08 & 3 & 0.32794185 & 1.5964632 \\
\hline 25 & 16 & 0.1 & 3 & 0.378865823 & 1.756697925 \\
\hline 25 & 16 & 0.2 & 3 & 0.549532546 & 2.624585164 \\
\hline 25 & 16 & 0.3 & 3 & 0.646627414 & 3.603661759 \\
\hline 25 & 16 & 0.4 & 3 & 0.709288162 & 4.693927712 \\
\hline 25 & 16 & 0.5 & 3 & 0.753073647 & 5.895383022 \\
\hline 25 & 16 & 0.6 & 3 & 0.785396148 & 7.208027688 \\
\hline 25 & 16 & 0 & 2 & 0 & 1 \\
\hline 25 & 16 & 0.02 & 2 & 0.178105065 & 1.236708381 \\
\hline 25 & 16 & 0.04 & 2 & 0.302358543 & 1.480543703 \\
\hline 25 & 16 & 0.06 & 2 & 0.393976703 & 1.731506006 \\
\hline 25 & 16 & 0.08 & 2 & 0.464324581 & 1.989595292 \\
\hline 25 & 16 & 0.1 & 2 & 0.520039004 & 2.254811559 \\
\hline 25 & 16 & 0.2 & 2 & 0.684244289 & 3.68779763 \\
\hline 25 & 16 & 0.3 & 2 & 0.764733998 & 5.298958256 \\
\hline 25 & 16 & 0.4 & 2 & 0.812523805 & 7.088293435 \\
\hline 25 & 16 & 0.5 & 2 & 0.844176401 & 9.055803169 \\
\hline 25 & 16 & 0.6 & 2 & 0.866684723 & 11.20148746 \\
\hline 35 & 8 & 0 & 9 & 0 & 1 \\
\hline 35 & 8 & 0.02 & 9 & 0.031268493 & 1.061152844 \\
\hline 35 & 8 & 0.04 & 9 & 0.060640838 & 1.124111248 \\
\hline 35 & 8 & 0.06 & 9 & 0.088284436 & 1.188875399 \\
\hline 35 & 8 & 0.08 & 9 & 0.114347546 & 1.255445299 \\
\hline 35 & 8 & 0.1 & 9 & 0.138961943 & 1.323820947 \\
\hline 35 & 8 & 0.2 & 9 & 0.244015077 & 1.692785404 \\
\hline 35 & 8 & 0.3 & 9 & 0.326221173 & 2.106893559 \\
\hline 35 & 8 & 0.4 & 9 & 0.392302443 & 2.566145412 \\
\hline 35 & 8 & 0.5 & 9 & 0.446579496 & 3.070540965 \\
\hline 35 & 8 & 0.6 & 9 & 0.491955911 & 3.620080215 \\
\hline 35 & 8 & 0 & 7 & 0 & 1 \\
\hline 35 & 8 & 0.02 & 7 & 0.04801255 & 1.096965167 \\
\hline 35 & 8 & 0.04 & 7 & 0.091625907 & 1.198398286 \\
\hline 35 & 8 & 0.06 & 7 & 0.131418204 & 1.304299544 \\
\hline
\end{tabular}




\begin{tabular}{|c|c|c|c|c|c|}
\hline 35 & 8 & 0.08 & 7 & 0.167870525 & 1.414668941 \\
\hline 35 & 8 & 0.1 & 7 & 0.201386444 & 1.529506478 \\
\hline 35 & 8 & 0.2 & 7 & 0.335256728 & 2.170716255 \\
\hline 35 & 8 & 0.3 & 7 & 0.430689342 & 2.92362952 \\
\hline 35 & 8 & 0.4 & 7 & 0.502160702 & 3.788246271 \\
\hline 35 & 8 & 0.5 & 7 & 0.557688558 & 4.76456651 \\
\hline 35 & 8 & 0.6 & 7 & 0.602072483 & 5.852590237 \\
\hline 35 & 8 & 0 & 6 & 0 & 1 \\
\hline 35 & 8 & 0.02 & 6 & 0.061801922 & 1.112112832 \\
\hline 35 & 8 & 0.04 & 6 & 0.116409513 & 1.229940872 \\
\hline 35 & 8 & 0.06 & 6 & 0.165009908 & 1.353484308 \\
\hline 35 & 8 & 0.08 & 6 & 0.208542675 & 1.48274314 \\
\hline 35 & 8 & 0.1 & 6 & 0.24776115 & 1.617717369 \\
\hline 35 & 8 & 0.2 & 6 & 0.397129131 & 2.378319453 \\
\hline 35 & 8 & 0.3 & 6 & 0.49700593 & 3.281806441 \\
\hline 35 & 8 & 0.4 & 6 & 0.568493093 & 4.328178334 \\
\hline 35 & 8 & 0.5 & 6 & 0.622188851 & 5.51743513 \\
\hline 35 & 8 & 0.6 & 6 & 0.663999948 & 6.84957683 \\
\hline 35 & 8 & 0 & 5 & 0 & 1 \\
\hline 35 & 8 & 0.02 & 5 & 0.082274315 & 1.138379478 \\
\hline 35 & 8 & 0.04 & 5 & 0.152039671 & 1.284777066 \\
\hline 35 & 8 & 0.06 & 5 & 0.211947307 & 1.439192951 \\
\hline 35 & 8 & 0.08 & 5 & 0.263948672 & 1.601627135 \\
\hline 35 & 8 & 0.1 & 5 & 0.309512019 & 1.772079616 \\
\hline 35 & 8 & 0.2 & 5 & 0.472713521 & 2.744616492 \\
\hline 35 & 8 & 0.3 & 5 & 0.573515917 & 3.917610816 \\
\hline 35 & 8 & 0.4 & 5 & 0.641962628 & 5.291062586 \\
\hline 35 & 8 & 0.5 & 5 & 0.691477592 & 6.864971805 \\
\hline 35 & 8 & 0.6 & 5 & 0.728961062 & 8.639338471 \\
\hline 35 & 8 & 0 & 3 & 0 & 1 \\
\hline 35 & 8 & 0.02 & 3 & 0.167870525 & 1.256941052 \\
\hline 35 & 8 & 0.04 & 3 & 0.287481397 & 1.532416419 \\
\hline 35 & 8 & 0.06 & 3 & 0.377027849 & 1.826426292 \\
\hline 35 & 8 & 0.08 & 3 & 0.446579496 & 2.138970669 \\
\hline 35 & 8 & 0.1 & 3 & 0.502160702 & 2.47004955 \\
\hline 35 & 8 & 0.2 & 3 & 0.668584528 & 4.403461526 \\
\hline 35 & 8 & 0.3 & 3 & 0.751617033 & 6.800236116 \\
\hline 35 & 8 & 0.4 & 3 & 0.801379273 & 9.660373319 \\
\hline 35 & 8 & 0.5 & 3 & 0.834530275 & 12.98387314 \\
\hline 35 & 8 & 0.6 & 3 & 0.858197904 & 16.77073557 \\
\hline
\end{tabular}




\begin{tabular}{|c|c|c|c|c|c|}
\hline 35 & 12 & 0 & 9 & 0 & 1 \\
\hline 35 & 12 & 0.02 & 9 & 0.031268493 & 1.052902878 \\
\hline 35 & 12 & 0.04 & 9 & 0.060640838 & 1.107095388 \\
\hline 35 & 12 & 0.06 & 9 & 0.088284436 & 1.162577718 \\
\hline 35 & 12 & 0.08 & 9 & 0.114347546 & 1.219349868 \\
\hline 35 & 12 & 0.1 & 9 & 0.138961943 & 1.277411838 \\
\hline 35 & 12 & 0.2 & 9 & 0.244015077 & 1.587068986 \\
\hline 35 & 12 & 0.3 & 9 & 0.326221173 & 1.928971633 \\
\hline 35 & 12 & 0.4 & 9 & 0.392302443 & 2.303119778 \\
\hline 35 & 12 & 0.5 & 9 & 0.446579496 & 2.709513422 \\
\hline 35 & 12 & 0.6 & 9 & 0.491955911 & 3.148152564 \\
\hline 35 & 12 & 0 & 7 & 0 & 1 \\
\hline 35 & 12 & 0.02 & 7 & 0.04801255 & 1.083670609 \\
\hline 35 & 12 & 0.04 & 7 & 0.091625907 & 1.170532557 \\
\hline 35 & 12 & 0.06 & 7 & 0.131418204 & 1.260586034 \\
\hline 35 & 12 & 0.08 & 7 & 0.167870525 & 1.353831039 \\
\hline 35 & 12 & 0.1 & 7 & 0.201386444 & 1.450267573 \\
\hline 35 & 12 & 0.2 & 7 & 0.335256728 & 1.980323161 \\
\hline 35 & 12 & 0.3 & 7 & 0.430689342 & 2.590166954 \\
\hline 35 & 12 & 0.4 & 7 & 0.502160702 & 3.279798952 \\
\hline 35 & 12 & 0.5 & 7 & 0.557688558 & 4.049219154 \\
\hline 35 & 12 & 0.6 & 7 & 0.602072483 & 4.89842756 \\
\hline 35 & 12 & 0 & 6 & 0 & 1 \\
\hline 35 & 12 & 0.02 & 6 & 0.061801922 & 1.098901509 \\
\hline 35 & 12 & 0.04 & 6 & 0.116409513 & 1.201885255 \\
\hline 35 & 12 & 0.06 & 6 & 0.165009908 & 1.308951427 \\
\hline 35 & 12 & 0.08 & 6 & 0.208542675 & 1.420100024 \\
\hline 35 & 12 & 0.1 & 6 & 0.24776115 & 1.535331048 \\
\hline 35 & 12 & 0.2 & 6 & 0.397129131 & 2.172722552 \\
\hline 35 & 12 & 0.3 & 6 & 0.49700593 & 2.912174701 \\
\hline 35 & 12 & 0.4 & 6 & 0.568493093 & 3.753687494 \\
\hline 35 & 12 & 0.5 & 6 & 0.622188851 & 4.697260932 \\
\hline 35 & 12 & 0.6 & 6 & 0.663999948 & 5.742895015 \\
\hline 35 & 12 & 0 & 5 & 0 & 1 \\
\hline 35 & 12 & 0.02 & 5 & 0.082274315 & 1.124456893 \\
\hline 35 & 12 & 0.04 & 5 & 0.152039671 & 1.254640953 \\
\hline 35 & 12 & 0.06 & 5 & 0.211947307 & 1.390552369 \\
\hline 35 & 12 & 0.08 & 5 & 0.263948672 & 1.532191141 \\
\hline 35 & 12 & 0.1 & 5 & 0.309512019 & 1.679557268 \\
\hline 35 & 12 & 0.2 & 5 & 0.472713521 & 2.502298237 \\
\hline
\end{tabular}




\begin{tabular}{|c|c|c|c|c|c|}
\hline 35 & 12 & 0.3 & 5 & 0.573515917 & 3.468223096 \\
\hline 35 & 12 & 0.4 & 5 & 0.641962628 & 4.577331844 \\
\hline 35 & 12 & 0.5 & 5 & 0.691477592 & 5.829624482 \\
\hline 35 & 12 & 0.6 & 5 & 0.728961062 & 7.22510101 \\
\hline 35 & 12 & 0 & 3 & 0 & 1 \\
\hline 35 & 12 & 0.02 & 3 & 0.167870525 & 1.241168262 \\
\hline 35 & 12 & 0.04 & 3 & 0.287481397 & 1.495575268 \\
\hline 35 & 12 & 0.06 & 3 & 0.377027849 & 1.763221205 \\
\hline 35 & 12 & 0.08 & 3 & 0.446579496 & 2.044106074 \\
\hline 35 & 12 & 0.1 & 3 & 0.502160702 & 2.338229875 \\
\hline 35 & 12 & 0.2 & 3 & 0.668584528 & 4.007432854 \\
\hline 35 & 12 & 0.3 & 3 & 0.751617033 & 6.007609125 \\
\hline 35 & 12 & 0.4 & 3 & 0.801379273 & 8.338758688 \\
\hline 35 & 12 & 0.5 & 3 & 0.834530275 & 11.00088154 \\
\hline 35 & 12 & 0.6 & 3 & 0.858197904 & 13.99397769 \\
\hline 35 & 16 & 0 & 9 & 0 & 1 \\
\hline 35 & 16 & 0.02 & 9 & 0.031268493 & 1.04831943 \\
\hline 35 & 16 & 0.04 & 9 & 0.060640838 & 1.097641858 \\
\hline 35 & 16 & 0.06 & 9 & 0.088284436 & 1.14796747 \\
\hline 35 & 16 & 0.08 & 9 & 0.114347546 & 1.199296267 \\
\hline 35 & 16 & 0.1 & 9 & 0.138961943 & 1.251628248 \\
\hline 35 & 16 & 0.2 & 9 & 0.244015077 & 1.528335932 \\
\hline 35 & 16 & 0.3 & 9 & 0.326221173 & 1.830123239 \\
\hline 35 & 16 & 0.4 & 9 & 0.392302443 & 2.156990168 \\
\hline 35 & 16 & 0.5 & 9 & 0.446579496 & 2.508936722 \\
\hline 35 & 16 & 0.6 & 9 & 0.491955911 & 2.885962898 \\
\hline 35 & 16 & 0 & 7 & 0 & 1 \\
\hline 35 & 16 & 0.02 & 7 & 0.04801255 & 1.076284528 \\
\hline 35 & 16 & 0.04 & 7 & 0.091625907 & 1.155051146 \\
\hline 35 & 16 & 0.06 & 7 & 0.131418204 & 1.236300044 \\
\hline 35 & 16 & 0.08 & 7 & 0.167870525 & 1.32003122 \\
\hline 35 & 16 & 0.1 & 7 & 0.201386444 & 1.406244676 \\
\hline 35 & 16 & 0.2 & 7 & 0.335256728 & 1.874546139 \\
\hline 35 & 16 & 0.3 & 7 & 0.430689342 & 2.404904577 \\
\hline 35 & 16 & 0.4 & 7 & 0.502160702 & 2.99731999 \\
\hline 35 & 16 & 0.5 & 7 & 0.557688558 & 3.651792379 \\
\hline 35 & 16 & 0.6 & 7 & 0.602072483 & 4.368321742 \\
\hline 35 & 16 & 0 & 6 & 0 & 1 \\
\hline 35 & 16 & 0.02 & 6 & 0.061801922 & 1.091561671 \\
\hline 35 & 16 & 0.04 & 6 & 0.116409513 & 1.186298347 \\
\hline
\end{tabular}




\begin{tabular}{|l|l|l|l|l|l|}
\hline 35 & 16 & 0.06 & 6 & 0.165009908 & 1.284210216 \\
\hline 35 & 16 & 0.08 & 6 & 0.208542675 & 1.385297279 \\
\hline 35 & 16 & 0.1 & 6 & 0.24776115 & 1.489559536 \\
\hline 35 & 16 & 0.2 & 6 & 0.397129131 & 2.058498724 \\
\hline 35 & 16 & 0.3 & 6 & 0.49700593 & 2.706817751 \\
\hline 35 & 16 & 0.4 & 6 & 0.568493093 & 3.434516619 \\
\hline 35 & 16 & 0.5 & 6 & 0.622188851 & 4.241595327 \\
\hline 35 & 16 & 0.6 & 6 & 0.663999948 & 5.128053874 \\
\hline 35 & 16 & 0 & 5 & 0 & 1 \\
\hline 35 & 16 & 0.02 & 5 & 0.082274315 & 1.116721898 \\
\hline 35 & 16 & 0.04 & 5 & 0.152039671 & 1.237898181 \\
\hline 35 & 16 & 0.06 & 5 & 0.211947307 & 1.363529036 \\
\hline 35 & 16 & 0.08 & 5 & 0.263948672 & 1.493614464 \\
\hline 35 & 16 & 0.1 & 5 & 0.309512019 & 1.628154465 \\
\hline 35 & 16 & 0.2 & 5 & 0.472713521 & 2.367673062 \\
\hline 35 & 16 & 0.3 & 5 & 0.573515917 & 3.218555978 \\
\hline 35 & 16 & 0.4 & 5 & 0.641962628 & 4.180803214 \\
\hline 35 & 16 & 0.5 & 5 & 0.691477592 & 5.254414769 \\
\hline 35 & 16 & 0.6 & 5 & 0.728961062 & 6.439390644 \\
\hline 35 & 16 & 0 & 3 & 0 & 1 \\
\hline 35 & 16 & 0.02 & 3 & 0.167870525 & 1.232405346 \\
\hline 35 & 16 & 0.04 & 3 & 0.287481397 & 1.475107365 \\
\hline 35 & 16 & 0.06 & 3 & 0.377027849 & 1.728106245 \\
\hline 35 & 16 & 0.08 & 3 & 0.446579496 & 1.991401986 \\
\hline 35 & 16 & 0.1 & 3 & 0.502160702 & 2.264994588 \\
\hline 35 & 16 & 0.2 & 3 & 0.668584528 & 3.787410515 \\
\hline 35 & 16 & 0.3 & 3 & 0.751617033 & 5.567247969 \\
\hline 35 & 16 & 0.4 & 3 & 0.801379273 & 7.604506949 \\
\hline 35 & 16 & 0.5 & 3 & 0.834530275 & 9.899187455 \\
\hline 35 & 16 & 0.6 & 3 & 0.858197904 & 12.45128949 \\
\hline
\end{tabular}




\section{APPENDIX 2.}

\section{RESULTS OF STRESS MAGNIFICATION FACTOR FOR TWO-SPAN BRIDGES}

Table A.2. Results of stress magnification factors,

and warping-bending stress ratios for two-span continuous bridges

\begin{tabular}{|c|c|c|c|c|c|c|}
\hline$L(m)$ & $W(m)$ & Theta(L/R) & No. of Bracing & WS/TS-MID & $\begin{array}{l}\text { SMF-MID } \\
\text { SPAN }\end{array}$ & $\begin{array}{c}\text { SMF- } \\
\text { SUPPORT }\end{array}$ \\
\hline 15 & 8 & 0 & 11 & 0 & 1 & 1 \\
\hline 15 & 8 & 0.02 & 11 & 0.0137875 & 1.01913111 & 1.0032003 \\
\hline 15 & 8 & 0.04 & 11 & 0.0272 & 1.03840431 & 1.0064005 \\
\hline 15 & 8 & 0.06 & 11 & 0.0402526 & 1.05781954 & 1.0096007 \\
\hline 15 & 8 & 0.08 & 11 & 0.0529596 & 1.07737682 & 1.012801 \\
\hline 15 & 8 & 0.1 & 11 & 0.0653345 & 1.09707612 & 1.0160012 \\
\hline 15 & 8 & 0.2 & 11 & 0.1226553 & 1.1977032 & 1.0320024 \\
\hline 15 & 8 & 0.3 & 11 & 0.1733517 & 1.30188117 & 1.0480035 \\
\hline 15 & 8 & 0.4 & 11 & 0.2185093 & 1.40961004 & 1.0640047 \\
\hline 15 & 8 & 0.5 & 11 & 0.2589887 & 1.5208898 & 1.0800058 \\
\hline 15 & 8 & 0.6 & 11 & 0.2954812 & 1.63572046 & 1.096007 \\
\hline 15 & 8 & 0 & 9 & 0 & 1 & 1 \\
\hline 15 & 8 & 0.02 & 9 & 0.0197343 & 1.02534643 & 1.0032832 \\
\hline 15 & 8 & 0.04 & 9 & 0.0387048 & 1.05089878 & 1.0065664 \\
\hline 15 & 8 & 0.06 & 9 & 0.056955 & 1.07665696 & 1.0098497 \\
\hline 15 & 8 & 0.08 & 9 & 0.0745252 & 1.10262096 & 1.0131329 \\
\hline 15 & 8 & 0.1 & 9 & 0.0914526 & 1.12879078 & 1.0164161 \\
\hline 15 & 8 & 0.2 & 9 & 0.1675796 & 1.26272729 & 1.0328321 \\
\hline 15 & 8 & 0.3 & 9 & 0.2319356 & 1.40180944 & 1.0492481 \\
\hline 15 & 8 & 0.4 & 9 & 0.2870547 & 1.54603723 & 1.0656641 \\
\hline 15 & 8 & 0.5 & 9 & 0.3347925 & 1.69541066 & 1.0820801 \\
\hline 15 & 8 & 0.6 & 9 & 0.3765385 & 1.84992973 & 1.0984961 \\
\hline 15 & 8 & 0 & 7 & 0 & 1 & 1 \\
\hline 15 & 8 & 0.02 & 7 & 0.0304964 & 1.03662305 & 1.0034278 \\
\hline 15 & 8 & 0.04 & 7 & 0.0591877 & 1.07356121 & 1.0068555 \\
\hline 15 & 8 & 0.06 & 7 & 0.0862297 & 1.11081455 & 1.0102833 \\
\hline 15 & 8 & 0.08 & 7 & 0.1117606 & 1.14838306 & 1.013711 \\
\hline 15 & 8 & 0.1 & 7 & 0.1359036 & 1.18626674 & 1.0171387 \\
\hline 15 & 8 & 0.2 & 7 & 0.2392871 & 1.38041271 & 1.0342774 \\
\hline 15 & 8 & 0.3 & 7 & 0.3205759 & 1.58243794 & 1.0514161 \\
\hline 15 & 8 & 0.4 & 7 & 0.386169 & 1.79234245 & 1.0685547 \\
\hline
\end{tabular}




\begin{tabular}{|c|c|c|c|c|c|c|}
\hline 15 & 8 & 0.5 & 7 & 0.4402122 & 2.01012623 & 1.0856934 \\
\hline 15 & 8 & 0.6 & 7 & 0.4855092 & 2.23578928 & 1.1028321 \\
\hline 15 & 8 & 0 & 5 & 0 & 1 & 1 \\
\hline 15 & 8 & 0.02 & 5 & 0.0529596 & 1.06202432 & 1.0037038 \\
\hline 15 & 8 & 0.04 & 5 & 0.1005919 & 1.12469268 & 1.0074075 \\
\hline 15 & 8 & 0.06 & 5 & 0.1436622 & 1.18800724 & 1.0111112 \\
\hline 15 & 8 & 0.08 & 5 & 0.1827959 & 1.251968 & 1.0148149 \\
\hline 15 & 8 & 0.1 & 5 & 0.2185093 & 1.31657496 & 1.0185186 \\
\hline 15 & 8 & 0.2 & 5 & 0.3586502 & 1.64930279 & 1.0370371 \\
\hline 15 & 8 & 0.3 & 5 & 0.4561721 & 1.99818566 & 1.0555556 \\
\hline 15 & 8 & 0.4 & 5 & 0.5279507 & 2.36322355 & 1.0740741 \\
\hline 15 & 8 & 0.5 & 5 & 0.5829908 & 2.74441648 & 1.0925926 \\
\hline 15 & 8 & 0.6 & 5 & 0.626536 & 3.14176445 & 1.1111112 \\
\hline 15 & 12 & 0 & 11 & 0 & 1 & 1 \\
\hline 15 & 12 & 0.02 & 11 & 0.0137875 & 1.01765943 & 1.0022859 \\
\hline 15 & 12 & 0.04 & 11 & 0.0272 & 1.03542037 & 1.0045718 \\
\hline 15 & 12 & 0.06 & 11 & 0.0402526 & 1.05328276 & 1.0068577 \\
\hline 15 & 12 & 0.08 & 11 & 0.0529596 & 1.07124661 & 1.0091436 \\
\hline 15 & 12 & 0.1 & 11 & 0.0653345 & 1.08931191 & 1.0114294 \\
\hline 15 & 12 & 0.2 & 11 & 0.1226553 & 1.18116023 & 1.0228588 \\
\hline 15 & 12 & 0.3 & 11 & 0.1733517 & 1.2755449 & 1.0342882 \\
\hline 15 & 12 & 0.4 & 11 & 0.2185093 & 1.37246593 & 1.0457176 \\
\hline 15 & 12 & 0.5 & 11 & 0.2589887 & 1.47192331 & 1.057147 \\
\hline 15 & 12 & 0.6 & 11 & 0.2954812 & 1.57391704 & 1.0685764 \\
\hline 15 & 12 & 0 & 9 & 0 & 1 & 1 \\
\hline 15 & 12 & 0.02 & 9 & 0.0197343 & 1.02385646 & 1.0023452 \\
\hline 15 & 12 & 0.04 & 9 & 0.0387048 & 1.04786003 & 1.0046903 \\
\hline 15 & 12 & 0.06 & 9 & 0.056955 & 1.07201061 & 1.0070355 \\
\hline 15 & 12 & 0.08 & 9 & 0.0745252 & 1.09630821 & 1.0093806 \\
\hline 15 & 12 & 0.1 & 9 & 0.0914526 & 1.12075283 & 1.0117258 \\
\hline 15 & 12 & 0.2 & 9 & 0.1675796 & 1.24518121 & 1.0234515 \\
\hline 15 & 12 & 0.3 & 9 & 0.2319356 & 1.37328505 & 1.0351772 \\
\hline 15 & 12 & 0.4 & 9 & 0.2870547 & 1.50506434 & 1.0469029 \\
\hline 15 & 12 & 0.5 & 9 & 0.3347925 & 1.64051909 & 1.0586286 \\
\hline 15 & 12 & 0.6 & 9 & 0.3765385 & 1.7796493 & 1.0703543 \\
\hline 15 & 12 & 0 & 7 & 0 & 1 & 1 \\
\hline 15 & 12 & 0.02 & 7 & 0.0304964 & 1.03514666 & 1.0024484 \\
\hline 15 & 12 & 0.04 & 7 & 0.0591877 & 1.07051839 & 1.0048968 \\
\hline 15 & 12 & 0.06 & 7 & 0.0862297 & 1.10611525 & 1.0073452 \\
\hline 15 & 12 & 0.08 & 7 & 0.1117606 & 1.14193723 & 1.0097936 \\
\hline
\end{tabular}




\begin{tabular}{|c|c|c|c|c|c|c|}
\hline 15 & 12 & 0.1 & 7 & 0.1359036 & 1.17798433 & 1.012242 \\
\hline 15 & 12 & 0.2 & 7 & 0.2392871 & 1.36159665 & 1.0244839 \\
\hline 15 & 12 & 0.3 & 7 & 0.3205759 & 1.55083703 & 1.0367258 \\
\hline 15 & 12 & 0.4 & 7 & 0.386169 & 1.74570545 & 1.0489677 \\
\hline 15 & 12 & 0.5 & 7 & 0.4402122 & 1.94620193 & 1.0612096 \\
\hline 15 & 12 & 0.6 & 7 & 0.4855092 & 2.15232646 & 1.0734515 \\
\hline 15 & 12 & 0 & 5 & 0 & 1 & 1 \\
\hline 15 & 12 & 0.02 & 5 & 0.0529596 & 1.06028121 & 1.0026456 \\
\hline 15 & 12 & 0.04 & 5 & 0.1005919 & 1.12102182 & 1.0052911 \\
\hline 15 & 12 & 0.06 & 5 & 0.1436622 & 1.18222401 & 1.0079366 \\
\hline 15 & 12 & 0.08 & 5 & 0.1827959 & 1.24388778 & 1.0105821 \\
\hline 15 & 12 & 0.1 & 5 & 0.2185093 & 1.30601311 & 1.0132276 \\
\hline 15 & 12 & 0.2 & 5 & 0.3586502 & 1.62356337 & 1.0264551 \\
\hline 15 & 12 & 0.3 & 5 & 0.4561721 & 1.95265294 & 1.0396826 \\
\hline 15 & 12 & 0.4 & 5 & 0.5279507 & 2.29328182 & 1.0529101 \\
\hline 15 & 12 & 0.5 & 5 & 0.5829908 & 2.64545001 & 1.0661376 \\
\hline 15 & 12 & 0.6 & 5 & 0.626536 & 3.0091575 & 1.0793651 \\
\hline 15 & 16 & 0 & 11 & 0 & 1 & 1 \\
\hline 15 & 16 & 0.02 & 11 & 0.0137875 & 1.04259598 & 1.017779 \\
\hline 15 & 16 & 0.04 & 11 & 0.0272 & 1.08598111 & 1.0355579 \\
\hline 15 & 16 & 0.06 & 11 & 0.0402526 & 1.13015531 & 1.0533368 \\
\hline 15 & 16 & 0.08 & 11 & 0.0529596 & 1.17511859 & 1.0711157 \\
\hline 15 & 16 & 0.1 & 11 & 0.0653345 & 1.22087096 & 1.0888946 \\
\hline 15 & 16 & 0.2 & 11 & 0.1226553 & 1.461469 & 1.1777892 \\
\hline 15 & 16 & 0.3 & 11 & 0.1733517 & 1.72179408 & 1.2666838 \\
\hline 15 & 16 & 0.4 & 11 & 0.2185093 & 2.00184619 & 1.3555784 \\
\hline 15 & 16 & 0.5 & 11 & 0.2589887 & 2.30162534 & 1.444473 \\
\hline 15 & 16 & 0.6 & 11 & 0.2954812 & 2.62113151 & 1.5333675 \\
\hline 15 & 16 & 0 & 9 & 0 & 1 & 1 \\
\hline 15 & 16 & 0.02 & 9 & 0.0197343 & 1.02302867 & 1.001824 \\
\hline 15 & 16 & 0.04 & 9 & 0.0387048 & 1.04617178 & 1.003648 \\
\hline 15 & 16 & 0.06 & 9 & 0.056955 & 1.06942923 & 1.005472 \\
\hline 15 & 16 & 0.08 & 9 & 0.0745252 & 1.09280103 & 1.007296 \\
\hline 15 & 16 & 0.1 & 9 & 0.0914526 & 1.11628718 & 1.00912 \\
\hline 15 & 16 & 0.2 & 9 & 0.1675796 & 1.23543311 & 1.0182399 \\
\hline 15 & 16 & 0.3 & 9 & 0.2319356 & 1.3574377 & 1.0273598 \\
\hline 15 & 16 & 0.4 & 9 & 0.2870547 & 1.48230096 & 1.0364797 \\
\hline 15 & 16 & 0.5 & 9 & 0.3347925 & 1.61002289 & 1.0455997 \\
\hline 15 & 16 & 0.6 & 9 & 0.3765385 & 1.74060348 & 1.0547196 \\
\hline 15 & 16 & 0 & 7 & 0 & 1 & 1 \\
\hline
\end{tabular}




\begin{tabular}{|c|c|c|c|c|c|c|}
\hline 15 & 16 & 0.02 & 7 & 0.0304964 & 1.03432642 & 1.0019043 \\
\hline 15 & 16 & 0.04 & 7 & 0.0591877 & 1.06882789 & 1.0038086 \\
\hline 15 & 16 & 0.06 & 7 & 0.0862297 & 1.10350445 & 1.0057129 \\
\hline 15 & 16 & 0.08 & 7 & 0.1117606 & 1.1383561 & 1.0076172 \\
\hline 15 & 16 & 0.1 & 7 & 0.1359036 & 1.17338285 & 1.0095215 \\
\hline 15 & 16 & 0.2 & 7 & 0.2392871 & 1.35114298 & 1.0190429 \\
\hline 15 & 16 & 0.3 & 7 & 0.3205759 & 1.53328045 & 1.0285643 \\
\hline 15 & 16 & 0.4 & 7 & 0.386169 & 1.71979526 & 1.0380857 \\
\hline 15 & 16 & 0.5 & 7 & 0.4402122 & 1.9106874 & 1.0476071 \\
\hline 15 & 16 & 0.6 & 7 & 0.4855092 & 2.10595688 & 1.0571285 \\
\hline 15 & 16 & 0 & 5 & 0 & 1 & 1 \\
\hline 15 & 16 & 0.02 & 5 & 0.0529596 & 1.05931278 & 1.0020576 \\
\hline 15 & 16 & 0.04 & 5 & 0.1005919 & 1.1189824 & 1.0041152 \\
\hline 15 & 16 & 0.06 & 5 & 0.1436622 & 1.17901102 & 1.0061728 \\
\hline 15 & 16 & 0.08 & 5 & 0.1827959 & 1.23939864 & 1.0082304 \\
\hline 15 & 16 & 0.1 & 5 & 0.2185093 & 1.30014525 & 1.010288 \\
\hline 15 & 16 & 0.2 & 5 & 0.3586502 & 1.60926328 & 1.020576 \\
\hline 15 & 16 & 0.3 & 5 & 0.4561721 & 1.92735625 & 1.030864 \\
\hline 15 & 16 & 0.4 & 5 & 0.5279507 & 2.25442417 & 1.041152 \\
\hline 15 & 16 & 0.5 & 5 & 0.5829908 & 2.59046703 & 1.05144 \\
\hline 15 & 16 & 0.6 & 5 & 0.626536 & 2.93548483 & 1.0617279 \\
\hline 25 & 8 & 0 & 15 & 0 & 1 & 1 \\
\hline 25 & 8 & 0.02 & 15 & 0.01417 & 1.02504545 & 1.0077068 \\
\hline 25 & 8 & 0.04 & 15 & 0.027944 & 1.05039334 & 1.0154136 \\
\hline 25 & 8 & 0.06 & 15 & 0.0413385 & 1.07604367 & 1.0231204 \\
\hline 25 & 8 & 0.08 & 15 & 0.0543688 & 1.10199643 & 1.0308272 \\
\hline 25 & 8 & 0.1 & 15 & 0.0670496 & 1.12825164 & 1.0385339 \\
\hline 25 & 8 & 0.2 & 15 & 0.125673 & 1.26406423 & 1.0770679 \\
\hline 25 & 8 & 0.3 & 15 & 0.1773645 & 1.40743777 & 1.1156019 \\
\hline 25 & 8 & 0.4 & 15 & 0.223285 & 1.55837227 & 1.1541358 \\
\hline 25 & 8 & 0.5 & 15 & 0.2643499 & 1.71686772 & 1.1926698 \\
\hline 25 & 8 & 0.6 & 15 & 0.3012907 & 1.88292412 & 1.2312037 \\
\hline 25 & 8 & 0 & 11 & 0 & 1 & 1 \\
\hline 25 & 8 & 0.02 & 11 & 0.0249554 & 1.03428598 & 1.0053401 \\
\hline 25 & 8 & 0.04 & 11 & 0.0486956 & 1.06900585 & 1.0106802 \\
\hline 25 & 8 & 0.06 & 11 & 0.0713072 & 1.10415954 & 1.0160203 \\
\hline 25 & 8 & 0.08 & 11 & 0.0928689 & 1.13974706 & 1.0213603 \\
\hline 25 & 8 & 0.1 & 11 & 0.113452 & 1.1757684 & 1.0267004 \\
\hline 25 & 8 & 0.2 & 11 & 0.2037843 & 1.36238242 & 1.0534009 \\
\hline 25 & 8 & 0.3 & 11 & 0.2774105 & 1.55984198 & 1.0801013 \\
\hline
\end{tabular}




\begin{tabular}{|c|c|c|c|c|c|c|}
\hline 25 & 8 & 0.4 & 11 & 0.3385728 & 1.7681471 & 1.1068017 \\
\hline 25 & 8 & 0.5 & 11 & 0.3901891 & 1.98729775 & 1.1335021 \\
\hline 25 & 8 & 0.6 & 11 & 0.4343326 & 2.21729396 & 1.1602026 \\
\hline 25 & 8 & 0 & 9 & 0 & 1 & 1 \\
\hline 25 & 8 & 0.02 & 9 & 0.0354907 & 1.04563018 & 1.005472 \\
\hline 25 & 8 & 0.04 & 9 & 0.0685485 & 1.09188732 & 1.010944 \\
\hline 25 & 8 & 0.06 & 9 & 0.0994154 & 1.13877147 & 1.016416 \\
\hline 25 & 8 & 0.08 & 9 & 0.1283021 & 1.18628264 & 1.021888 \\
\hline 25 & 8 & 0.1 & 9 & 0.1553933 & 1.23442083 & 1.02736 \\
\hline 25 & 8 & 0.2 & 9 & 0.2689878 & 1.48451697 & 1.05472 \\
\hline 25 & 8 & 0.3 & 9 & 0.355649 & 1.75028847 & 1.08208 \\
\hline 25 & 8 & 0.4 & 9 & 0.4239407 & 2.03173532 & 1.10944 \\
\hline 25 & 8 & 0.5 & 9 & 0.4791437 & 2.32885754 & 1.1368 \\
\hline 25 & 8 & 0.6 & 9 & 0.5246919 & 2.64165512 & 1.16416 \\
\hline 25 & 8 & 0 & 7 & 0 & 1 & 1 \\
\hline 25 & 8 & 0.02 & 7 & 0.0543688 & 1.06686655 & 1.0057129 \\
\hline 25 & 8 & 0.04 & 7 & 0.1031305 & 1.13475218 & 1.0114258 \\
\hline 25 & 8 & 0.06 & 7 & 0.14711 & 1.20365688 & 1.0171387 \\
\hline 25 & 8 & 0.08 & 7 & 0.1869779 & 1.27358065 & 1.0228516 \\
\hline 25 & 8 & 0.1 & 7 & 0.223285 & 1.34452349 & 1.0285645 \\
\hline 25 & 8 & 0.2 & 7 & 0.3650581 & 1.71452376 & 1.0571289 \\
\hline 25 & 8 & 0.3 & 7 & 0.4630644 & 2.11000082 & 1.0856934 \\
\hline 25 & 8 & 0.4 & 7 & 0.5348609 & 2.53095466 & 1.1142578 \\
\hline 25 & 8 & 0.5 & 7 & 0.5897213 & 2.97738529 & 1.1428223 \\
\hline 25 & 8 & 0.6 & 7 & 0.6330062 & 3.4492927 & 1.1713867 \\
\hline 25 & 8 & 0 & 5 & 0 & 1 & 1 \\
\hline 25 & 8 & 0.02 & 5 & 0.0926669 & 1.11273674 & 1.0061657 \\
\hline 25 & 8 & 0.04 & 5 & 0.169616 & 1.22743903 & 1.0123314 \\
\hline 25 & 8 & 0.06 & 5 & 0.2345337 & 1.34410691 & 1.018497 \\
\hline 25 & 8 & 0.08 & 5 & 0.2900371 & 1.46274038 & 1.0246627 \\
\hline 25 & 8 & 0.1 & 5 & 0.3380356 & 1.58333942 & 1.0308284 \\
\hline 25 & 8 & 0.2 & 5 & 0.5052715 & 2.2158184 & 1.0616568 \\
\hline 25 & 8 & 0.3 & 5 & 0.60505 & 2.89743697 & 1.0924852 \\
\hline 25 & 8 & 0.4 & 5 & 0.671336 & 3.62819511 & 1.1233136 \\
\hline 25 & 8 & 0.5 & 5 & 0.7185696 & 4.40809284 & 1.154142 \\
\hline 25 & 8 & 0.6 & 5 & 0.7539329 & 5.23713015 & 1.1849704 \\
\hline 25 & 12 & 0 & 15 & 0 & 1 & 1 \\
\hline 25 & 12 & 0.02 & 15 & 0.01417 & 1.02199637 & 1.0055048 \\
\hline 25 & 12 & 0.04 & 15 & 0.027944 & 1.04420877 & 1.0110097 \\
\hline 25 & 12 & 0.06 & 15 & 0.0413385 & 1.0666372 & 1.0165145 \\
\hline
\end{tabular}




\begin{tabular}{|c|c|c|c|c|c|c|}
\hline 25 & 12 & 0.08 & 15 & 0.0543688 & 1.08928165 & 1.0220194 \\
\hline 25 & 12 & 0.1 & 15 & 0.0670496 & 1.11214214 & 1.0275242 \\
\hline 25 & 12 & 0.2 & 15 & 0.125673 & 1.22968496 & 1.0550485 \\
\hline 25 & 12 & 0.3 & 15 & 0.1773645 & 1.35262846 & 1.0825727 \\
\hline 25 & 12 & 0.4 & 15 & 0.223285 & 1.48097264 & 1.110097 \\
\hline 25 & 12 & 0.5 & 15 & 0.2643499 & 1.6147175 & 1.1376212 \\
\hline 25 & 12 & 0.6 & 15 & 0.3012907 & 1.75386304 & 1.1651455 \\
\hline 25 & 12 & 0 & 11 & 0 & 1 & 1 \\
\hline 25 & 12 & 0.02 & 11 & 0.0249554 & 1.03180256 & 1.0038143 \\
\hline 25 & 12 & 0.04 & 11 & 0.0486956 & 1.06391507 & 1.0076287 \\
\hline 25 & 12 & 0.06 & 11 & 0.0713072 & 1.09633746 & 1.011443 \\
\hline 25 & 12 & 0.08 & 11 & 0.0928689 & 1.12906971 & 1.0152574 \\
\hline 25 & 12 & 0.1 & 11 & 0.113452 & 1.16211184 & 1.0190717 \\
\hline 25 & 12 & 0.2 & 11 & 0.2037843 & 1.33197058 & 1.0381435 \\
\hline 25 & 12 & 0.3 & 11 & 0.2774105 & 1.50957613 & 1.0572152 \\
\hline 25 & 12 & 0.4 & 11 & 0.3385728 & 1.69492851 & 1.0762869 \\
\hline 25 & 12 & 0.5 & 11 & 0.3901891 & 1.8880277 & 1.0953587 \\
\hline 25 & 12 & 0.6 & 11 & 0.4343326 & 2.08887371 & 1.1144304 \\
\hline 25 & 12 & 0 & 9 & 0 & 1 & 1 \\
\hline 25 & 12 & 0.02 & 9 & 0.0354907 & 1.04310632 & 1.0039086 \\
\hline 25 & 12 & 0.04 & 9 & 0.0685485 & 1.08666045 & 1.0078171 \\
\hline 25 & 12 & 0.06 & 9 & 0.0994154 & 1.13066245 & 1.0117257 \\
\hline 25 & 12 & 0.08 & 9 & 0.1283021 & 1.17511232 & 1.0156343 \\
\hline 25 & 12 & 0.1 & 9 & 0.1553933 & 1.22001006 & 1.0195429 \\
\hline 25 & 12 & 0.2 & 9 & 0.2689878 & 1.45121676 & 1.0390857 \\
\hline 25 & 12 & 0.3 & 9 & 0.355649 & 1.69362014 & 1.0586286 \\
\hline 25 & 12 & 0.4 & 9 & 0.4239407 & 1.94722021 & 1.0781714 \\
\hline 25 & 12 & 0.5 & 9 & 0.4791437 & 2.21201696 & 1.0977143 \\
\hline 25 & 12 & 0.6 & 9 & 0.5246919 & 2.48801041 & 1.1172571 \\
\hline 25 & 12 & 0 & 7 & 0 & 1 & 1 \\
\hline 25 & 12 & 0.02 & 7 & 0.0543688 & 1.06418888 & 1.0040806 \\
\hline 25 & 12 & 0.04 & 7 & 0.1031305 & 1.12910568 & 1.0081613 \\
\hline 25 & 12 & 0.06 & 7 & 0.14711 & 1.19475038 & 1.0122419 \\
\hline 25 & 12 & 0.08 & 7 & 0.1869779 & 1.26112299 & 1.0163225 \\
\hline 25 & 12 & 0.1 & 7 & 0.223285 & 1.32822351 & 1.0204032 \\
\hline 25 & 12 & 0.2 & 7 & 0.3650581 & 1.67464473 & 1.0408064 \\
\hline 25 & 12 & 0.3 & 7 & 0.4630644 & 2.03926365 & 1.0612095 \\
\hline 25 & 12 & 0.4 & 7 & 0.5348609 & 2.42208027 & 1.0816127 \\
\hline 25 & 12 & 0.5 & 7 & 0.5897213 & 2.82309459 & 1.1020159 \\
\hline 25 & 12 & 0.6 & 7 & 0.6330062 & 3.24230662 & 1.1224191 \\
\hline
\end{tabular}




\begin{tabular}{|c|c|c|c|c|c|c|}
\hline 25 & 12 & 0 & 5 & 0 & 1 & 1 \\
\hline 25 & 12 & 0.02 & 5 & 0.0926669 & 1.10970656 & 1.0044041 \\
\hline 25 & 12 & 0.04 & 5 & 0.169616 & 1.22081707 & 1.0088081 \\
\hline 25 & 12 & 0.06 & 5 & 0.2345337 & 1.33333158 & 1.0132122 \\
\hline 25 & 12 & 0.08 & 5 & 0.2900371 & 1.44725008 & 1.0176162 \\
\hline 25 & 12 & 0.1 & 5 & 0.3380356 & 1.56257256 & 1.0220203 \\
\hline 25 & 12 & 0.2 & 5 & 0.5052715 & 2.16024479 & 1.0440406 \\
\hline 25 & 12 & 0.3 & 5 & 0.60505 & 2.79301673 & 1.0660609 \\
\hline 25 & 12 & 0.4 & 5 & 0.671336 & 3.46088837 & 1.0880811 \\
\hline 25 & 12 & 0.5 & 5 & 0.7185696 & 4.16385971 & 1.1101014 \\
\hline 25 & 12 & 0.6 & 5 & 0.7539329 & 4.90193075 & 1.1321217 \\
\hline 25 & 16 & 0 & 15 & 0 & 1 & 1 \\
\hline 25 & 16 & 0.02 & 15 & 0.01417 & 1.02030239 & 1.0042815 \\
\hline 25 & 16 & 0.04 & 15 & 0.027944 & 1.0407728 & 1.008563 \\
\hline 25 & 16 & 0.06 & 15 & 0.0413385 & 1.06141123 & 1.0128445 \\
\hline 25 & 16 & 0.08 & 15 & 0.0543688 & 1.08221768 & 1.0171261 \\
\hline 25 & 16 & 0.1 & 15 & 0.0670496 & 1.10319215 & 1.0214076 \\
\hline 25 & 16 & 0.2 & 15 & 0.125673 & 1.21058481 & 1.0428151 \\
\hline 25 & 16 & 0.3 & 15 & 0.1773645 & 1.32217795 & 1.0642227 \\
\hline 25 & 16 & 0.4 & 15 & 0.223285 & 1.43797159 & 1.0856303 \\
\hline 25 & 16 & 0.5 & 15 & 0.2643499 & 1.55796573 & 1.1070379 \\
\hline 25 & 16 & 0.6 & 11 & 0.3012907 & 1.68216035 & 1.1284454 \\
\hline 25 & 16 & 0 & 11 & 0 & 1 & 1 \\
\hline 25 & 16 & 0.02 & 11 & 0.0249554 & 1.03042285 & 1.0029667 \\
\hline 25 & 16 & 0.04 & 11 & 0.0486956 & 1.06108678 & 1.0059334 \\
\hline 25 & 16 & 0.06 & 11 & 0.0713072 & 1.09199173 & 1.0089001 \\
\hline 25 & 16 & 0.08 & 11 & 0.0928689 & 1.12313768 & 1.0118668 \\
\hline 25 & 16 & 0.1 & 11 & 0.113452 & 1.15452465 & 1.0148334 \\
\hline 25 & 16 & 0.2 & 11 & 0.2037843 & 1.31507462 & 1.0296669 \\
\hline 25 & 16 & 0.3 & 11 & 0.2774105 & 1.48164985 & 1.0445003 \\
\hline 25 & 16 & 0.4 & 11 & 0.3385728 & 1.65425033 & 1.0593338 \\
\hline 25 & 16 & 0.5 & 11 & 0.3901891 & 1.83287607 & 1.0741672 \\
\hline 25 & 16 & 0.6 & 9 & 0.4343326 & 2.01752705 & 1.0890007 \\
\hline 25 & 16 & 0 & 9 & 0 & 1 & 1 \\
\hline 25 & 16 & 0.02 & 9 & 0.0354907 & 1.04170413 & 1.00304 \\
\hline 25 & 16 & 0.04 & 9 & 0.0685485 & 1.08375655 & 1.0060799 \\
\hline 25 & 16 & 0.06 & 9 & 0.0994154 & 1.12615731 & 1.0091199 \\
\hline 25 & 16 & 0.08 & 9 & 0.1283021 & 1.16890641 & 1.0121599 \\
\hline 25 & 16 & 0.1 & 9 & 0.1553933 & 1.21200385 & 1.0151999 \\
\hline 25 & 16 & 0.2 & 9 & 0.2689878 & 1.4327161 & 1.0303997 \\
\hline
\end{tabular}




\begin{tabular}{|c|c|c|c|c|c|c|}
\hline 25 & 16 & 0.3 & 9 & 0.355649 & 1.66213682 & 1.0455996 \\
\hline 25 & 16 & 0.4 & 9 & 0.4239407 & 1.900266 & 1.0607995 \\
\hline 25 & 16 & 0.5 & 9 & 0.4791437 & 2.14710364 & 1.0759994 \\
\hline 25 & 16 & 0.6 & 7 & 0.5246919 & 2.40264974 & 1.0911992 \\
\hline 25 & 16 & 0 & 7 & 0 & 1 & 1 \\
\hline 25 & 16 & 0.02 & 7 & 0.0543688 & 1.06270125 & 1.0031738 \\
\hline 25 & 16 & 0.04 & 7 & 0.1031305 & 1.12596864 & 1.0063476 \\
\hline 25 & 16 & 0.06 & 7 & 0.14711 & 1.18980218 & 1.0095214 \\
\hline 25 & 16 & 0.08 & 7 & 0.1869779 & 1.25420187 & 1.0126952 \\
\hline 25 & 16 & 0.1 & 7 & 0.223285 & 1.3191677 & 1.015869 \\
\hline 25 & 16 & 0.2 & 7 & 0.3650581 & 1.65248906 & 1.031738 \\
\hline 25 & 16 & 0.3 & 7 & 0.4630644 & 1.99996407 & 1.047607 \\
\hline 25 & 16 & 0.4 & 7 & 0.5348609 & 2.36159273 & 1.063476 \\
\hline 25 & 16 & 0.5 & 7 & 0.5897213 & 2.73737504 & 1.079345 \\
\hline 25 & 16 & 0.6 & 7 & 0.6330062 & 3.127311 & 1.095214 \\
\hline 25 & 16 & 0 & 5 & 0 & 1 & 1 \\
\hline 25 & 16 & 0.02 & 5 & 0.0926669 & 1.10802307 & 1.0034253 \\
\hline 25 & 16 & 0.04 & 5 & 0.169616 & 1.2171381 & 1.0068507 \\
\hline 25 & 16 & 0.06 & 5 & 0.2345337 & 1.32734511 & 1.010276 \\
\hline 25 & 16 & 0.08 & 5 & 0.2900371 & 1.4386441 & 1.0137014 \\
\hline 25 & 16 & 0.1 & 5 & 0.3380356 & 1.55103508 & 1.0171267 \\
\hline 25 & 16 & 0.2 & 5 & 0.5052715 & 2.12936967 & 1.0342535 \\
\hline 25 & 16 & 0.3 & 5 & 0.60505 & 2.7350038 & 1.0513802 \\
\hline 25 & 16 & 0.4 & 5 & 0.671336 & 3.36793747 & 1.068507 \\
\hline 25 & 16 & 0.5 & 5 & 0.7185696 & 4.02817068 & 1.0856337 \\
\hline 25 & 16 & 0.6 & 5 & 0.7539329 & 4.71570343 & 1.1027605 \\
\hline 35 & 8 & 0 & 19 & 0 & 1 & 1 \\
\hline 35 & 8 & 0.02 & 19 & 0.014694 & 1.02645957 & 1.0071725 \\
\hline 35 & 8 & 0.04 & 19 & 0.0289624 & 1.05325844 & 1.0143451 \\
\hline 35 & 8 & 0.06 & 19 & 0.0428235 & 1.08039664 & 1.0215176 \\
\hline 35 & 8 & 0.08 & 19 & 0.0562944 & 1.10787416 & 1.0286902 \\
\hline 35 & 8 & 0.1 & 19 & 0.0693914 & 1.13569102 & 1.0358627 \\
\hline 35 & 8 & 0.2 & 19 & 0.1297774 & 1.27986516 & 1.0717255 \\
\hline 35 & 8 & 0.3 & 19 & 0.1828042 & 1.43252245 & 1.1075882 \\
\hline 35 & 8 & 0.4 & 19 & 0.2297398 & 1.59366289 & 1.143451 \\
\hline 35 & 8 & 0.5 & 19 & 0.2715768 & 1.76328649 & 1.1793137 \\
\hline 35 & 8 & 0.6 & 19 & 0.3091031 & 1.94139323 & 1.2151765 \\
\hline 35 & 8 & 0 & 15 & 0 & 1 & 1 \\
\hline 35 & 8 & 0.02 & 15 & 0.0227712 & 1.03513244 & 1.0072674 \\
\hline 35 & 8 & 0.04 & 15 & 0.0445284 & 1.07080368 & 1.0145349 \\
\hline
\end{tabular}




\begin{tabular}{|c|c|c|c|c|c|c|}
\hline 35 & 8 & 0.06 & 15 & 0.0653378 & 1.10701372 & 1.0218023 \\
\hline 35 & 8 & 0.08 & 15 & 0.0852602 & 1.14376256 & 1.0290698 \\
\hline 35 & 8 & 0.1 & 15 & 0.104351 & 1.18105019 & 1.0363373 \\
\hline 35 & 8 & 0.2 & 15 & 0.1889816 & 1.37557031 & 1.0726745 \\
\hline 35 & 8 & 0.3 & 15 & 0.2589994 & 1.58356034 & 1.1090118 \\
\hline 35 & 8 & 0.4 & 15 & 0.3178882 & 1.80502029 & 1.1453491 \\
\hline 35 & 8 & 0.5 & 15 & 0.3681061 & 2.03995015 & 1.1816864 \\
\hline 35 & 8 & 0.6 & 15 & 0.4114369 & 2.28834992 & 1.2180237 \\
\hline 35 & 8 & 0 & 13 & 0 & 1 & 1 \\
\hline 35 & 8 & 0.02 & 13 & 0.029536 & 1.04221136 & 1.0073469 \\
\hline 35 & 8 & 0.04 & 13 & 0.0573774 & 1.08511838 & 1.0146939 \\
\hline 35 & 8 & 0.06 & 13 & 0.0836658 & 1.12872106 & 1.0220408 \\
\hline 35 & 8 & 0.08 & 13 & 0.1085277 & 1.17301939 & 1.0293877 \\
\hline 35 & 8 & 0.1 & 13 & 0.1320762 & 1.21801338 & 1.0367347 \\
\hline 35 & 8 & 0.2 & 13 & 0.2333344 & 1.45341818 & 1.0734694 \\
\hline 35 & 8 & 0.3 & 13 & 0.3134341 & 1.70621439 & 1.1102041 \\
\hline 35 & 8 & 0.4 & 13 & 0.3783798 & 1.976402 & 1.1469388 \\
\hline 35 & 8 & 0.5 & 13 & 0.4321002 & 2.26398102 & 1.1836734 \\
\hline 35 & 8 & 0.6 & 13 & 0.4772742 & 2.56895146 & 1.2204081 \\
\hline 35 & 8 & 0 & 11 & 0 & 1 & 1 \\
\hline 35 & 8 & 0.02 & 11 & 0.0397339 & 1.05371386 & 1.0074632 \\
\hline 35 & 8 & 0.04 & 11 & 0.076431 & 1.10840799 & 1.0149264 \\
\hline 35 & 8 & 0.06 & 11 & 0.1104264 & 1.16408241 & 1.0223895 \\
\hline 35 & 8 & 0.08 & 11 & 0.1420081 & 1.22073712 & 1.0298527 \\
\hline 35 & 8 & 0.1 & 11 & 0.1714242 & 1.27837214 & 1.0373159 \\
\hline 35 & 8 & 0.2 & 11 & 0.2926766 & 1.5812517 & 1.0746318 \\
\hline 35 & 8 & 0.3 & 11 & 0.3829715 & 1.9086387 & 1.1119478 \\
\hline 35 & 8 & 0.4 & 11 & 0.4528226 & 2.26053317 & 1.1492637 \\
\hline 35 & 8 & 0.5 & 11 & 0.5084669 & 2.63693509 & 1.1865797 \\
\hline 35 & 8 & 0.6 & 11 & 0.5538386 & 3.03784446 & 1.2238956 \\
\hline 35 & 8 & 0 & 7 & 0 & 1 & 1 \\
\hline 35 & 8 & 0.02 & 7 & 0.0852602 & 1.12033448 & 1.007998 \\
\hline 35 & 8 & 0.04 & 7 & 0.157124 & 1.24529467 & 1.0159961 \\
\hline 35 & 8 & 0.06 & 7 & 0.2185188 & 1.37488062 & 1.0239941 \\
\hline 35 & 8 & 0.08 & 7 & 0.2715768 & 1.50909234 & 1.0319922 \\
\hline 35 & 8 & 0.1 & 7 & 0.3178882 & 1.64792983 & 1.0399902 \\
\hline 35 & 8 & 0.2 & 7 & 0.4824206 & 2.41150375 & 1.0799804 \\
\hline 35 & 8 & 0.3 & 7 & 0.5830043 & 3.29072182 & 1.1199707 \\
\hline 35 & 8 & 0.4 & 7 & 0.6508553 & 4.28558404 & 1.1599609 \\
\hline 35 & 8 & 0.5 & 7 & 0.6997157 & 5.39609039 & 1.1999512 \\
\hline
\end{tabular}




\begin{tabular}{|c|c|c|c|c|c|c|}
\hline 35 & 8 & 0.6 & 7 & 0.7365795 & 6.6222409 & 1.2399414 \\
\hline 35 & 12 & 0 & 19 & 0 & 1 & 1 \\
\hline 35 & 12 & 0.02 & 19 & 0.014694 & 1.02316059 & 1.0051232 \\
\hline 35 & 12 & 0.04 & 19 & 0.0289624 & 1.04656354 & 1.0102465 \\
\hline 35 & 12 & 0.06 & 19 & 0.0428235 & 1.07020886 & 1.0153697 \\
\hline 35 & 12 & 0.08 & 19 & 0.0562944 & 1.09409656 & 1.020493 \\
\hline 35 & 12 & 0.1 & 19 & 0.0693914 & 1.11822664 & 1.0256162 \\
\hline 35 & 12 & 0.2 & 19 & 0.1297774 & 1.24251264 & 1.0512325 \\
\hline 35 & 12 & 0.3 & 19 & 0.1828042 & 1.37285804 & 1.0768487 \\
\hline 35 & 12 & 0.4 & 19 & 0.2297398 & 1.50926283 & 1.102465 \\
\hline 35 & 12 & 0.5 & 19 & 0.2715768 & 1.65172702 & 1.1280812 \\
\hline 35 & 12 & 0.6 & 19 & 0.3091031 & 1.80025059 & 1.1536975 \\
\hline 35 & 12 & 0 & 15 & 0 & 1 & 1 \\
\hline 35 & 12 & 0.02 & 15 & 0.0227712 & 1.03175224 & 1.005191 \\
\hline 35 & 12 & 0.04 & 15 & 0.0445284 & 1.06388935 & 1.0103821 \\
\hline 35 & 12 & 0.06 & 15 & 0.0653378 & 1.09641132 & 1.0155731 \\
\hline 35 & 12 & 0.08 & 15 & 0.0852602 & 1.12931813 & 1.0207641 \\
\hline 35 & 12 & 0.1 & 15 & 0.104351 & 1.16260981 & 1.0259552 \\
\hline 35 & 12 & 0.2 & 15 & 0.1889816 & 1.33484099 & 1.0519104 \\
\hline 35 & 12 & 0.3 & 15 & 0.2589994 & 1.51669354 & 1.0778656 \\
\hline 35 & 12 & 0.4 & 15 & 0.3178882 & 1.70816746 & 1.1038208 \\
\hline 35 & 12 & 0.5 & 15 & 0.3681061 & 1.90926274 & 1.129776 \\
\hline 35 & 12 & 0.6 & 15 & 0.4114369 & 2.11997939 & 1.1557312 \\
\hline 35 & 12 & 0 & 13 & 0 & 1 & 1 \\
\hline 35 & 12 & 0.02 & 13 & 0.029536 & 1.03884667 & 1.0052478 \\
\hline 35 & 12 & 0.04 & 13 & 0.0573774 & 1.07819025 & 1.0104956 \\
\hline 35 & 12 & 0.06 & 13 & 0.0836658 & 1.11803072 & 1.0157434 \\
\hline 35 & 12 & 0.08 & 13 & 0.1085277 & 1.1583681 & 1.0209912 \\
\hline 35 & 12 & 0.1 & 13 & 0.1320762 & 1.19920236 & 1.026239 \\
\hline 35 & 12 & 0.2 & 13 & 0.2333344 & 1.41082717 & 1.0524781 \\
\hline 35 & 12 & 0.3 & 13 & 0.3134341 & 1.63487441 & 1.0787172 \\
\hline 35 & 12 & 0.4 & 13 & 0.3783798 & 1.87134408 & 1.1049562 \\
\hline 35 & 12 & 0.5 & 13 & 0.4321002 & 2.12023619 & 1.1311953 \\
\hline 35 & 12 & 0.6 & 13 & 0.4772742 & 2.38155074 & 1.1574344 \\
\hline 35 & 12 & 0 & 11 & 0 & 1 & 1 \\
\hline 35 & 12 & 0.02 & 11 & 0.0397339 & 1.05018935 & 1.0053308 \\
\hline 35 & 12 & 0.04 & 11 & 0.076431 & 1.10107888 & 1.0106617 \\
\hline 35 & 12 & 0.06 & 11 & 0.1104264 & 1.15266862 & 1.0159925 \\
\hline 35 & 12 & 0.08 & 11 & 0.1420081 & 1.20495858 & 1.0213234 \\
\hline 35 & 12 & 0.1 & 11 & 0.1714242 & 1.25794874 & 1.0266542 \\
\hline
\end{tabular}




\begin{tabular}{|c|c|c|c|c|c|c|}
\hline 35 & 12 & 0.2 & 11 & 0.2926766 & 1.53340277 & 1.0533085 \\
\hline 35 & 12 & 0.3 & 11 & 0.3829715 & 1.82636212 & 1.0799627 \\
\hline 35 & 12 & 0.4 & 11 & 0.4528226 & 2.13682679 & 1.1066169 \\
\hline 35 & 12 & 0.5 & 11 & 0.5084669 & 2.46479679 & 1.1332712 \\
\hline 35 & 12 & 0.6 & 11 & 0.5538386 & 2.81027212 & 1.1599254 \\
\hline 35 & 12 & 0 & 7 & 0 & 1 & 1 \\
\hline 35 & 12 & 0.02 & 7 & 0.0852602 & 1.11258381 & 1.0057129 \\
\hline 35 & 12 & 0.04 & 7 & 0.157124 & 1.22847168 & 1.0114258 \\
\hline 35 & 12 & 0.06 & 7 & 0.2185188 & 1.34766367 & 1.0171387 \\
\hline 35 & 12 & 0.08 & 7 & 0.2715768 & 1.47015979 & 1.0228515 \\
\hline 35 & 12 & 0.1 & 7 & 0.3178882 & 1.59596002 & 1.0285644 \\
\hline 35 & 12 & 0.2 & 7 & 0.4824206 & 2.27452294 & 1.0571289 \\
\hline 35 & 12 & 0.3 & 7 & 0.5830043 & 3.03568882 & 1.0856933 \\
\hline 35 & 12 & 0.4 & 7 & 0.6508553 & 3.87945767 & 1.1142578 \\
\hline 35 & 12 & 0.5 & 7 & 0.6997157 & 4.80582947 & 1.1428222 \\
\hline 35 & 12 & 0.6 & 7 & 0.7365795 & 5.81480423 & 1.1713867 \\
\hline 35 & 16 & 0 & 19 & 0 & 1 & 1 \\
\hline 35 & 16 & 0.02 & 19 & 0.014694 & 1.02316059 & 1.0051232 \\
\hline 35 & 16 & 0.04 & 19 & 0.0289624 & 1.04656354 & 1.0102465 \\
\hline 35 & 16 & 0.06 & 19 & 0.0428235 & 1.07020886 & 1.0153697 \\
\hline 35 & 16 & 0.08 & 19 & 0.0562944 & 1.09409656 & 1.020493 \\
\hline 35 & 16 & 0.1 & 19 & 0.0693914 & 1.11822664 & 1.0256162 \\
\hline 35 & 16 & 0.2 & 19 & 0.1297774 & 1.24251264 & 1.0512325 \\
\hline 35 & 16 & 0.3 & 19 & 0.1828042 & 1.37285804 & 1.0768487 \\
\hline 35 & 16 & 0.4 & 19 & 0.2297398 & 1.50926283 & 1.102465 \\
\hline 35 & 16 & 0.5 & 19 & 0.2715768 & 1.65172702 & 1.1280812 \\
\hline 35 & 16 & 0.6 & 19 & 0.3091031 & 1.80025059 & 1.1536975 \\
\hline 35 & 16 & 0 & 15 & 0 & 1 & 1 \\
\hline 35 & 16 & 0.02 & 15 & 0.0227712 & 1.0298743 & 1.0040374 \\
\hline 35 & 16 & 0.04 & 15 & 0.0445284 & 1.06004795 & 1.0080749 \\
\hline 35 & 16 & 0.06 & 15 & 0.0653378 & 1.09052092 & 1.0121123 \\
\hline 35 & 16 & 0.08 & 15 & 0.0852602 & 1.12129322 & 1.0161497 \\
\hline 35 & 16 & 0.1 & 15 & 0.104351 & 1.15236485 & 1.0201872 \\
\hline 35 & 16 & 0.2 & 15 & 0.1889816 & 1.31221293 & 1.0403744 \\
\hline 35 & 16 & 0.3 & 15 & 0.2589994 & 1.47954424 & 1.0605616 \\
\hline 35 & 16 & 0.4 & 15 & 0.3178882 & 1.65435876 & 1.0807488 \\
\hline 35 & 16 & 0.5 & 15 & 0.3681061 & 1.83665651 & 1.100936 \\
\hline 35 & 16 & 0.6 & 15 & 0.4114369 & 2.02643749 & 1.1211232 \\
\hline 35 & 16 & 0 & 13 & 0 & 1 & 1 \\
\hline 35 & 16 & 0.02 & 13 & 0.029536 & 1.03697735 & 1.0040816 \\
\hline
\end{tabular}




\begin{tabular}{|c|c|c|c|c|c|c|}
\hline 35 & 16 & 0.04 & 13 & 0.0573774 & 1.07434118 & 1.0081632 \\
\hline 35 & 16 & 0.06 & 13 & 0.0836658 & 1.11209148 & 1.0122448 \\
\hline 35 & 16 & 0.08 & 13 & 0.1085277 & 1.15022825 & 1.0163264 \\
\hline 35 & 16 & 0.1 & 13 & 0.1320762 & 1.18875149 & 1.020408 \\
\hline 35 & 16 & 0.2 & 13 & 0.2333344 & 1.38716481 & 1.040816 \\
\hline 35 & 16 & 0.3 & 13 & 0.3134341 & 1.59523993 & 1.061224 \\
\hline 35 & 16 & 0.4 & 13 & 0.3783798 & 1.81297687 & 1.081632 \\
\hline 35 & 16 & 0.5 & 13 & 0.4321002 & 2.04037563 & 1.1020399 \\
\hline 35 & 16 & 0.6 & 13 & 0.4772742 & 2.27743619 & 1.1224479 \\
\hline 35 & 16 & 0 & 11 & 0 & 1 & 1 \\
\hline 35 & 16 & 0.02 & 11 & 0.0397339 & 1.04823124 & 1.0041462 \\
\hline 35 & 16 & 0.04 & 11 & 0.076431 & 1.09700704 & 1.0082923 \\
\hline 35 & 16 & 0.06 & 11 & 0.1104264 & 1.14632745 & 1.0124385 \\
\hline 35 & 16 & 0.08 & 11 & 0.1420081 & 1.19619246 & 1.0165847 \\
\hline 35 & 16 & 0.1 & 11 & 0.1714242 & 1.24660208 & 1.0207309 \\
\hline 35 & 16 & 0.2 & 11 & 0.2926766 & 1.50681926 & 1.0414618 \\
\hline 35 & 16 & 0.3 & 11 & 0.3829715 & 1.78065157 & 1.0621927 \\
\hline 35 & 16 & 0.4 & 11 & 0.4528226 & 2.06809903 & 1.0829236 \\
\hline 35 & 16 & 0.5 & 11 & 0.5084669 & 2.36916162 & 1.1036545 \\
\hline 35 & 16 & 0.6 & 11 & 0.5538386 & 2.68383936 & 1.1243854 \\
\hline 35 & 16 & 0 & 7 & 0 & 1 & 1 \\
\hline 35 & 16 & 0.02 & 7 & 0.0852602 & 1.10827776 & 1.0044433 \\
\hline 35 & 16 & 0.04 & 7 & 0.157124 & 1.21912531 & 1.0088866 \\
\hline 35 & 16 & 0.06 & 7 & 0.2185188 & 1.33254271 & 1.0133299 \\
\hline 35 & 16 & 0.08 & 7 & 0.2715768 & 1.44852996 & 1.0177733 \\
\hline 35 & 16 & 0.1 & 7 & 0.3178882 & 1.56708706 & 1.0222166 \\
\hline 35 & 16 & 0.2 & 7 & 0.4824206 & 2.19842027 & 1.0444332 \\
\hline 35 & 16 & 0.3 & 7 & 0.5830043 & 2.8939997 & 1.0666498 \\
\hline 35 & 16 & 0.4 & 7 & 0.6508553 & 3.65382533 & 1.0888664 \\
\hline 35 & 16 & 0.5 & 7 & 0.6997157 & 4.47789718 & 1.111083 \\
\hline 35 & 16 & 0.6 & 7 & 0.7365795 & 5.36621524 & 1.1332996 \\
\hline
\end{tabular}




\section{APPENDIX 3.}

\section{NUMBER OF BRACING EFFECT ON STRESS MAGNIFICATION FACTOR \\ OF SINGLE SPAN BRIDGES}

The data in this Appendix is specific to a certain L/R ratio based on the curvature limit in equation (15) developed by Khalafalla [2]. For each bridge span and width, L/R limit was calculated. Then, the V-Load method was applied for such bridges (i.e. of 3 different span values of 15, 25 and $35 \mathrm{~m}$ and different bridge widths of 8,12 and $16 \mathrm{~m}$ ) and the fixed L/R ratio for each span. In each specific bridge, the number of bracing spacing changes from 2 to 5 for span length of $15 \mathrm{~m}$ as depicted in Table A.3.1, from 2 to 7 for span length of $25 \mathrm{~m}$ as depicted in Table A.3.2 and from 2 to 9 for span length of $35 \mathrm{~m}$ as depicted in Table A.3.3. Along with Tables A.3.1 through A.3.3, Figures A.3.1 through A.3.3 present the results in graphical form. Using statistical package of curve fit, empirical equations were developed as shown in each of these figures. These equations formed the basis of equations 21 and 22 in this report.

Table A.3.1. Effect of number of bracing spacing on the stress magnification factor for single span bridges of $15 \mathrm{~m}$ span based on curvature limitation, L/R, obtained from Khalafalla's equations

\begin{tabular}{|c|c|c|c|}
\hline \multicolumn{4}{|c|}{ STRESS MAGNIFICATION FACTOR, L=15 } \\
\hline $\mathbf{N}$ & $\mathbf{W}=\mathbf{8}$ & $\mathbf{W}=\mathbf{1 2}$ & $\mathbf{W = 1 6}$ \\
\hline 2 & 1.067 & 1.057 & 1.054 \\
\hline 3 & 1.039 & 1.035 & 1.033 \\
\hline 4 & 1.027 & 1.025 & 1.023 \\
\hline 5 & 1.022 & 1.019 & 1.017 \\
\hline
\end{tabular}

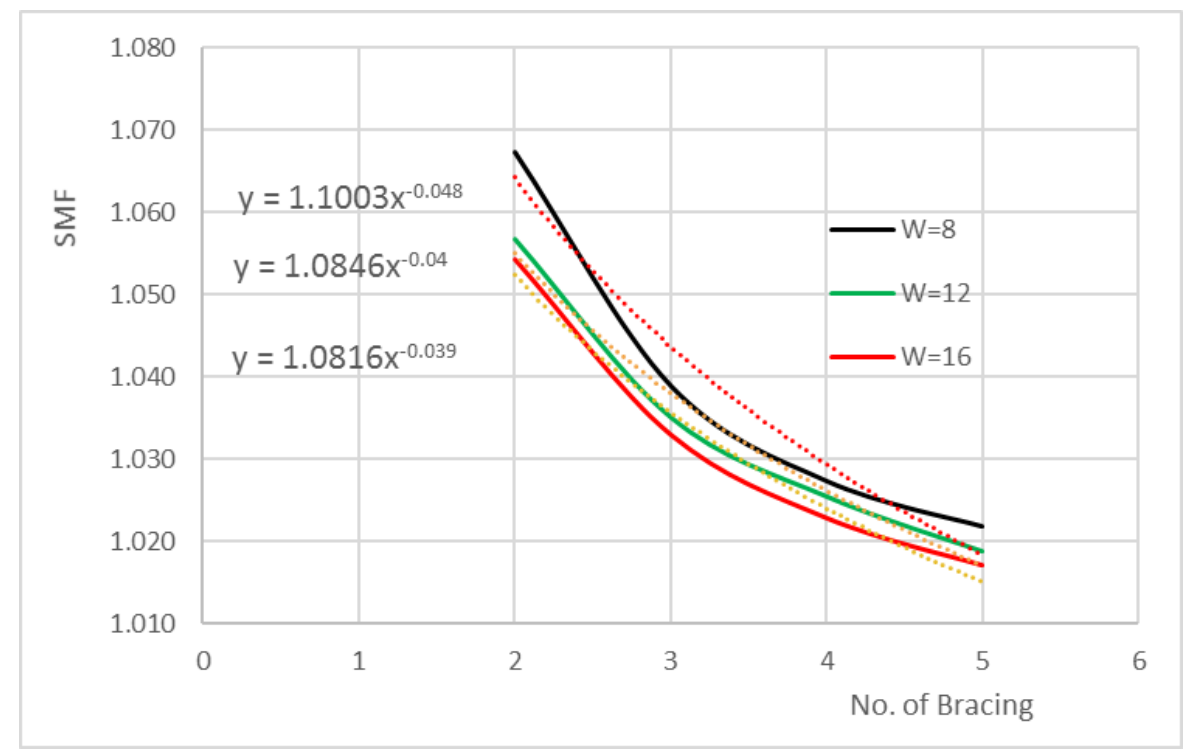


Figure A.3.1. Effect of number of bracing spacing on the stress magnification factor for $15 \mathrm{~m}$ single span bridges based on curvature limitation, L/R, obtained from Khalafalla's equations

Table A.3.2. Effect of number of bracing spacing on the stress magnification factor for $25 \mathrm{~m}$ single span bridges based on curvature limitation, L/R, obtained from Khalafalla's equations

\begin{tabular}{|c|c|c|c|}
\hline \multicolumn{4}{|c|}{ STRESS MAGNIFICATION FACTOR, L= 25 } \\
\hline $\mathbf{N}$ & $\mathbf{W = 8}$ & $\mathbf{W}=\mathbf{1 2}$ & $\mathbf{W = 1 6}$ \\
\hline 2 & 1.091 & 1.085 & 1.081 \\
\hline 3 & 1.058 & 1.048 & 1.049 \\
\hline 4 & 1.047 & 1.040 & 1.037 \\
\hline 5 & 1.032 & 1.025 & 1.025 \\
\hline 7 & 1.022 & 1.018 & 1.015 \\
\hline
\end{tabular}

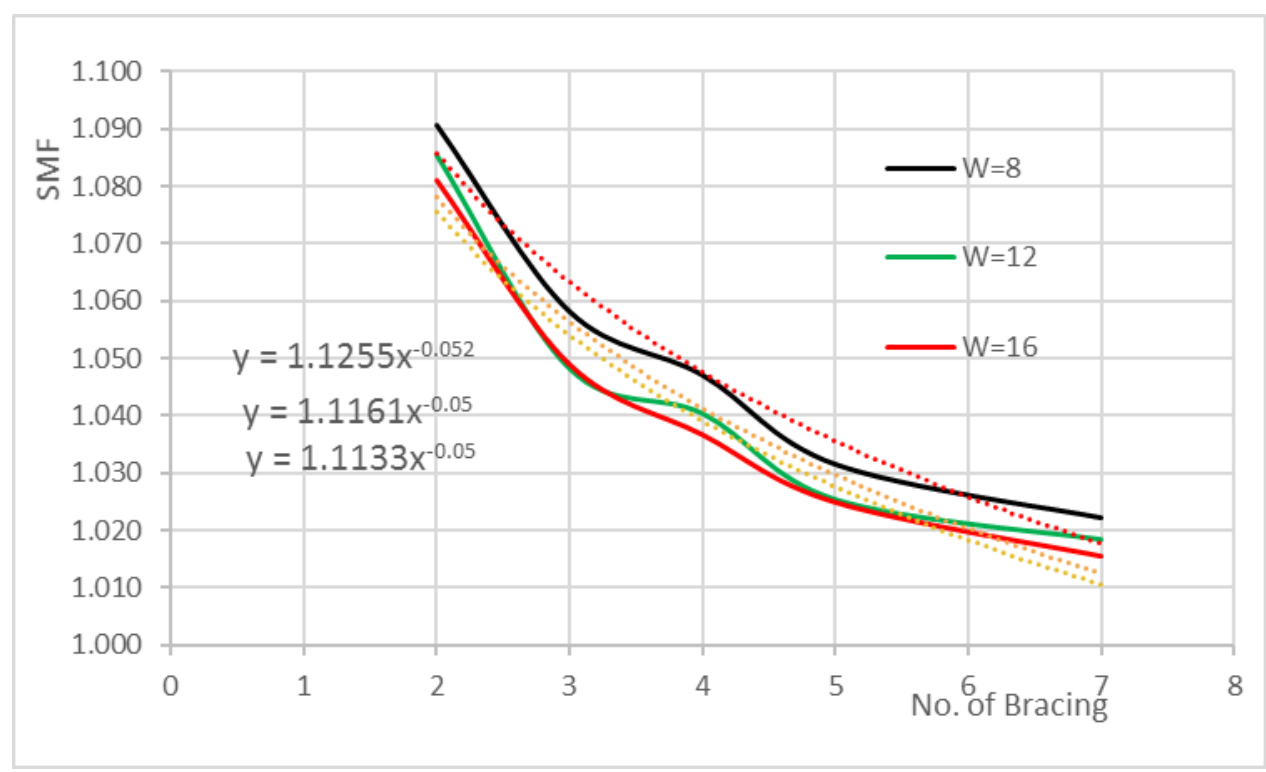

Figure A.3.2. Table A.3.1. Effect of number of bracing spacing on the stress magnification factor for $25 \mathrm{~m}$ single span bridges based on curvature limitation, $L / R$, obtained from Khalafalla's equations 
Table A.3.3. Effect of number of bracing spacing on the stress magnification factor for $35 \mathrm{~m}$ single span bridges based on curvature limitation, L/R, obtained from Khalafalla's equations

\begin{tabular}{|c|c|c|c|}
\hline \multicolumn{4}{|c|}{ STRESS MAGNIFICATION FACTOR, L=35 } \\
\hline $\mathbf{N}$ & $\mathbf{W}=\mathbf{8}$ & $\mathbf{W}=\mathbf{1 2}$ & $\mathbf{W = 1 6}$ \\
\hline 3 & 1.081 & 1.073 & 1.068 \\
\hline 5 & 1.043 & 1.037 & 1.034 \\
\hline 6 & 1.034 & 1.029 & 1.026 \\
\hline 7 & 1.029 & 1.025 & 1.022 \\
\hline 9 & 1.018 & 1.015 & 1.014 \\
\hline
\end{tabular}

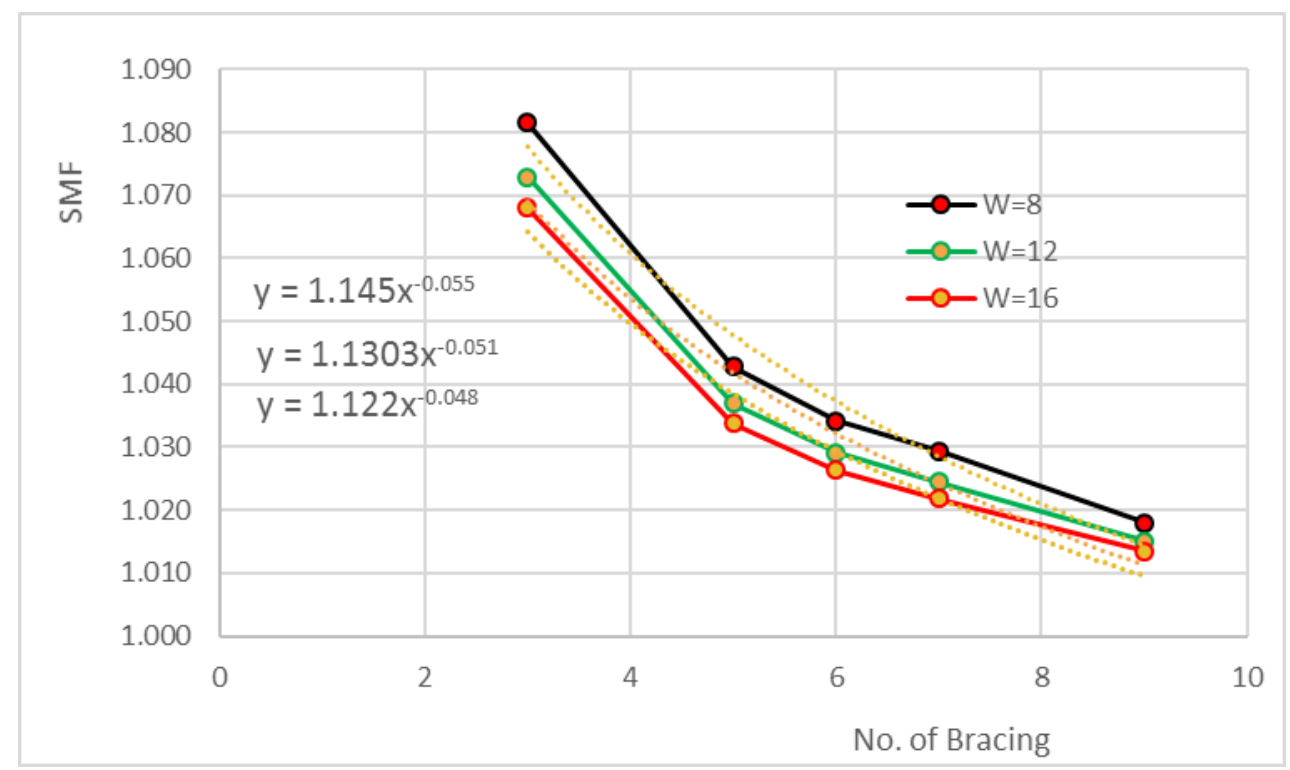

Figure A.3.3. Effect of number of bracing spacing on the stress magnification factor for $35 \mathrm{~m}$ single span bridges based on curvature limitation, L/R, obtained from Khalafalla's equations 


\section{APPENDIX 4.}

\section{TWO SPAN BRIDGE, NUMBER OF BRACING EFFECT ON STRESS MAGNIFICATION FACTOR}

The data in this Appendix is specific to a certain L/R ratio based on the curvature limit in equation (15) developed by Khalafalla [2]. For each bridge span and width, L/R limit was calculated. Then, the V-Load method was applied for such bridges (i.e. of 3 different span values of 15, 25 and $35 \mathrm{~m}$ and different bridge widths of 8,12 and $16 \mathrm{~m}$ ) and the fixed L/R ratio for each span. In each specific bridge, the number of bracing spacing changes from 2 to 5 for span length of $15 \mathrm{~m}$ as depicted in Table A.4.1, from 2 to 7 for span length of $25 \mathrm{~m}$ as depicted in Table A.4.2 and from 2 to 7 for span length of $35 \mathrm{~m}$ as depicted in Table A.4.3. Along with Tables A.4.1 through A.4.3, Figures A.4.1 through A.4.3 present the results in graphical form. Using statistical package of curve fit, empirical equations were developed as shown in each of these figures. These equations formed the basis of equations 21 and 22 in this report.

Table A.4.1. Effect of number of bracing spacing on the stress magnification factor for two-span (15-15 $\mathrm{m}$ ) bridges based on curvature limitation, L/R, obtained from Khalafalla's equations

\begin{tabular}{|c|c|c|c|c|c|c|}
\hline \multicolumn{7}{|c|}{ STRESS MAAGNIFICATION FACTOR } \\
\hline $\mathbf{L}$ & $\mathbf{W}$ & $\mathbf{L} / \mathbf{R}$ & $\mathbf{N}=\mathbf{2}$ & $\mathbf{N}=\mathbf{3}$ & $\mathbf{N}=\mathbf{4}$ & $\mathbf{N}=\mathbf{5}$ \\
\hline 15 & 8 & 0.014631 & 1.046318 & 1.027254 & 1.018844 & 1.014204 \\
\hline 15 & 12 & 0.015229 & 1.046603 & 1.027105 & 1.018389 & 1.013601 \\
\hline 15 & 16 & 0.015668 & 1.047026 & 1.034606 & 1.027165 & 1.01822 \\
\hline
\end{tabular}

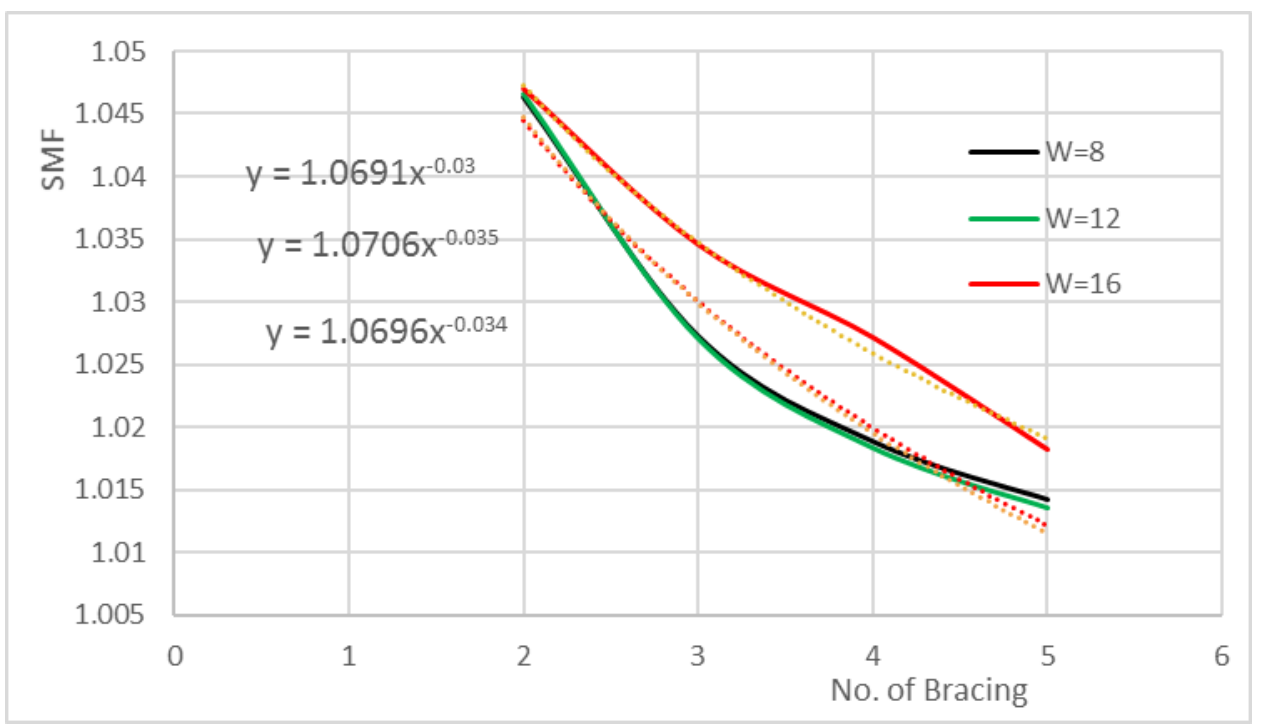

Figure A.4.1. Effect of number of bracing spacing on the stress magnification factor for two-span (15-15 $\mathrm{m}$ ) bridges based on curvature limitation, L/R, obtained from Khalafalla's equations 
Table A.4.2. Effect of number of bracing spacing on the stress magnification factor for two-span (25-25 $\mathrm{m}$ ) bridges based on curvature limitation, $L / R$, obtained from Khalafalla's equations

\begin{tabular}{|c|c|c|c|c|c|c|c|}
\hline \multicolumn{7}{|c|}{ STRESS MAAGNIFICATION FACTOR } \\
\hline $\mathbf{L}$ & $\mathbf{W}$ & $\mathbf{L} / \mathbf{R}$ & $\mathbf{N}=\mathbf{2}$ & $\mathbf{N}=\mathbf{3}$ & $\mathbf{N}=\mathbf{4}$ & $\mathbf{N}=\mathbf{5}$ & $\mathbf{N}=\mathbf{7}$ \\
\hline 25 & 8 & 0.015196 & 1.088642 & 1.052352 & 1.035622 & 1.026709 & 1.019488 \\
\hline 25 & 12 & 0.015816 & 1.088979 & 1.051913 & 1.034798 & 1.02564 & 1.017737 \\
\hline 25 & 16 & 0.016272 & 1.089667 & 1.051936 & 1.034497 & 1.025144 & 1.016791 \\
\hline
\end{tabular}

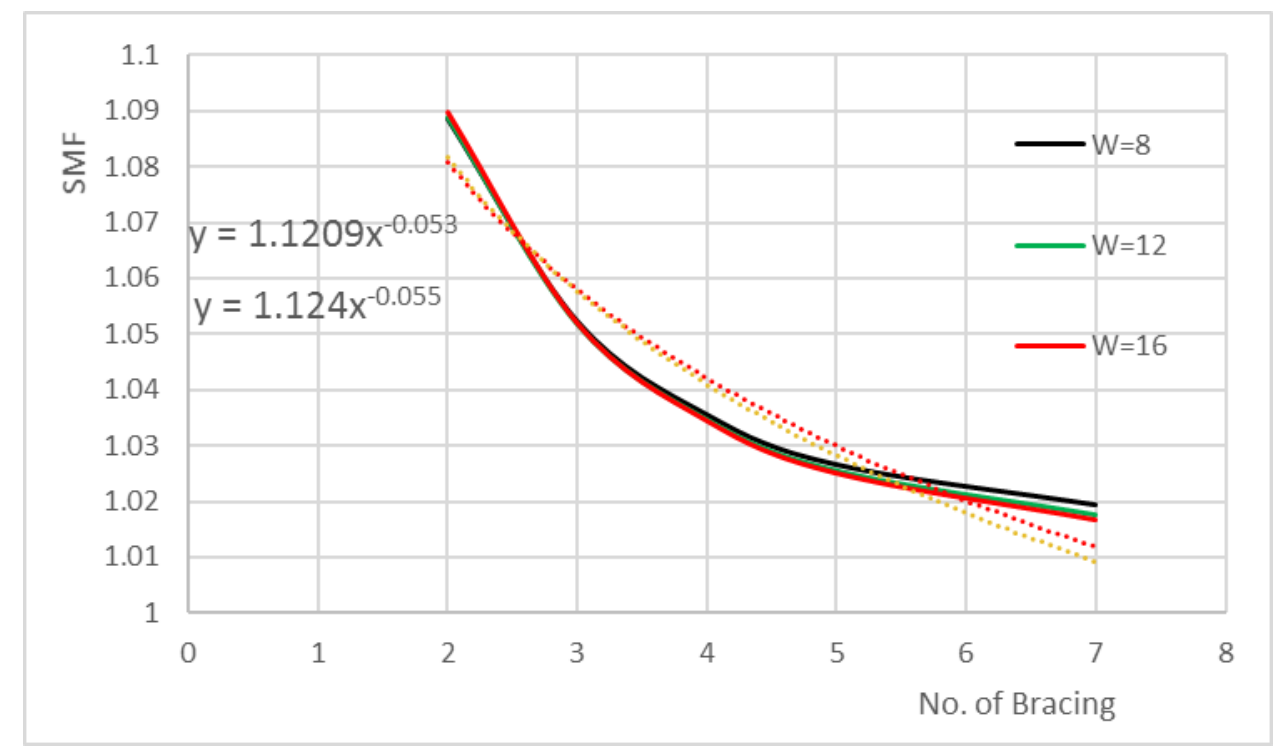

Figure A.4.2. Effect of number of bracing spacing on the stress magnification factor for two-span (25-25 $\mathrm{m}$ ) bridges based on curvature limitation, L/R, obtained from Khalafalla's equations 
Table A.4.3. Effect of number of bracing spacing on the stress magnification factor for two-span (35-35 $\mathrm{m}$ ) bridges based on curvature limitation, L/R, obtained from Khalafalla's equations

\begin{tabular}{|c|c|c|c|c|c|c|c|}
\hline \multicolumn{7}{|c|}{ STRESS MAAGNIFICATION FACTOR } \\
\hline L & W & L/R & $\mathbf{N}=\mathbf{2}$ & $\mathbf{N}=\mathbf{3}$ & $\mathbf{N}=\mathbf{4}$ & $\mathbf{N}=\mathbf{5}$ & $\mathbf{N}=\mathbf{7}$ \\
\hline 25 & 8 & 0.015196 & 1.088642 & 1.052352 & 1.035622 & 1.026709 & 1.019488 \\
\hline 25 & 12 & 0.015816 & 1.088979 & 1.051913 & 1.034798 & 1.02564 & 1.017737 \\
\hline 25 & 16 & 0.016272 & 1.089667 & 1.051936 & 1.034497 & 1.025144 & 1.016791 \\
\hline
\end{tabular}

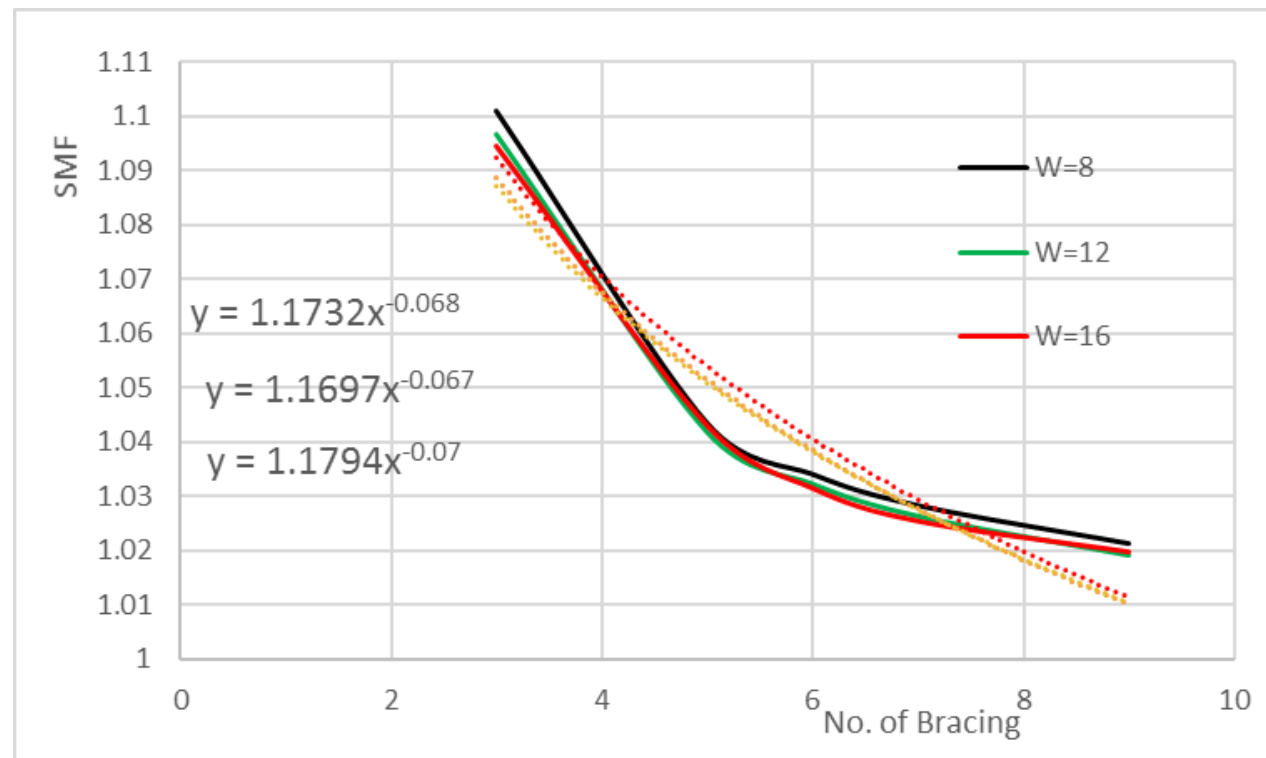

Figure A.4.3. Effect of number of bracing spacing on the stress magnification factor for two-span (35-35 $\mathrm{m}$ ) bridges based on curvature limitation, L/R, obtained from Khalafalla's equations 


\section{References}

[1] Itani, A.M., Reno, M.L., 2000. Horizontally Curved Bridges, Bridge Engineering Handbook, CRC Press.

[2] Khalafalla, I. 2009 Curvature Limitations in Bridge Codes, M.A.SC. Thesis, Civil Engineering Department, Ryerson University, Toronto, Ontario, Canada.

[3] Womack, K., and Crookston, B. 2003. Method of Analysis Comparison Study for a Curved Steel Girder Bridge. Final Report, Department of Civil \& Environmental Engineering, Utah State University Utah.

[4] AASHTO. 2014. Guidelines for Steel Girder Bridge Analysis. AASHTO/NSBA Steel Bridge Collaboration Task Group 13. American Association of State Highway and Transportation Officials.

[5] SCI. 2012. Design of Composite Highway Bridge Curved in Plan. Steel Construction Institute, UK.

[6] GRUBB, G.A. 1984. Horizontally Curved I-Girder Bridge Analysis: V-Load Method. Transportation Research Record 982.

[7] CHBDC. 2014. Canadian Highway Bridge Design Code. Canadian Standard Association, Toronto. Ontario, Canada.

[8] AASHTO. 2003. AASHTO Guide Specifications for Horizontally Curved Steel Girder Highway Bridges. American Association of State Highway and Transportation Officials.

[9] AASHTO. 2017. AASHTO LRFD Bridge Design Specifications. American Association of State Highway and Transportation Officials.

[10] Heins, C. P., and Jin, J. O. 1984. Live Load Distribution on Braced Curved I-Girders. ASCE Journal of Structural Engineering, 110(3): 523-530.

[11] Fiecht, A. L., Fenves, G. L., and Frank, K. H. 1987. Approximate Analysis of Horizontally Curved Girder Bridges. Center for Transportation Research, University of Texas at Austin, Texas State Department of Highways and Public Transportation, Transportation Planning Division.

[12] FHWA. 2012. Steel Bridge Design Handbook Design, Example 3: Three-Span, Continuous Horizontally Curved Composite Steel I-Girder Bridge Structural Analysis. Publication No. FHWA-IF-12-052 - Vol. 8, U.S. Department of Transportation, Federal Highway Administration.

[13] AASHTO. 1993. AASHTO Guide Specifications for Horizontally Curved Steel Girder Highway Bridges. American Association of State Highway and Transportation Officials.

[14] Davidson J. S., Keller M. A., and Yoo, C. H. 1996. Cross-frame Spacing and Parametric Effects in 
Horizontally Curved I-Girder Bridges. ASCE Journal of Structural Engineering, 122(9): 1089-1096.

[15] Khalafalla, I., and Sennah, K. 2014. Curvature Limitations for Slab-On-I-Girder Bridges. ASCE Journal of Bridge Civil Engineering, 19(9): 04014031(1-14). 